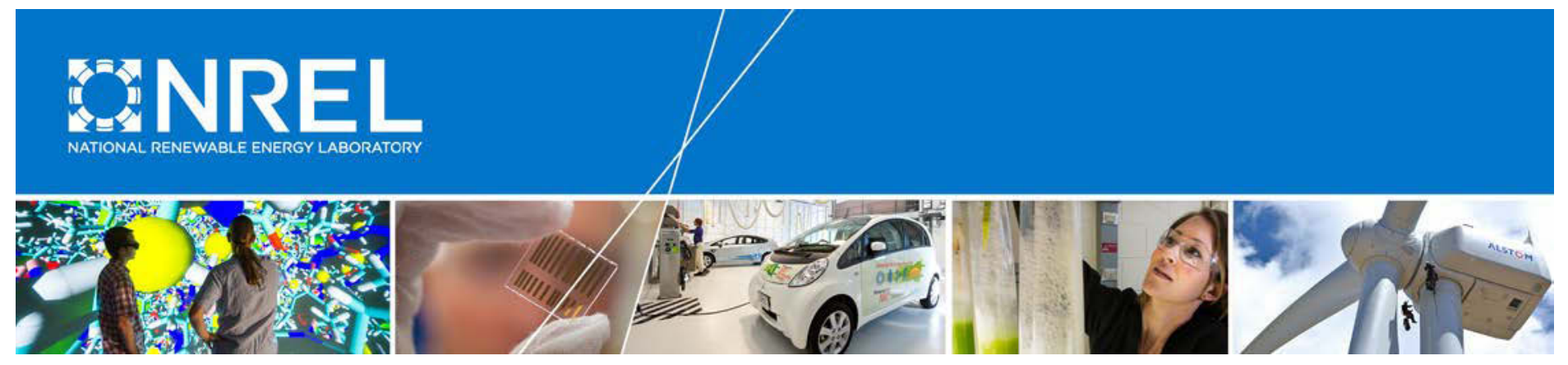

\title{
Charging Electric Vehicles in Smart Cities: An EVI-Pro Analysis of Columbus, Ohio
}

Eric Wood, Clément Rames, Matteo Muratori, Sesha Raghavan, and Stanley Young National Renewable Energy Laboratory (NREL)

NREL is a national laboratory of the U.S. Department of Energy Office of Energy Efficiency \& Renewable Energy Operated by the Alliance for Sustainable Energy, LLC

This report is available at no cost from the National Renewable Energy Laboratory (NREL) at www.nrel.gov/publications.

Technical Report

NREL/TP-5400-70367

February 2018 


\section{Charging Electric Vehicles in Smart Cities: An EVI-Pro Analysis of Columbus, Ohio}

Eric Wood, Clément Rames, Matteo Muratori, Sesha Raghavan, and Stanley Young National Renewable Energy Laboratory (NREL)

National Renewable Energy Laboratory 15013 Denver West Parkway Golden, CO 80401

303-275-3000 • www.nrel.gov
NREL is a national laboratory of the U.S. Department of Energy Office of Energy Efficiency \& Renewable Energy Operated by the Alliance for Sustainable Energy, LLC

This report is available at no cost from the National Renewable Energy Laboratory (NREL) at www.nrel.gov/publications.

\section{Technical Report}

NREL/TP-5400-70367

February 2018

Contract No. DE-AC36-08GO28308 


\section{NOTICE}

This report was prepared as an account of work sponsored by an agency of the United States government. Neither the United States government nor any agency thereof, nor any of their employees, makes any warranty, express or implied, or assumes any legal liability or responsibility for the accuracy, completeness, or usefulness of any information, apparatus, product, or process disclosed, or represents that its use would not infringe privately owned rights. Reference herein to any specific commercial product, process, or service by trade name, trademark, manufacturer, or otherwise does not necessarily constitute or imply its endorsement, recommendation, or favoring by the United States government or any agency thereof. The views and opinions of authors expressed herein do not necessarily state or reflect those of the United States government or any agency thereof.

This report is available at no cost from the National Renewable Energy Laboratory (NREL) at www.nrel.gov/publications.

Available electronically at SciTech Connect http:/www.osti.gov/scitech

Available for a processing fee to U.S. Department of Energy and its contractors, in paper, from:

U.S. Department of Energy

Office of Scientific and Technical Information

P.O. Box 62

Oak Ridge, TN 37831-0062

OSTI http://www.osti.gov

Phone: 865.576.8401

Fax: 865.576.5728

Email: reports@osti.gov

Available for sale to the public, in paper, from:

U.S. Department of Commerce

National Technical Information Service

5301 Shawnee Road

Alexandria, VA 22312

NTIS http://www.ntis.gov

Phone: 800.553 .6847 or 703.605 .6000

Fax: 703.605.6900

Email: orders@ntis.gov 


\section{Acknowledgments}

This study was supported by the U.S. Department of Energy's Vehicle Technologies Office. The authors would specifically like to thank Michael Berube, Robert Graham, Jacob Ward, Rachael Nealer, David Gohlke, and Kelly Fleming for their guidance and support.

Additional thanks to members of the Smart Columbus working group on EV charging infrastructure, including the below individuals. Their feedback was invaluable in tailoring this analysis to the mid-Ohio region.

- Jeffrey W. Lehman American Electric Power

- Ryan Harty American Honda Motor Company

- Dan Santini. Argonne National Laboratory

- Marcy Rood Argonne National Laboratory

- Scott Miller ChargePoint

- Norman (Bud) L. Braughton. City of Columbus

- Mark W. Law City of Columbus

- Kevin McSweeney City of Columbus

- Randall J. Bowman City of Columbus

- Andrew Wolpert City of Columbus

- Sam Spofforth Clean Fuels Ohio

- Tim Krock Columbus Regional Airport Authority

- Mandy Bishop GPD Group

- Edward Ungar HNTB

- Thea Walsh Mid-Ohio Regional Planning Commission

- Ramteen Sioshansi The Ohio State University

- Diane Turchetta U.S. Department of Transportation 


\section{List of Acronyms}

$\begin{array}{ll}\text { BEV } & \text { battery electric vehicle } \\ \text { BEVxx } & \text { battery electric vehicle with a range of xx miles } \\ \text { DCFC } & \text { direct current fast charge } \\ \text { EV } & \text { electric vehicle } \\ \text { EVI-Pro } & \text { Electric Vehicle Infrastructure Projection Model } \\ \text { eVMT } & \text { electric vehicle miles traveled } \\ \text { EVSE } & \text { electric vehicle supply equipment } \\ \text { GPS } & \text { global positioning system } \\ \text { HEV } & \text { hybrid electric vehicle } \\ \text { IHS } & \text { IHS Markit (formerly Polk) } \\ \text { kW } & \text { kilowatt } \\ \text { L1 } & \text { Level 1 charging station } \\ \text { L2 } & \text { Level } 2 \text { charging station } \\ \text { LDV } & \text { light-duty vehicle } \\ \text { MORPC } & \text { Mid-Ohio Regional Planning Commission } \\ \text { MUD } & \text { multiple-unit dwelling } \\ \text { NREL } & \text { National Renewable Energy Laboratory } \\ \text { PEV } & \text { plug-in electric vehicle (BEV or PHEV) } \\ \text { PHEV } & \text { plug-in hybrid electric vehicle } \\ \text { PHEVxx } & \text { plug-in hybrid electric vehicle with a range of xx miles } \\ \text { SOC } & \text { state of charge } \\ \text { SUD } & \text { single-unit dwelling } \\ \text { SUV } & \text { sport utility vehicle } \\ \text { TAZ } & \text { traffic analysis zone } \\ \text { VMT } & \text { vehicle miles travelled }\end{array}$

iv 


\section{Table of Contents}

List of Acronyms .............................................................................................................................. iv

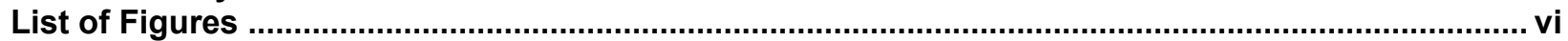

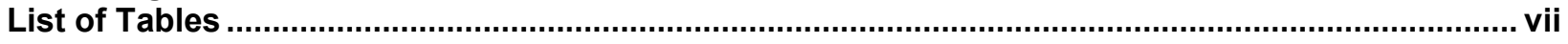

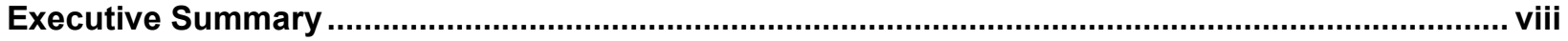

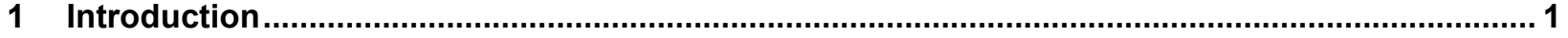

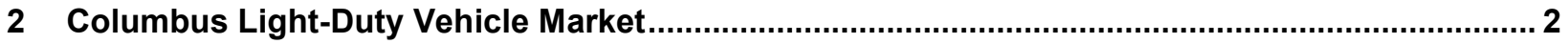

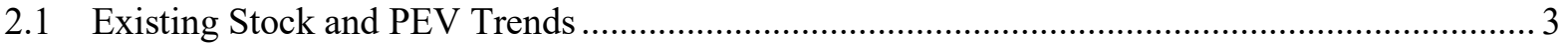

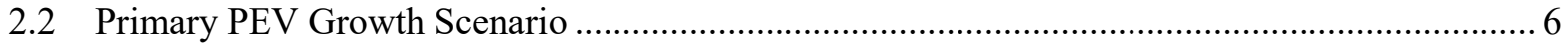

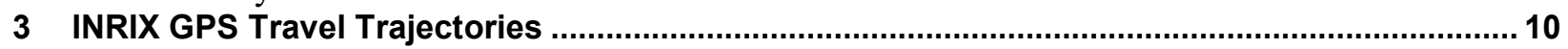

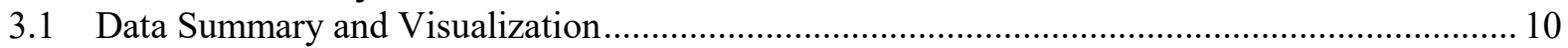

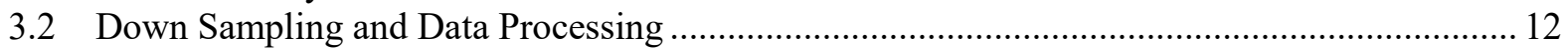

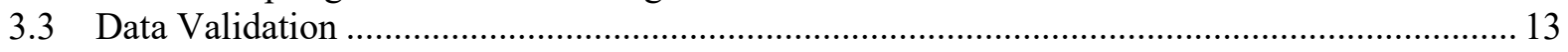

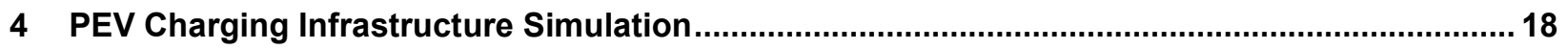

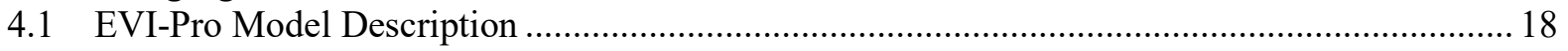

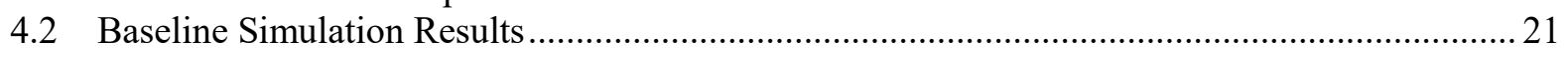

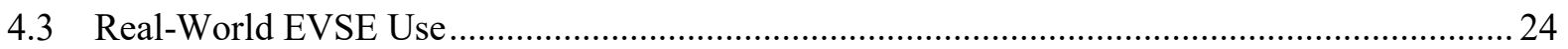

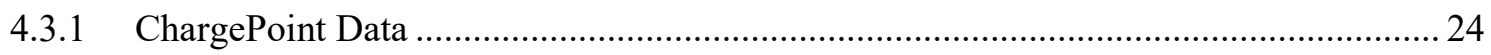

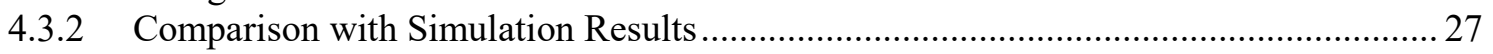

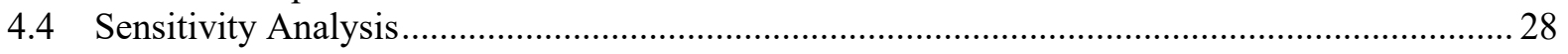

4.4.1 Local PEV Market and Ambient Conditions …..................................................... 28

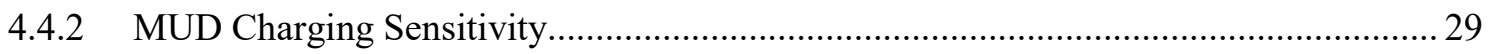

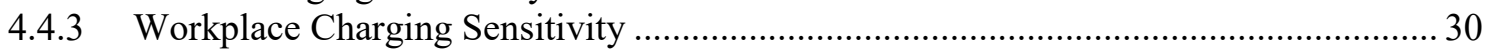

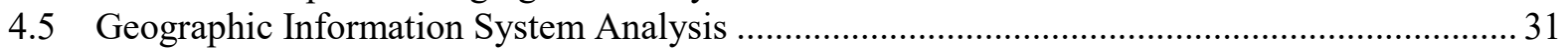

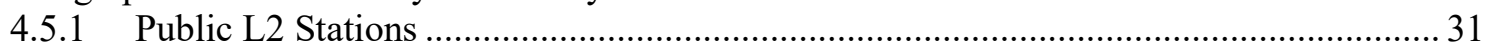

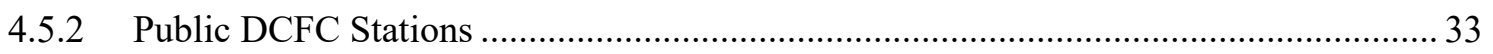

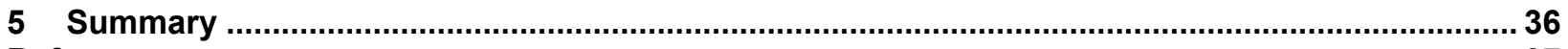

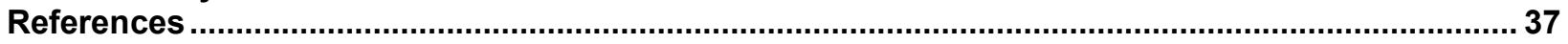

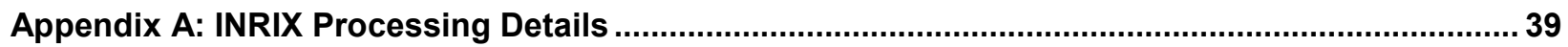

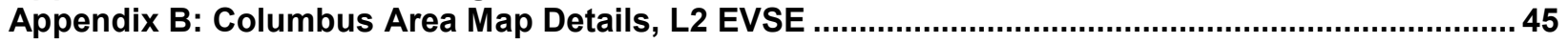




\section{List of Figures}

Figure 1. Seven-county Columbus region considered in this study

Figure 2. LDVs registered in Columbus (seven-county region) as of the end of 2016 by fuel type.

"Flexible" indicates E-85 capable vehicles and "Convertible" indicates vehicles that were ready-made by the manufacturer for alternative fuel systems. Based on NREL analysis of IHS data (IHS 2017).

Figure 3. PEV shares by model and geography (through 2016, per NREL analysis of IHS registration

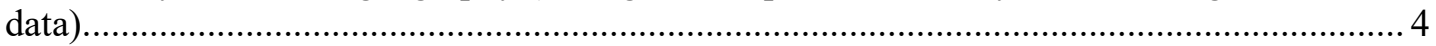

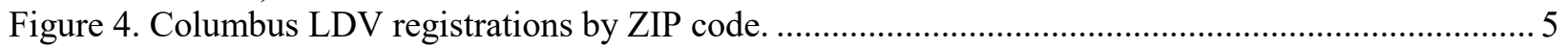

Figure 5. Columbus combined HEV and PEV registrations by ZIP code. ............................................ 5

Figure 6. Columbus PEV registrations by ZIP code............................................................................ 6

Figure 7. PEV sales by year and vehicle type (top) and PEV stock by year and vehicle type assumed in this study for Columbus (bottom). PEV stock is consistent with sales assumptions, assuming no PEV retirement over the period considered.

Figure 8. Share of PEV registrations versus share of HEV registrations for the 50 largest U.S. LDV

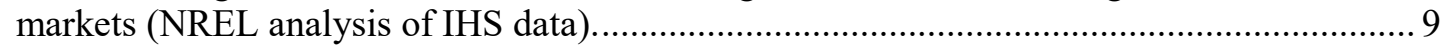

Figure 9. Full geographic extent of the INRIX travel data set for Columbus in 2016 .............................. 10

Figure 10. Trip-destination frequency map derived from the INRIX travel data set for Columbus........... 11

Figure 11. Trip waypoint frequency derived from the INRIX travel data set for Columbus in 2016......... 12

Figure 12. Distribution of daily VMT from multiple sources............................................................... 14

Figure 13. Distribution of trips by time of day from multiple sources. ................................................... 14

Figure 14. Driving time (black) and dwell times at home (blue), work (red), and public (green) locations for INRIX (solid lines), CHTS (dashed lines), and MTS (dotted lines) data sets................. 15

Figure 15. Aggregate LDV trip counts by TAZ from the MORPC 2015 traffic demand model of Columbus.

Figure 16. Trip counts from the 2016 INRIX travel data set for Columbus versus MORPC-modeled trip counts by TAZ (each as a percent of all trips).

Figure 17. Graphical representation of inputs/outputs and data flow in EVI-Pro................................... 18

Figure 18. Simulated battery SOC over time for 18 potential combinations of charging of a BEV100 in the example travel day shown in Table 5...................................................................... 20

Figure 19. Simulated battery SOC over time for the optimal charging option of a BEV100 in the example travel day shown in Table 5 . Red line indicates consumers minimum allowable battery state of charge. 21

Figure 20. Simulated charging load profiles by time of day, station type, and vehicle type based on the INRIX travel data simulated in EVI-Pro assuming preferential residential charging and PHEVs attempting to maximize eVMT.

Figure 21. Daily distribution of ChargePoint charging events by EVSE type and day of the week (note the

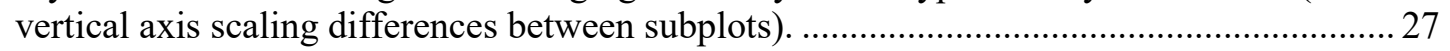

Figure 22. Sensitivity analysis of estimated Columbus PEV charging plug requirements......................... 29

Figure 23. Simulated charging load profiles by time of day, station type, and vehicle type based on the INRIX travel data simulated in EVI-Pro assuming free workplace charging and PHEVs attempting to maximize eVMT.

Figure 24. Simulated PEV charging "hot spots" for L2 public charging (0.3-mi diameter) color coded by $\operatorname{tier}\left(1^{\text {st }}\right.$ tier $=$ red, $2^{\text {nd }}$ tier $=$ orange, $3^{\text {rd }}$ tier $=$ yellow $)$, existing L2 EVSE (blue pentagons $)$, and future sites under consideration by local planners (green stars). Purple outline denotes Columbus urban area. ....

Figure 25. Sixteen existing DCFC station locations in Columbus as of August 2017 (blue dots) and 13 hypothetical future locations to improve DCFC coverage (red dots). Purple outline denotes Columbus urban area.

Figure A1. Schematic of trip destinations clustering algorithm 
Figure A2. Approximately 663 thousand MORPC land-use polygons covering the Columbus area......... 40

Figure A3. Land-use types for the area surrounding John Glenn Columbus International Airport............ 41

Figure A4. Median dwell times for trip destinations in the INRIX travel data by land-use type...............42

Figure A5. Median dwell times for trip destinations in the INRIX travel data for non-residential destinations by land-use type.

Figure A6. Box plot of dwell time in the processed 2016 INRIX data set for Columbus by MORPC landuse type.

Figure B1. Simulated PEV charging "hot spots" for public L2 EVSE (0.3-mi diameter) color coded by use $\left(1^{\text {st }}\right.$ tier $=$ red, $2^{\text {nd }}$ tier $=$ orange, $3^{\text {rd }}$ tier $=$ yellow $)$, existing public L2 EVSE $($ blue pentagons), and future sites under consideration (green stars). Northern half of Franklin County......

Figure B2. Simulated PEV charging "hot spots" for public L2 EVSE (0.3-mi diameter) color coded by use $\left(1^{\text {st }}\right.$ tier $=$ red, $2^{\text {nd }}$ tier $=$ orange, $3^{\text {rd }}$ tier $=$ yellow $)$, existing public L2 EVSE (blue pentagons), and future sites under consideration (green stars). Southern half of Franklin County.

Figure B3. Simulated PEV charging "hot spots" for public L2 EVSE (0.3-mi diameter) color coded by use $\left(1^{\text {st }}\right.$ tier $=$ red, $2^{\text {nd }}$ tier $=$ orange, $3^{\text {rd }}$ tier $=$ yellow $)$, existing public L2 EVSE (blue pentagons), and future sites under consideration (green stars). Delaware County.

Figure B4. Simulated PEV charging "hot spots" for public L2 EVSE (0.3-mi diameter) color coded by use $\left(1^{\text {st }}\right.$ tier $=$ red, $2^{\text {nd }}$ tier $=$ orange, $3^{\text {rd }}$ tier $=$ yellow $)$, existing public L2 EVSE (blue pentagons), and future sites under consideration (green stars). Union County.

Figure B5. Simulated PEV charging "hot spots" for public L2 EVSE (0.3-mi diameter) color coded by use $\left(1^{\text {st }}\right.$ tier $=$ red, $2^{\text {nd }}$ tier $=$ orange, $3^{\text {rd }}$ tier $=$ yellow $)$, existing public L2 EVSE (blue pentagons), and future sites under consideration (green stars). Madison County.

Figure B6. Simulated PEV charging "hot spots" for public L2 EVSE (0.3-mi diameter) color coded by use $\left(1^{\text {st }}\right.$ tier $=$ red, $2^{\text {nd }}$ tier $=$ orange, $3^{\text {rd }}$ tier $=$ yellow $)$, existing public L2 EVSE $($ blue pentagons), and future sites under consideration (green stars). Fairfield County.

Figure B7. Simulated PEV charging "hot spots" for public L2 EVSE (0.3-mi diameter) color coded by use $\left(1^{\text {st }}\right.$ tier $=$ red, $2^{\text {nd }}$ tier $=$ orange, $3^{\text {rd }}$ tier $=$ yellow $)$, existing public L2 EVSE (blue pentagons), and future sites under consideration (green stars). Licking County.

Figure B8. Simulated PEV charging "hot spots" for public L2 EVSE (0.3-mi diameter) color coded by use $\left(1^{\text {st }}\right.$ tier $=$ red, $2^{\text {nd }}$ tier $=$ orange, $3^{\text {rd }}$ tier $=$ yellow $)$, existing public L2 EVSE (blue pentagons), and future sites under consideration (green stars). Marion County.

\section{List of Tables}

Table 1. Columbus PEV Adoption Goals by Year as a Percent of All LDV Sales ..... 6

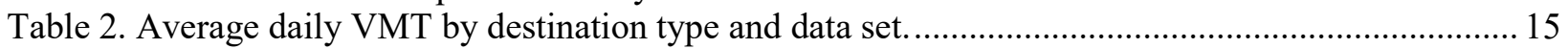

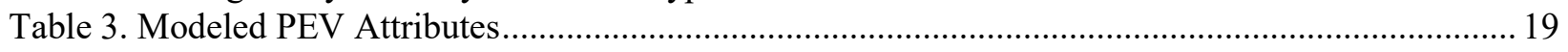

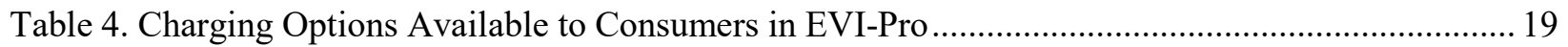

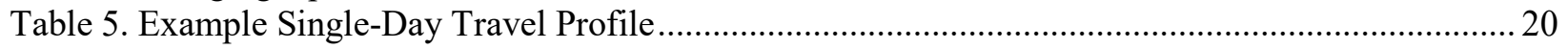

Table 6. Estimated Plug Counts by County, Location, and Power Level .............................................. 23

Table 7. ChargePoint Charging Statistics by Location and Level ........................................................ 25

Table 8. Charging Statistics by Location Type and Level, ChargePoint Data........................................ 26

Table 9. EVI-Pro Station Use Compared to ChargePoint Data ............................................................. 28 


\section{Executive Summary}

In June 2016, the City of Columbus, Ohio, won the U.S. Department of Transportation Smart City Challenge, laying the foundation to become a model for future sustainable transportation in the United States and abroad. With the support of the U.S. Department of Energy's Vehicle Technologies Office, the National Renewable Energy Laboratory worked with the City of Columbus, The Ohio State University, Clean Fuels Ohio, the Mid-Ohio Regional Planning Commission, and American Electric Power to develop a plan for the expansion of the region's network of charging stations to support increased adoption of plug-in electric vehicles (PEVs) in the local market. Potential sites include multi-unit dwellings to support PEV ownership in urban environments, workplaces to maximize electric vehicle miles, and strategic locations along highway corridors to enable regional travel.

The National Renewable Energy Laboratory's Electric Vehicle Infrastructure Projection (EVIPro) model was used to generate scenarios of regional charging infrastructure to support consumer PEV adoption based on travel patterns provided by INRIX (a commercial mapping/traffic company) that are used to characterize regional travel in the Columbus area and anticipate future demand for PEV charging. Moreover, charging loads considering different levels of residential and public charging are reported to better inform the impact of PEV adoption on the electric load. This report provides guidance on PEV charging infrastructure to stakeholders in the Columbus area to reduce range anxiety as a barrier to PEV sales and ensure the effective use of private/public investments in PEV charging infrastructure.

Results indicate that approximately 400 Level 2 plugs at multi-unit dwellings and 350 Level 2 plugs at non-residential locations are required to support Columbus' primary PEV goal of 5,300 PEVs on the road by the end of 2019. This analysis finds that while consumer demand for fast charging is expected to remain low (due to modest anticipated adoption of short-range battery electric vehicles), a minimum level of fast charging coverage across the city is required to ease consumer range anxiety concerns by providing a safety net for unexpected charging events. Sensitivity analyses around some key assumptions have also been performed; of these, consumer preference for PHEV versus BEV and for their electric driving range, ambient conditions, and availability of residential charging at multi-unit dwellings were identified as key determinants of the non-residential PEV charging infrastructure required to support PEV adoption. The results discussed in this report can be leveraged by similar U.S. cities as part of a strategy to accelerate PEV adoption in the light-duty vehicle market. 


\section{Introduction}

Transitioning from the current U.S. urban mobility paradigm, which heavily relies on vehicles powered by petroleum-derived fuels, to an efficient and sustainable mobility system is a key priority for modern cities. Electro-mobility has the potential to profoundly reshape the current urban transportation paradigm by eliminating tailpipe emissions and enabling the integration of the transportation and electric power sectors via a smart electric grid. Consisting mainly of shortdistance trips, urban travel patterns are well suited to plug-in electric vehicles (PEVs). As winner of the U.S. Department of Transportation's Smart Cities Challenge, Columbus, Ohio, is positioned to become a living laboratory to explore future urban mobility solutions. The most widely recognized benefits of vehicle electrification include lower operational and maintenance costs for consumers, reduced greenhouse gas emissions, improved air quality, reduced dependence on petroleum, and potential positive synergies with the electric grid (Melaina 2016).

The passenger PEV market has experienced rapid growth in recent years (International Energy Agency 2017), propelled by rapidly falling battery costs (Nykvist and Nilsson 2015), federal and local incentives (Internal Revenue Service 2016, U.S. Department of Energy 2017), and consumer preferences driven by environmental awareness and technology preference (Egbue and Long 2012). Yet, PEV adoption in Columbus remains modest compared to the large number of gasoline vehicles currently on the road. To enable widespread PEV adoption, a convenient and effective charging infrastructure network must be deployed across the region. This network should allow long-distance travel for battery electric vehicles (BEVs), empower residents who do not have access to residential charging (e.g., deploying charging stations at multiple-unit dwellings [MUDs] and workplaces), and provide a reliable charging alternative for all PEV drivers while at the same time offering an attractive business case to service providers.

This report seeks to provide guidance on PEV charging infrastructure to stakeholders in the Columbus area-both to reduce range anxiety as a barrier to PEV sales and to ensure the effective use of private/public investments in PEV charging infrastructure. Findings from this study are expected to be relevant for other U.S. cities similar to Columbus and to provide useful insights for accelerating PEV adoption.

This report is organized into four main parts. First, an analysis of the existing Columbus lightduty vehicle (LDV) market is conducted and near-term PEV adoption goals are reviewed to estimate future PEV sales. Second, detailed global positioning system (GPS) travel data from INRIX (a commercial traffic/mapping provider) are described, including a discussion of data quality control measures. Third, these travel data are used in NREL's Electric Vehicle Infrastructure Projection (EVI-Pro) model to estimate the total number of charging stations, their type, and their location required to support PEV adoption goals in Columbus with comparisons made to real-world data from ChargePoint (a manufacturer and operator of electric vehicle supply equipment, EVSE). Finally, a sensitivity analysis is conducted to highlight sources of uncertainty, and simulation results are used to generate a set of "hot-spot" locations for consideration by the city and other stakeholders for installing new PEV charging stations. 


\section{Columbus Light-Duty Vehicle Market}

Despite significant Federal and State incentives that have promoted PEV adoption over the past several years (Internal Revenue Service 2016, U.S. Department of Energy 2017), only 2,080 PEVs were registered in Columbus as of the end of 2016 compared to a total of 1.70 million gasoline LDVs. IHS Markit (IHS) (formerly R.L. Polk) vehicle registration data are used as a source for the existing light-duty vehicle fleet in Columbus as of the end of 2016 (IHS 2017). PEV sales trends are derived from the IHS data and are used to develop a projection for nearterm PEV sales in the Columbus region based on the City's stated PEV adoption goal of 1.8\% of LDV sales by 2019. For this analysis, the Columbus region is defined as the seven-county area surrounding the City of Columbus (Franklin, Delaware, Licking, Fairfield, Pickaway, Madison, and Union Counties), as shown in Figure 1. In the remainder of this report, any reference to "Columbus" refers to this seven-county region.

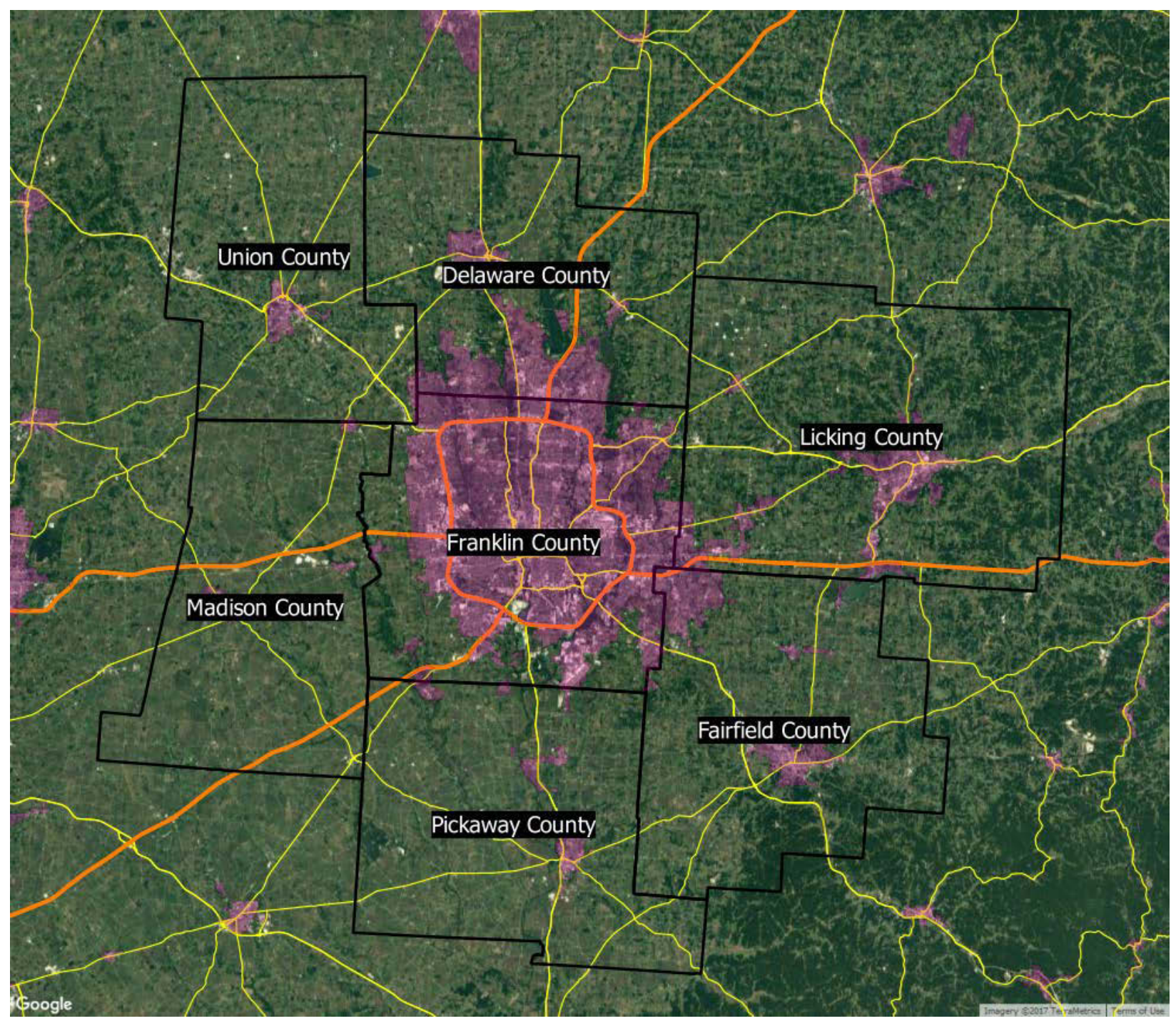

Figure 1. Seven-county Columbus region considered in this study.

Satellite imagery credit: @ 2017 Google, Map Data @ 2017 Tele Atlas 


\subsection{Existing Stock and PEV Trends}

IHS data report a total of 1.70 million LDVs registered in Columbus as of the end of 2016. Figure 2 summarizes the LDVs registered in Columbus by fuel type. Similar to national averages, LDV registrations in Columbus are dominated by gasoline vehicles $(90.03 \%$ of total registrations) with modest shares of E85 flexible fuel vehicles (6.91\%), diesel vehicles (1.66\%), and hybrid electric vehicles (HEVs) (1.22\%). Plug-in hybrid electric vehicles (PHEVs) and battery electric vehicles (BEVs) represented $0.08 \%$ and $0.04 \%$, respectively, of the total Columbus LDV stock as of the end of 2016 with a total of 2,100 vehicles. Given that the majority of passenger PEV models currently available had been available on the market in Columbus for six years or less in this vintage of IHS data, it is not surprising that they represent a meager share of the overall LDV registrations in Columbus.

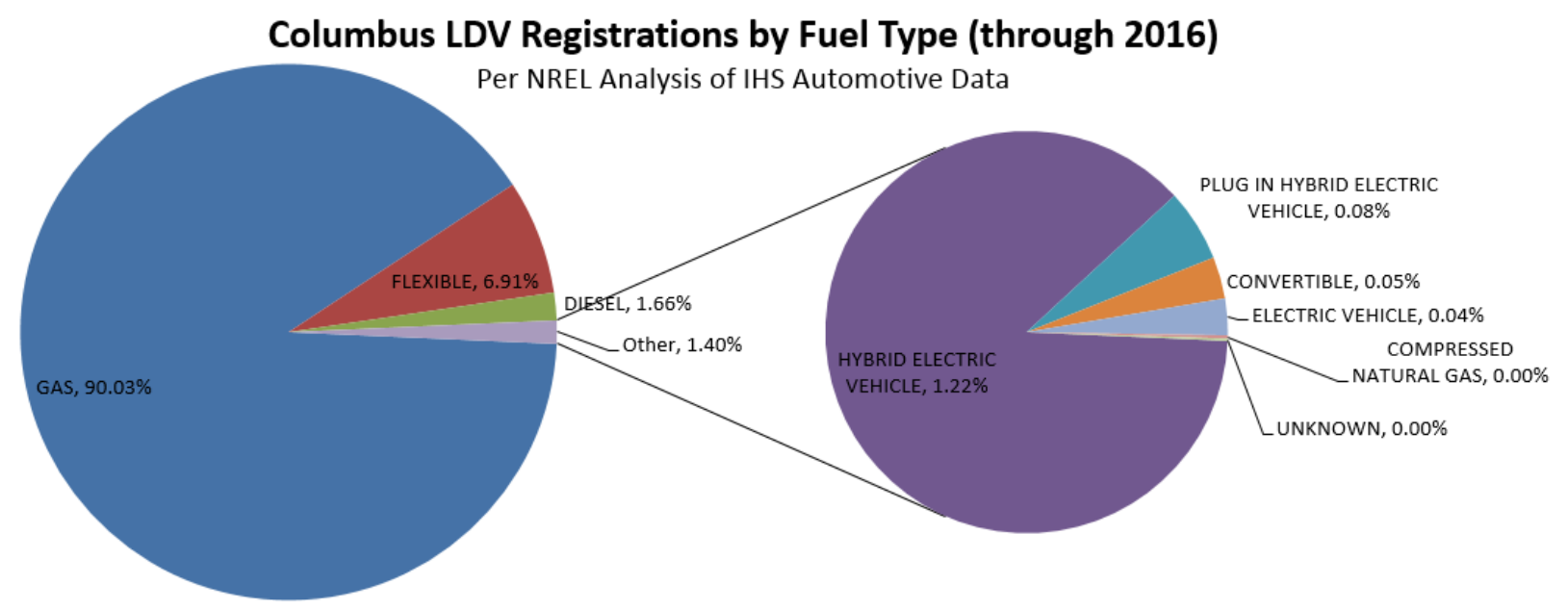

Figure 2. LDVs registered in Columbus (seven-county region) as of the end of 2016 by fuel type. "Flexible" indicates E-85 capable vehicles and "Convertible" indicates vehicles that were readymade by the manufacturer for alternative fuel systems. Based on NREL analysis of IHS data (IHS 2017).

Given the relatively small sample of PEV registrations in Columbus, other national and regional data are considered to inform PEV sales projections. Figure 3 illustrates PEV sales for the ten top-selling PEV models in the United States (Chevrolet Volt, Nissan Leaf, Tesla Model S, Toyota Plug-In Prius, Ford Fusion Energi, Ford C-Max Energi, BMW i3 REx, Volkswagen e-Golf, and Tesla Model X) in multiple geographic regions: United States (split between California and the United States less California), Ohio, and Columbus. The U.S. numbers provide a national context on the relative consumer preference for the various models (there are approximately 500,000 total PEVs on the road as of 2016). Given the large share of PEV sales in California, which accounts for about half of the national PEV sales, the national-level reporting is split between just California (238,000 total PEVs) and the rest of the United States without California $(262,400$ total PEVs). Ohio is included to provide a regional perspective $(7,300$ total PEVs registered).

PEV registrations in Ohio and Columbus are consistent and show similar trends. In general, we find the Ohio and Columbus markets to be relatively PHEV dominant $(67 \%$ and $66 \%$ of PEVs, respectively, compared to $53 \%$ at the national level). This PHEV preference relative to national 
adoption is evident in decreased shares of the Nissan Leaf (a BEV) and increased shares of the Chevrolet Volt and BMW i3 REx registrations (both PHEVs). The greater success of PHEVs in Ohio could be the result of a variety of factors, including socio-economic and demographic differences, brand loyalty, local advertisement, model selection, charging infrastructure availability, and others. In general, the low overall level of PEV sales (especially outside California) makes comparison across regions difficult.

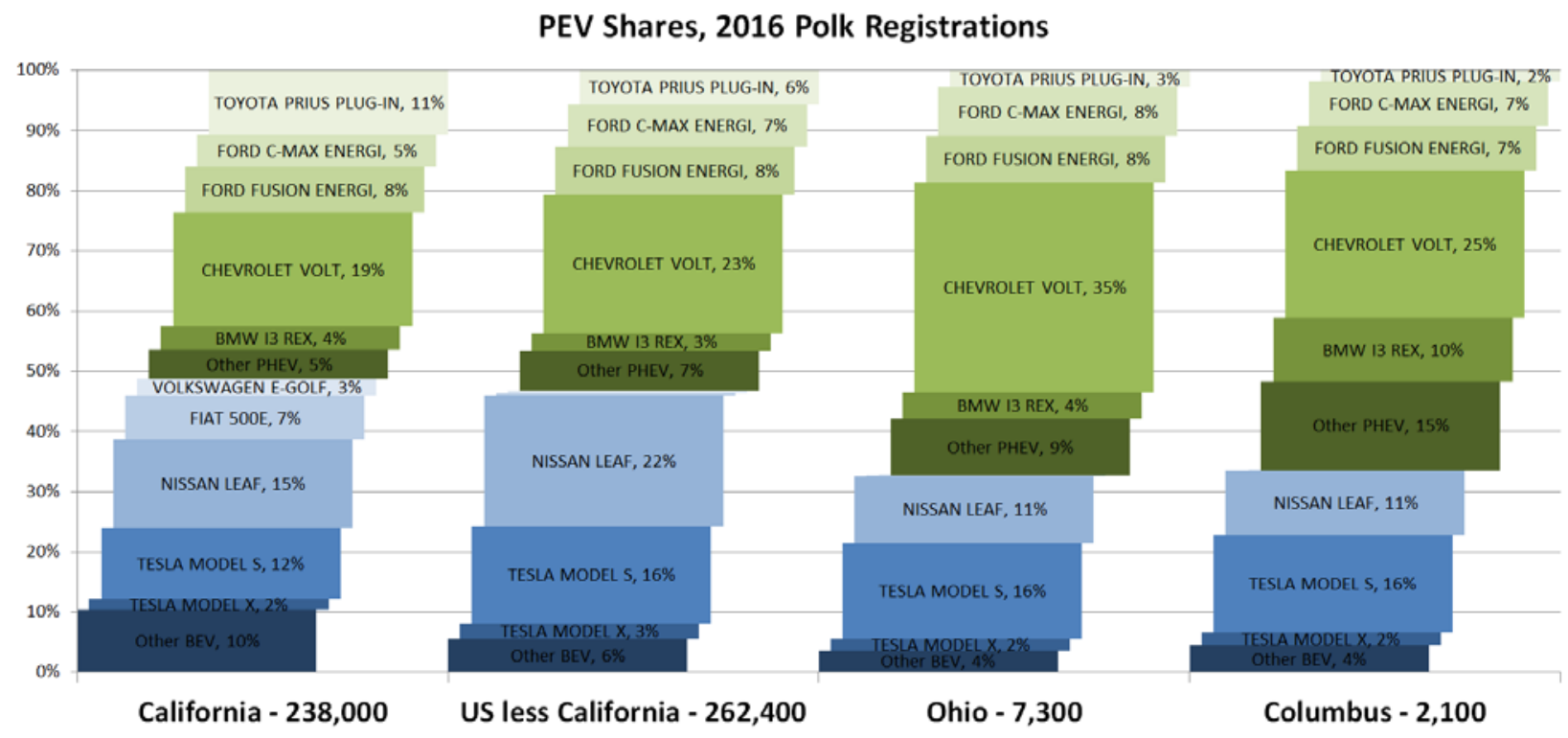

Figure 3. PEV shares by model and geography (through 2016, per NREL analysis of IHS registration data).

Figures 4 through 6 show geographic analysis (at the ZIP code level) of LDV registrations in Columbus to better illustrate vehicle adoption and assess future potential for market growth in the area. Figure 4 shows all LDV registrations (roughly 1.70 million vehicles), Figure 5 shows HEV and PEV registrations (23,000 vehicles), and Figure 6 shows PEV registrations only (2,100 vehicles). The spatial disaggregation of LDV registrations reveals that PEV registrations are concentrated in particular ZIP codes (specifically, Hilliard, 43026: northwest of the western junction of I-70 and I-270). Clustering effects in the adoption of alternative fuel vehicles, driven by socio- economic and behavioral factors influencing the decision of individual customers to buy different vehicles that correlate with household location, are expected and have been documented in several previous studies (Kahn and Vaughn 2009). 


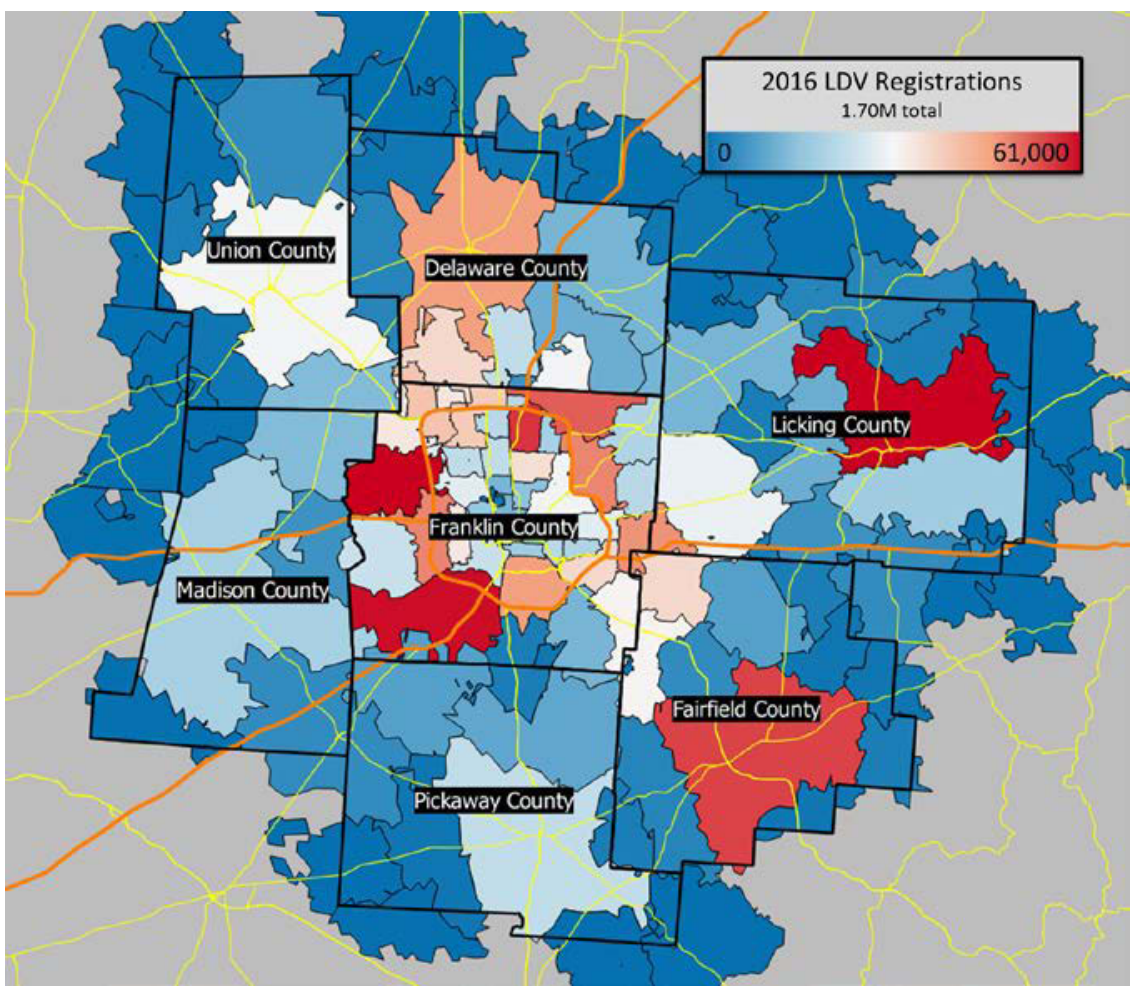

Figure 4. Columbus LDV registrations by ZIP code.

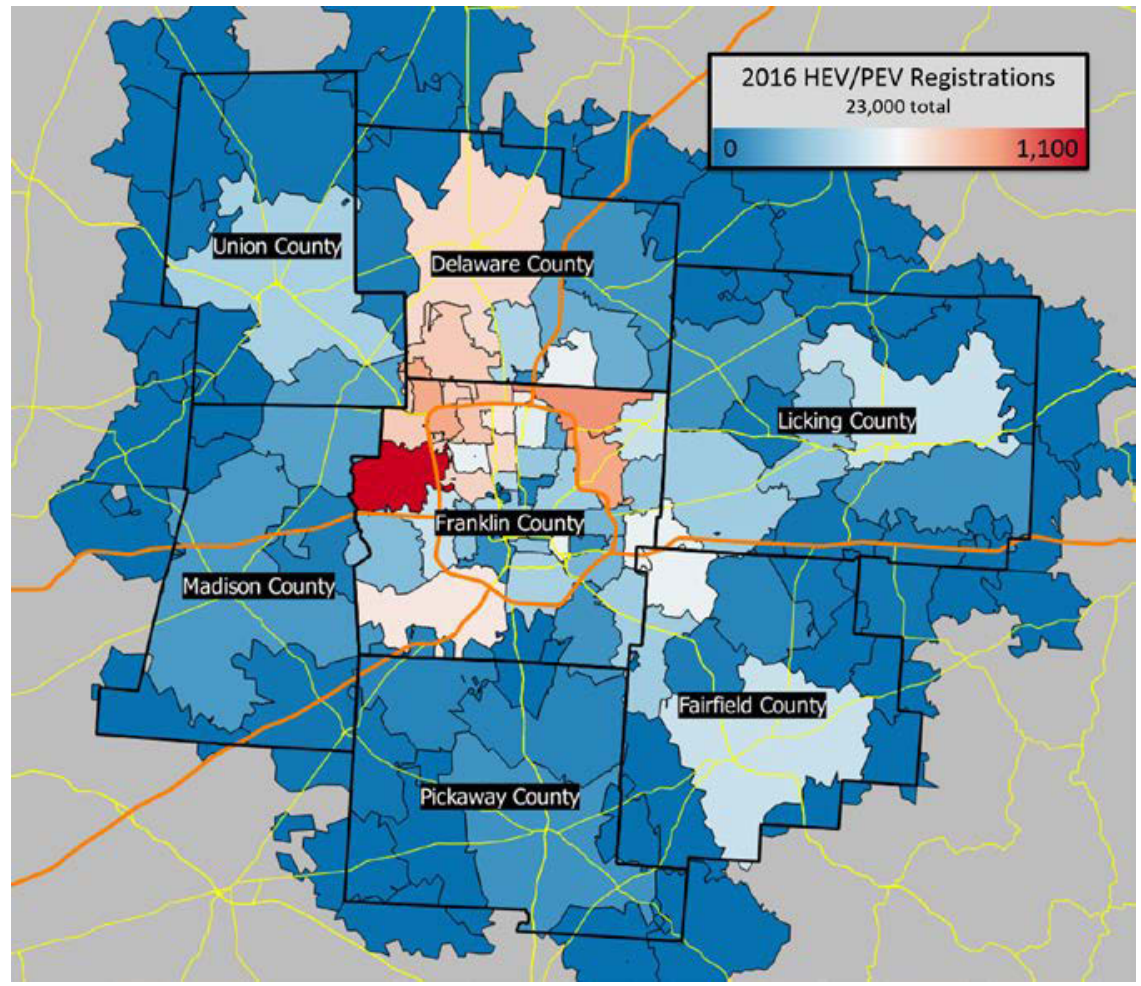

Figure 5. Columbus combined HEV and PEV registrations by ZIP code. 


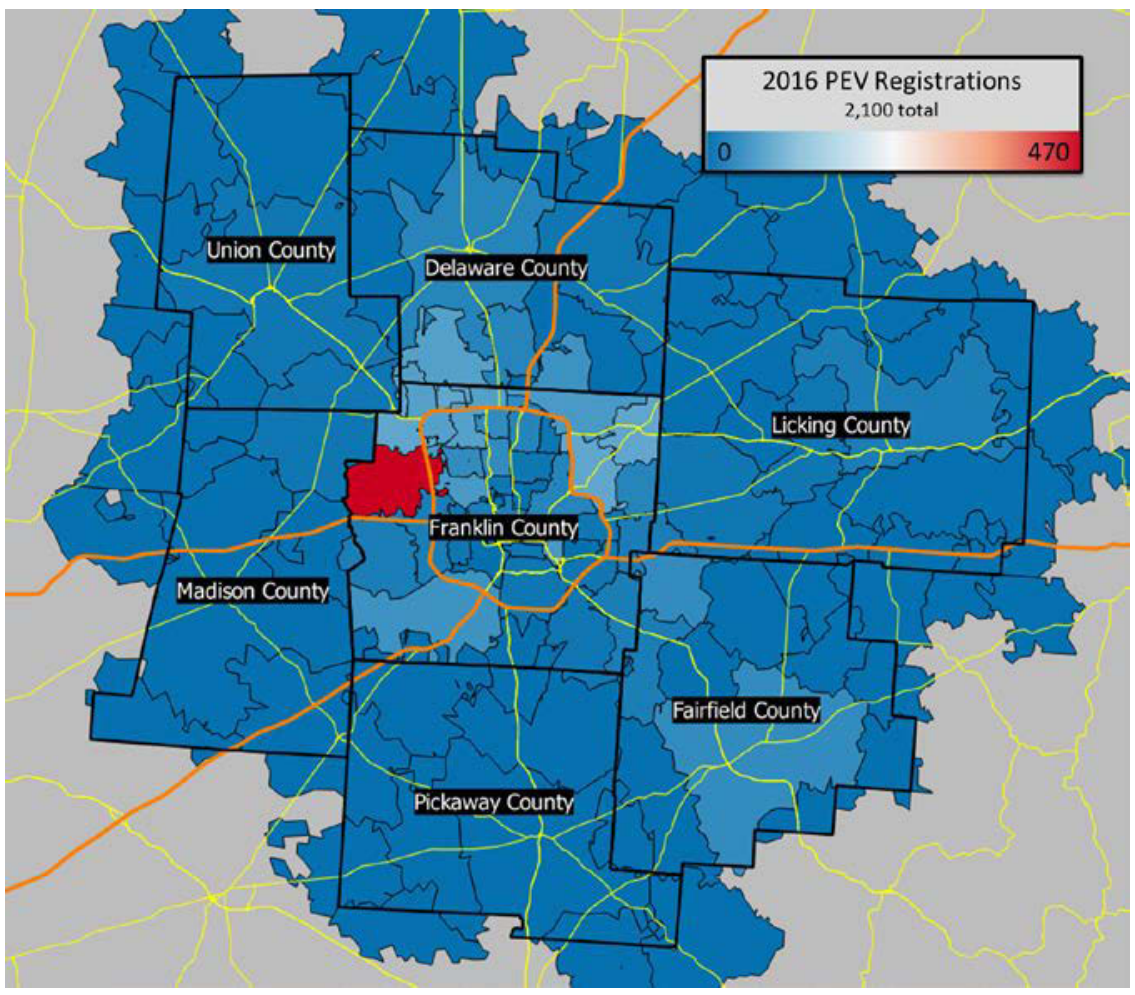

Figure 6. Columbus PEV registrations by ZIP code.

\subsection{Primary PEV Growth Scenario}

As part of the Smart Columbus Initiative, the city has set specific goals for annual PEV sales, as a percentage of all LDV sales, from 2017 to 2019 (see Table 1). Based on historical sales, approximately 91,500 LDVs are sold per year in Columbus. Therefore, we estimate the Columbus goal to translate to 3,200 new PEVs registered in Columbus over three years, bringing the Columbus PEV fleet to 5,300 vehicles by the end of 2019 (assuming no PEV retirement over this period).

Table 1. Columbus PEV Adoption Goals by Year as a Percent of All LDV Sales

\begin{tabular}{cc}
\hline Year & PEV Sales Goal \\
\hline 2017 & $0.6 \%$ \\
2018 & $1.1 \%$ \\
2019 & $1.8 \%$ \\
\hline
\end{tabular}

More information is required to properly project the charging infrastructure required to support this level of PEV adoption, including registrations by residence type, registrations by powertrain type (PHEV/BEV), electric range of the vehicles sold, and a spatial disaggregation of PEV registrations (e.g., at the ZIP-code level).

As access to PEV charging can be more challenging at apartment buildings and townhomes, it is important to consider the number of PEVs that may be adopted by residents of MUDs. Overall, census data reveal that $24 \%$ of Columbus residents live in MUDs, led by Franklin County with 
$29 \%$ (the six adjacent counties have MUD populations between $10 \%$ and $16 \%$ ). This analysis assumes that MUD residents will be less inclined to adopt PEVs than their single-unit dwelling (SUD) counterparts, due primarily to uncertainty regarding availability of a consistent home charging option. As such, $12 \%$ of PEVs are assumed to be owned by MUD residents in the baseline 2019 scenario.

Figure 7 shows PEV sales and stock shares by powertrain type and electric range assumed here considering six generic PEVs: PHEV20, PHEV50, BEV100, BEV250, PHEV20 SUV, BEV250 SUV (numeric suffix indicates electric range, in miles; SUV indicates a sport utility vehicle). These estimates are based on historical IHS registration data extrapolated forward in time to disaggregate PEV sales between PHEVs and BEVs. Key assumptions for this estimate are: 1) as the Columbus PEV market matures, its PHEV/BEV split will begin to approach the national trend (assuming that Columbus sales reach a 50/50 PHEV/BEV split by 2019); and 2) market trends show a preference for longer electric ranges as evidenced by release or announcement of new PEV models with greater battery capacity (e.g., the second-generation Chevrolet Volt and Nissan Leaf, Chevrolet Bolt, and Tesla Model 3).

As PEV adoption increases in Columbus, it is unlikely that sales will continue to be as spatially concentrated as observed to date (see Figure 6). At the same time, it is also unlikely that PEV sales will follow the same spatial distribution of all LDVs (since socio-economic and demographic factors have been shown to introduce significant clustering effects in the adoption of alternative fuel vehicles). We use insights from the past spatial adoption of HEVs and PEVs (Figure 5) as a proxy for future adoption of PEVs.

Nationally, the notion that HEVs serve as a reasonable proxy for PEV adoption is supported by Figure 8, which shows a positive correlation between existing HEV and PEV registration shares across the 50 largest U.S. LDV markets. Some notable clusters of cities include the group of West Coast cities featuring more than 3\% HEV stock and 0.6\% PEV stock (San Jose, California; Los Angeles, California; Seattle, Washington; Portland, Oregon; and San Diego, California) and the group of South-Central cities featuring less than $0.9 \%$ HEV stock and $0.06 \%$ PEV stock (Memphis, Tennessee; Oklahoma City, Oklahoma; Tulsa, Oklahoma; El Paso, Texas). The similarity in stock of advanced technology vehicles between these clusters of cities likely correlates well with similarities in socio-economic and demographic factors as well as perception of "green and advanced" technology in these regions.

Brand loyalty and presence of local manufacturing may also play a role in specific cities. San Jose exhibits a relatively high PEV-to-HEV ratio and is located a few miles from Tesla's primary manufacturing facility in Fremont. Similarly, Detroit's high PEV-to-HEV ratio could partially be explained by the influence of Chevrolet Volts, which are manufactured in the greater Detroit metropolitan area (also Detroit's strong domestic brand loyalty may contribute to relatively poor HEV adoption, which has historically been led by the Toyota Prius). Influence of PEV purchase incentives also plays a significant role, as evidenced by the large PEV-to-HEV ratio in Atlanta, which until recently offered one of the largest BEV purchase incentives in the nation. 


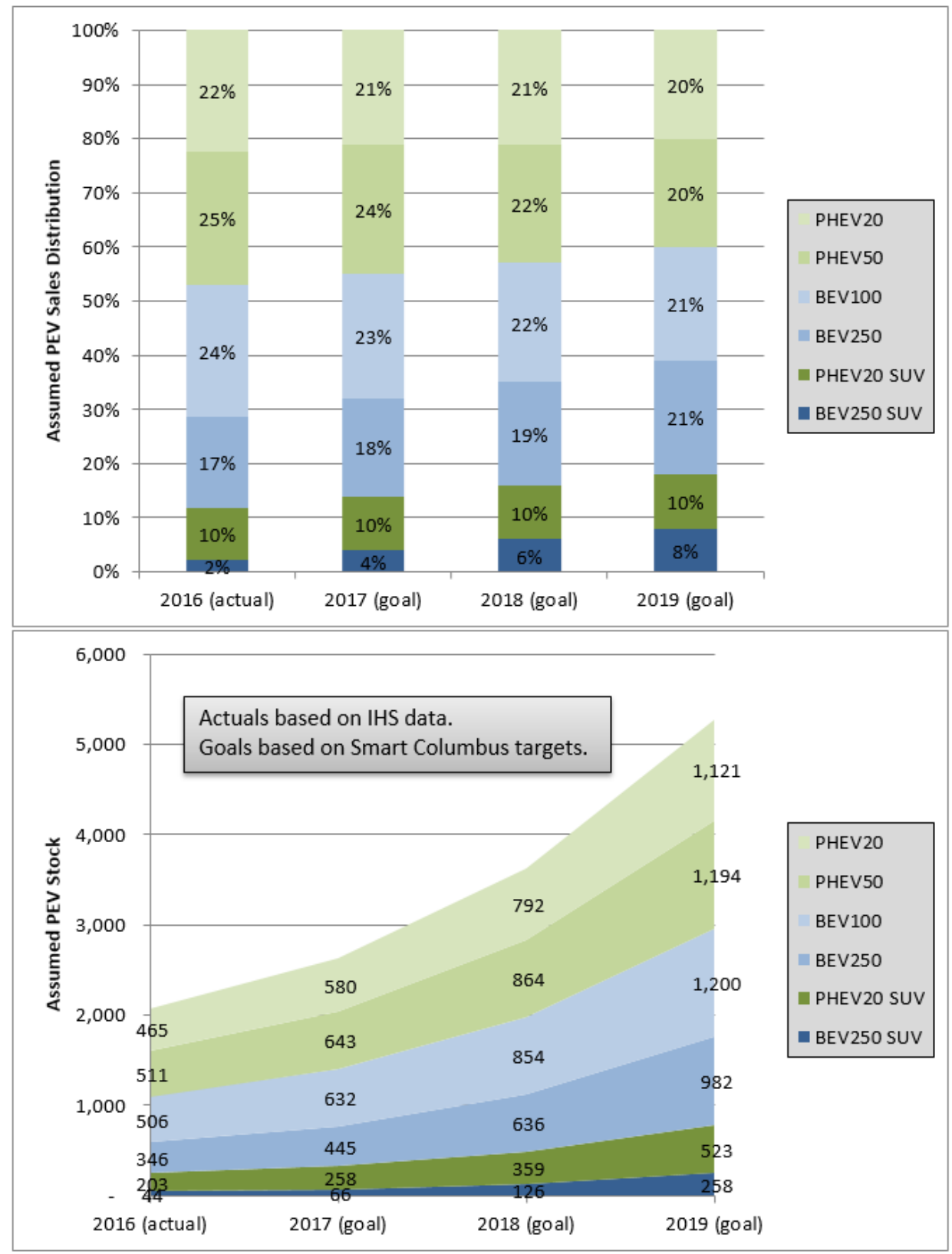

Figure 7. PEV sales by year and vehicle type (top) and PEV stock by year and vehicle type assumed in this study for Columbus (bottom). PEV stock is consistent with sales assumptions, assuming no PEV retirement over the period considered. 


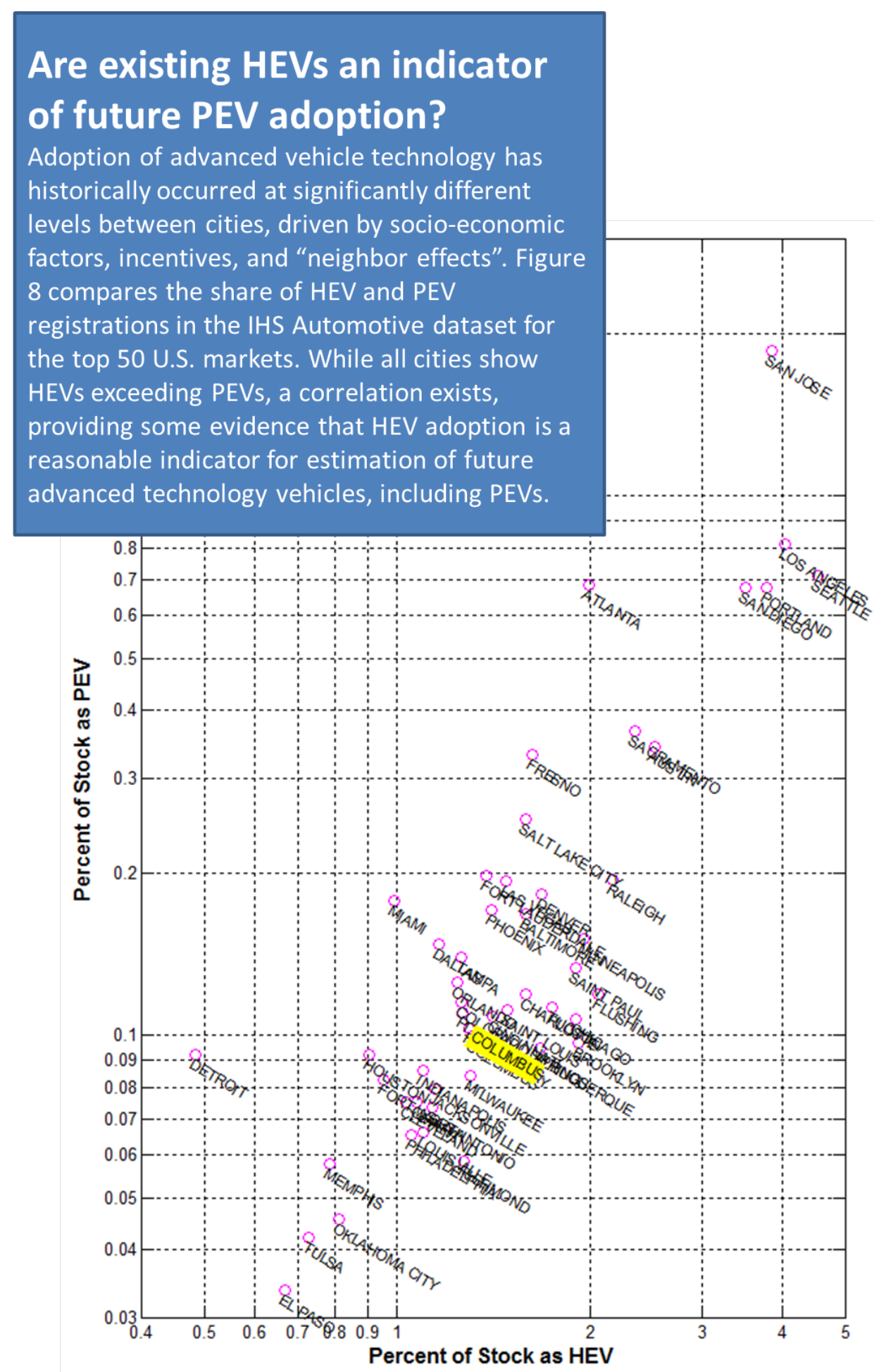

Figure 8. Share of PEV registrations versus share of HEV registrations for the 50 largest U.S. LDV markets (NREL analysis of IHS data). 


\section{INRIX GPS Travel Trajectories}

Travel patterns are one of the main drivers of PEV charging infrastructure requirements. To properly model PEV charging infrastructure requirements in Columbus, NREL acquired individual GPS travel trajectories from INRIX, a commercial traffic/mapping provider that works with automotive manufacturers, commercial fleet operators, mobile companies, and state and local transportation departments to provide real-time traffic and mobility analytics. INRIX products are based on anonymized GPS data collected from hundreds of millions of devices.

\subsection{Data Summary and Visualization}

The INRIX data set used in this study includes all GPS travel trajectories (mode imputed as driving trips by INRIX) that intersected the Columbus region (as defined in Figure 1) at any time during 2016. Each travel trajectory features trip-level data such as start and end times and GPS coordinates (including origin, destination, and intermediate waypoints). The data set contains a total of 7.82 million unique device identifiers, 32.9 million trips, 1.04 billion miles of driving, and 2.58 billion GPS waypoints. Figures 9, 10, and 11 show the full geographic extent of the data set, including spatial distribution of trip destinations in Columbus and frequency of road use based on INRIX GPS waypoints.

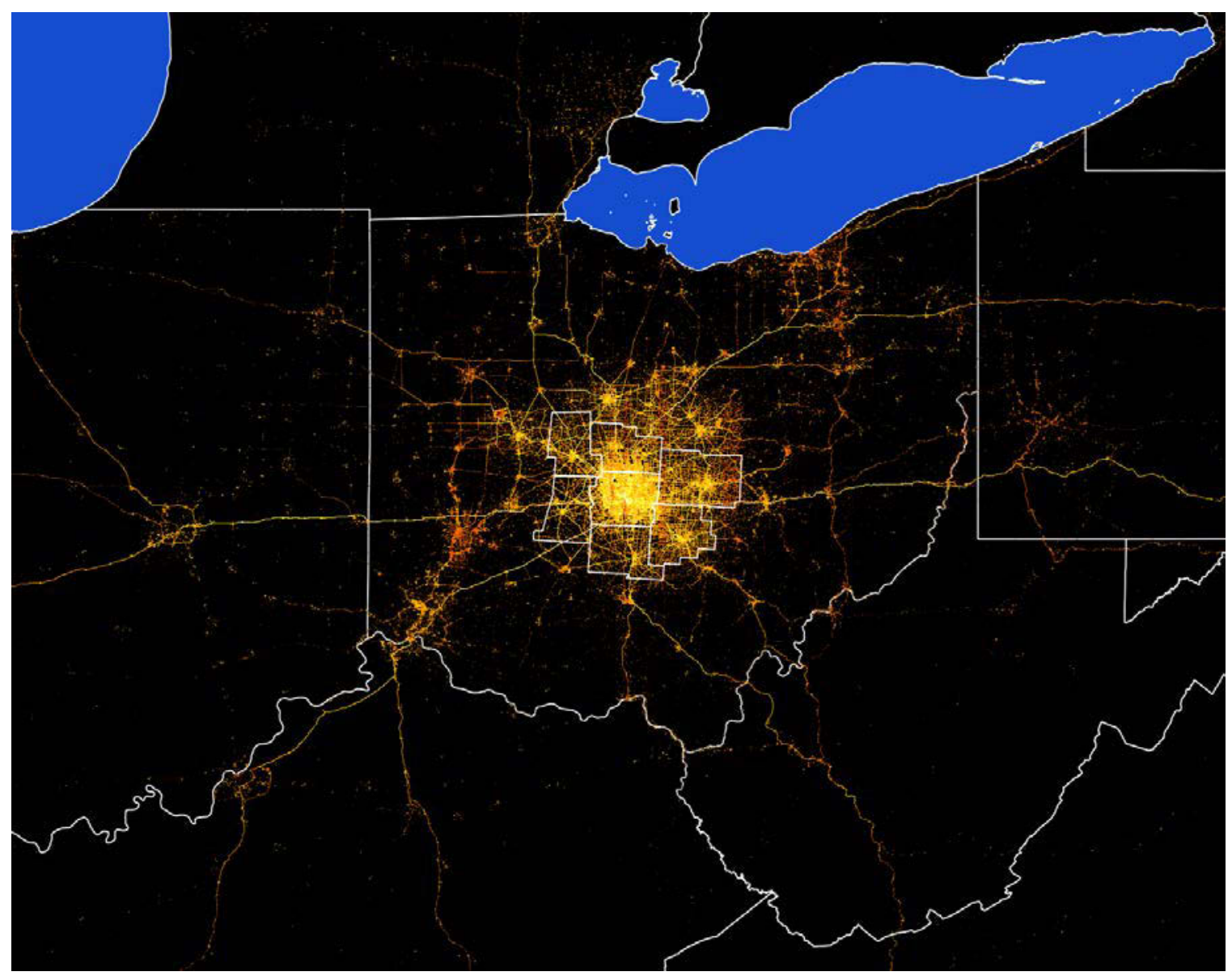

Figure 9. Full geographic extent of the INRIX travel data set for Columbus in 2016. 


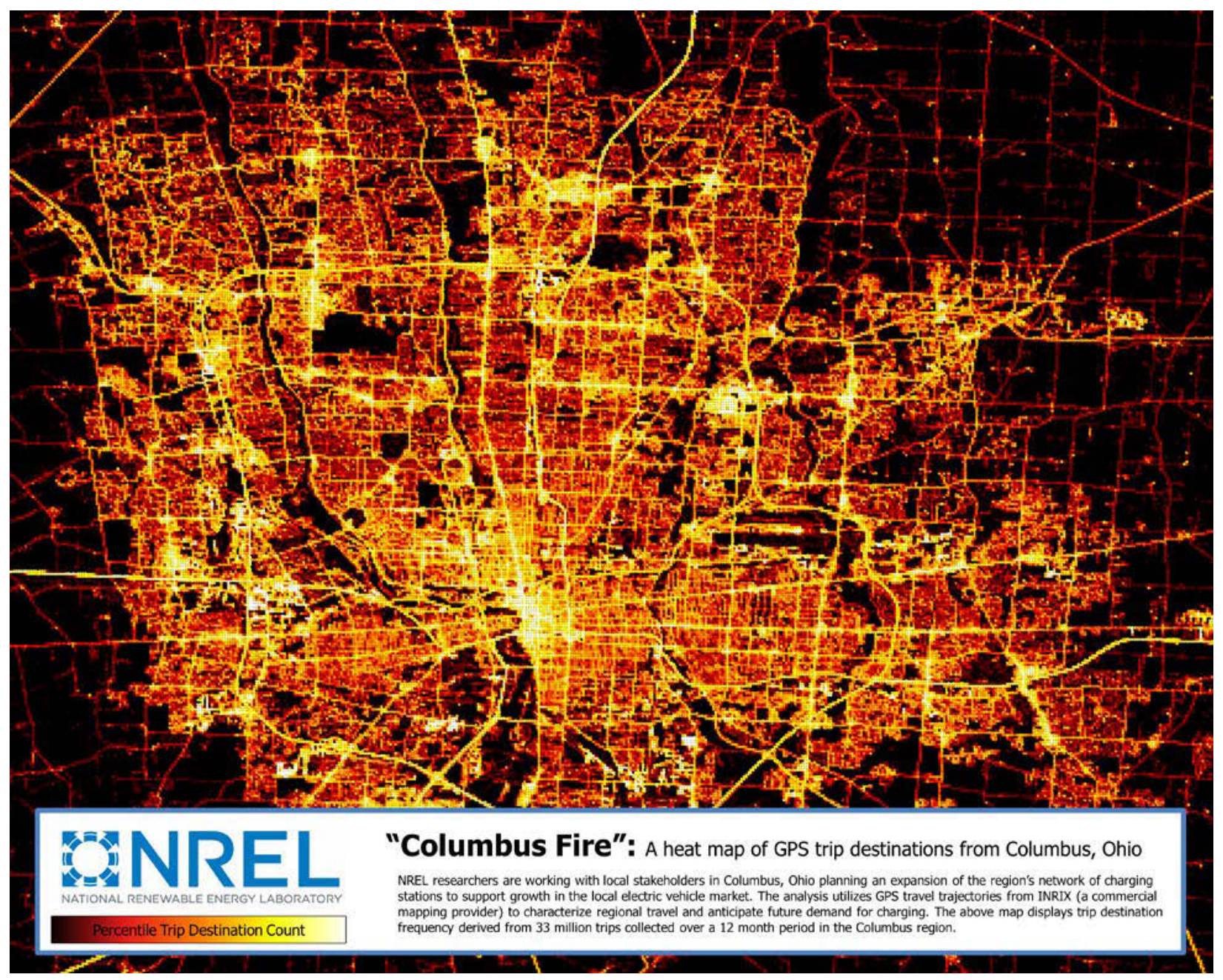

Figure 10. Trip-destination frequency map derived from the INRIX travel data set for Columbus.

While the trip destination map (Figure 10) shows a fairly homogeneous coverage of the City of Columbus, the road use map (Figure 11) mainly highlights interstates, highways, and major arterial roads. This reflects different vehicle spatial distribution during parked time (destination) compared to driving time (trip waypoint). The trip-destination information (Figure 10) is more relevant to study stationary PEV charging, and will be leveraged in this study to estimate PEV charging requirements in Columbus. 


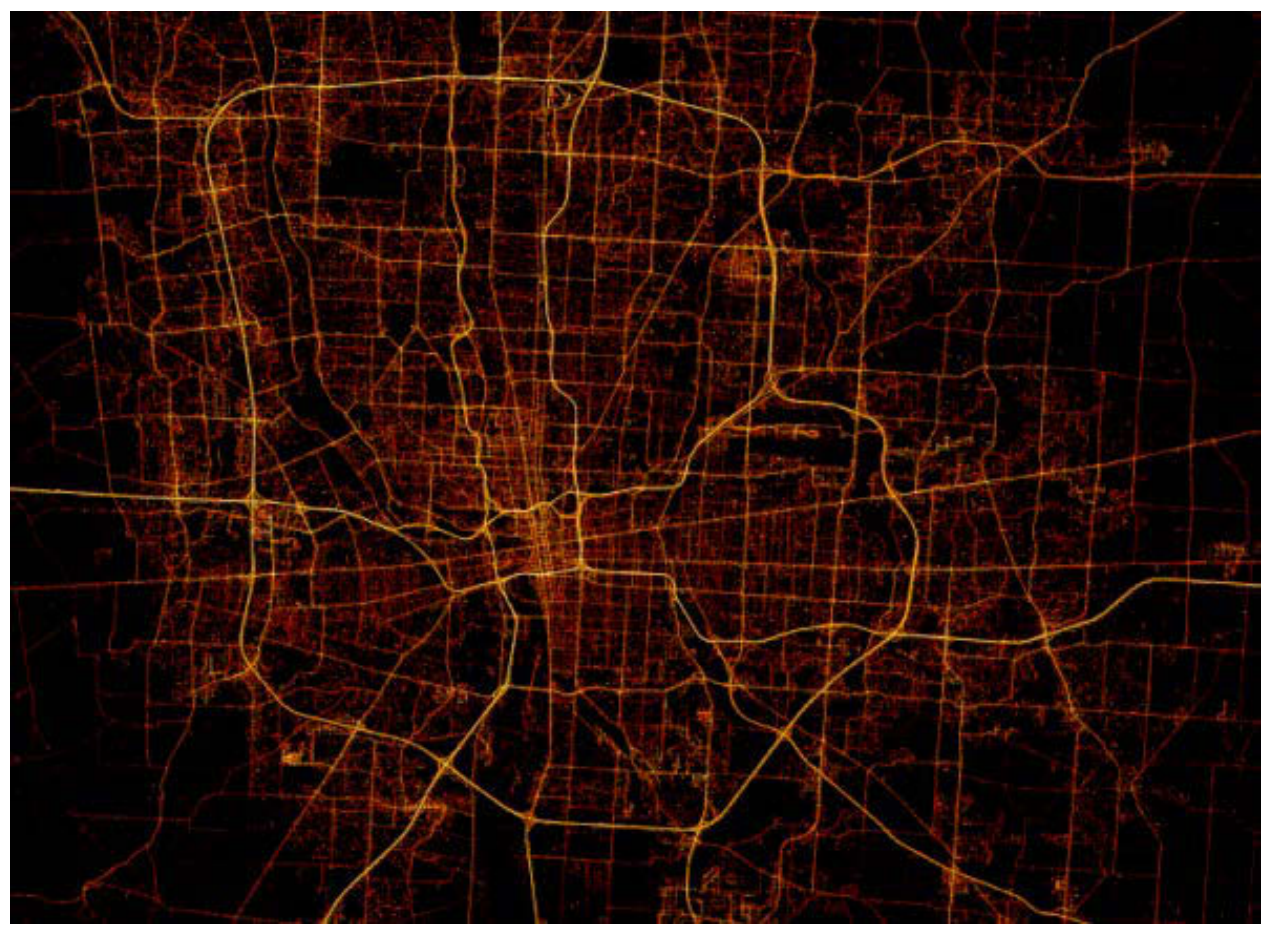

Figure 11. Trip waypoint frequency derived from the INRIX travel data set for Columbus in 2016.

\subsection{Down Sampling and Data Processing}

The GPS travel trajectories in the INRIX travel data set are an aggregation of heterogeneous data from multiple providers, including data from commercial and heavy-duty vehicles. The data were filtered to include only LDV travel, which includes two source types as defined by INRIX: 1) embedded GPS (provided primarily by automotive manufacturers from in-vehicle navigation systems), and 2) mobile devices (provided primarily by phone companies from applications installed on cellular devices). Data from embedded GPS sources primarily consisted of device identifiers with only one associated trip, implying that the device identifier associated with an individual vehicle is changed after each driving event (likely to impede tracking individual vehicles through time). This device identification rotation schedule, however, effectively makes INRIX LDV data from embedded GPS sources unusable for PEV driving/ charging simulations due to the inability to chain trips, simulate full days of PEV operation, and estimate battery state of charge (SOC) (a critical measure for estimating demand for PEV charging stations). A sufficiently large sample of full 24-hour travel data from mobile devices was instead available for reconstruction and was used in this study. One caveat to this approach, however, is that since the subset of INRIX GPS data that was selected comes exclusively from consumer mobile devices, no assurances can be made that all trips from these devices took place in the same vehicle over the course of the travel day, that all trips from that vehicle-travel-day are captured, and that trips from an individual vehicle are not duplicated by the presence of multiple mobile devices. A comparison of the processed INRIX travel data set and traditional travel surveys is presented in Section 3.3 to assess the suitability of this approach and data processing to capture travel habits to model PEV charging requirements.

Prior to using the INRIX travel data subset in PEV driving/charging simulations, a number of data processing steps were completed, including: 
- Removing the first and last vehicle-day for each device identifier (to remove incomplete travel days)

- Editing trip origins to ensure consistency with previous destination in the trip chain

- Computing driving distance based on adjusted origin, waypoints, and original destination

- Assessing trip destinations (i.e., home and workplace location for each device identifier)

- Implementing spatial joins on county, ZIP code, traffic analysis zone, and land use data layers.

Down sampling and data processing for all LDV trips in the INRIX travel data set remove approximately $86 \%$ of the original data, reducing the data set used in this study to approximately 46,700 unique device identifiers, 1.41 million full travel days, 4.48 million trips, and 35.8 million miles of driving. Additional processing details and analysis results on the INRIX GPS data are included in Appendix A.

\subsection{Data Validation}

The processed 2016 INRIX travel data for Columbus are compared to traditional travel surveys to check for consistency and compare trends. Figure 12 shows the distribution of daily vehicle miles traveled (VMT) from the processed INRIX travel data and comparable distributions from the 2009 National Household Travel Survey (NHTS), the 2012 California Household Travel Survey (CHTS), and the 2011 Massachusetts Travel Survey (MTS). While the processed INRIX travel data show slightly lower values compared to the traditional travel surveys, the overall shape of the distributions is similar.

Similarly, Figure 13 shows a comparison of trip counts by time of day from the processed 2016 INRIX travel data for Columbus and comparable data from the 2012 CHTS and the 2011 MTS. All three data sets show a similar pattern of morning/afternoon peaks with trip counts tapering off in the early evening and few trips taking place during the night.

Figure 14 compares the distribution of cumulative dwell times at different location types for the processed 2016 INRIX travel data for Columbus and comparable data from the 2012 CHTS and the 2011 MTS. In addition, the home and workplace location identification methods are validated using the same travel surveys. Results highlight that in the processed 2016 INRIX travel data set, vehicles spend more time parked at home locations and less time parked in public locations compared to data in the CHTS or MTS. Vehicles in the processed 2016 INRIX travel data set also spend slightly less time driving compared to CHTS and MTS data. 


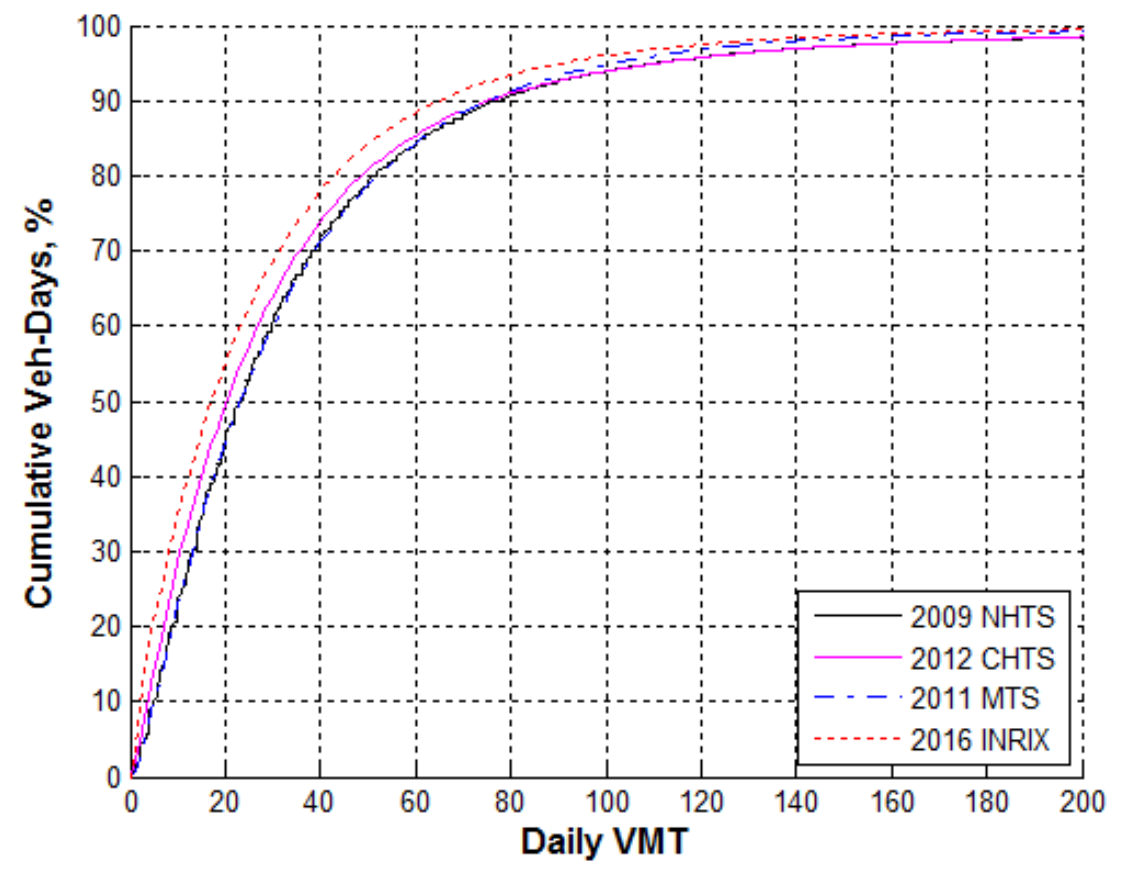

Figure 12. Distribution of daily VMT from multiple sources.

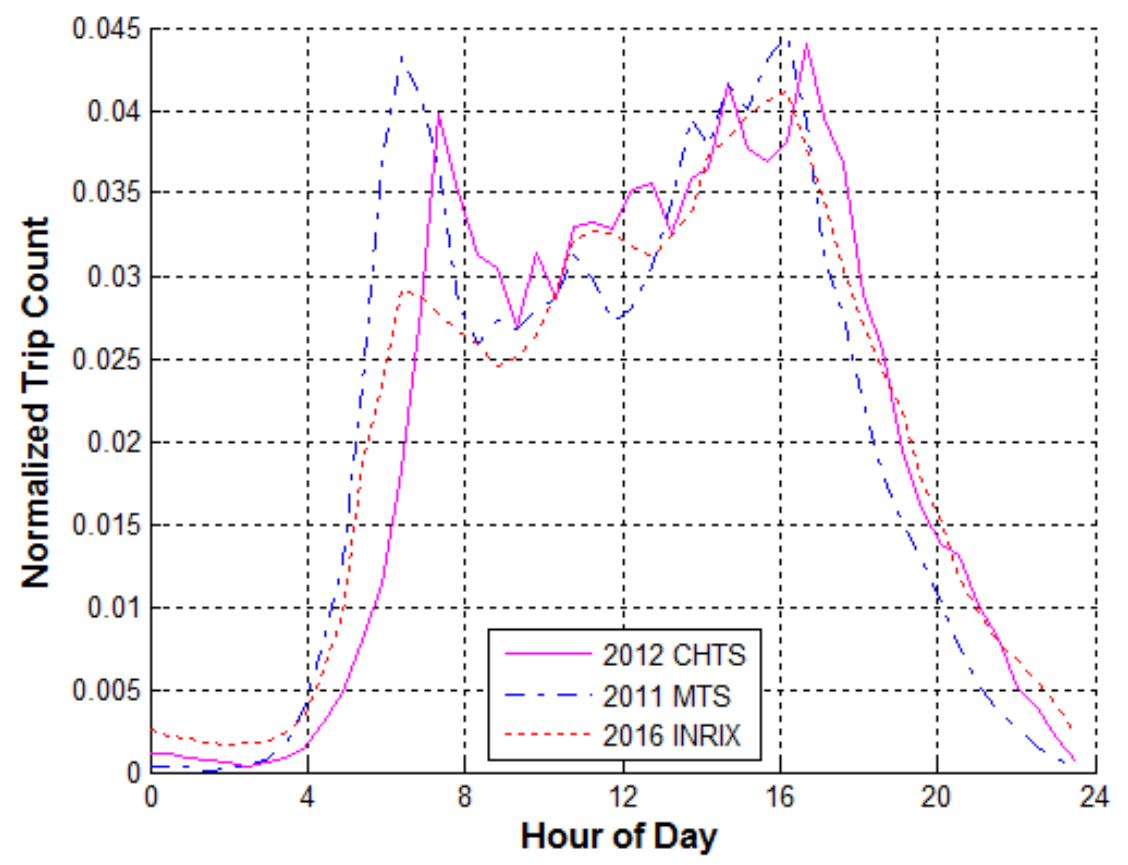

Figure 13. Distribution of trips by time of day from multiple sources. 


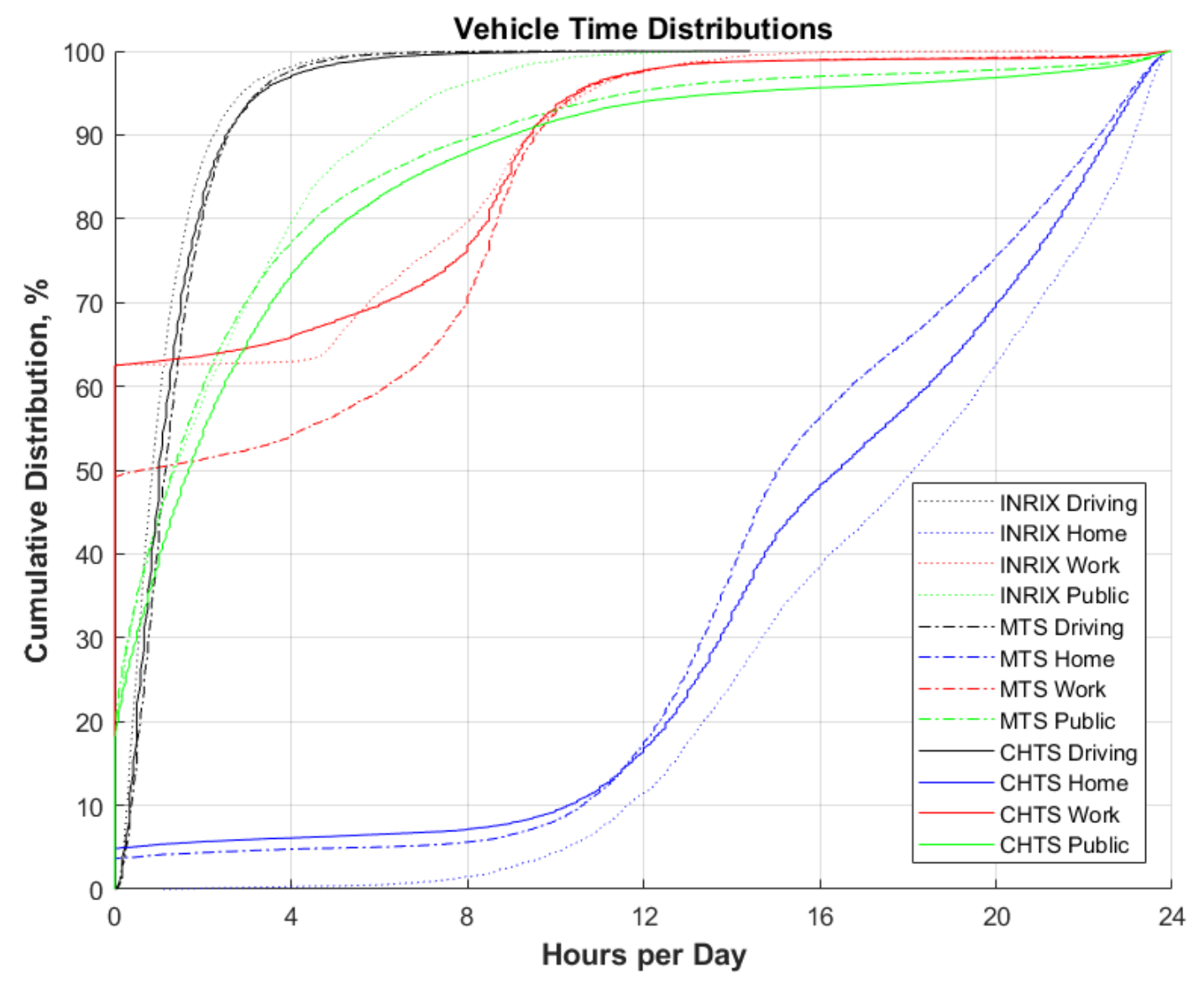

Figure 14. Driving time (black) and dwell times at home (blue), work (red), and public (green) locations for INRIX (solid lines), CHTS (dashed lines), and MTS (dotted lines) data sets.

Table 2 summarizes daily miles traveled and percent of trips by destination type for the three data sets. While daily miles travelled to home and public locations are similar across the three data sets, distance travelled to work is shorter in the INRIX data. The proportion of trips to different destinations is fairly similar across all three data sets.

Table 2. Average daily VMT by destination type and data set.

\begin{tabular}{lcccccc}
\hline & \multicolumn{2}{c}{ Home } & \multicolumn{2}{c}{ Work } & \multicolumn{2}{c}{ Public } \\
& Avg VMT & $\%$ Trips & Avg VMT & $\%$ Trips & Avg VMT & $\%$ Trips \\
\hline INRIX & 12 & $12 \%$ & 9 & $37 \%$ & 18 & $51 \%$ \\
CHTS & 13 & $11 \%$ & 14 & $35 \%$ & 21 & $54 \%$ \\
MTS & 13 & $14 \%$ & 14 & $35 \%$ & 19 & $51 \%$ \\
\hline
\end{tabular}

As additional validation, the processed INRIX data are compared to estimated trip counts by traffic analysis zone (TAZ) from the Mid-Ohio Regional Planning Commission's (MORPC) 2015 travel demand model (Figure 15). The majority of driving trips in the MORPC results are in TAZs within the bounds of Franklin County, and fewer trips are in TAZs from the small towns 
and rural areas outside Franklin County. MORPC 2015 LDV trip count estimates are compared to the processed 2016 INRIX travel data set in Figure 16, which shows a generally good agreement between trends in the MORPC and INRIX data sets. Data from the 2016 INRIX travel data set will therefore be used in this study to estimate PEV charging requirements in Columbus.

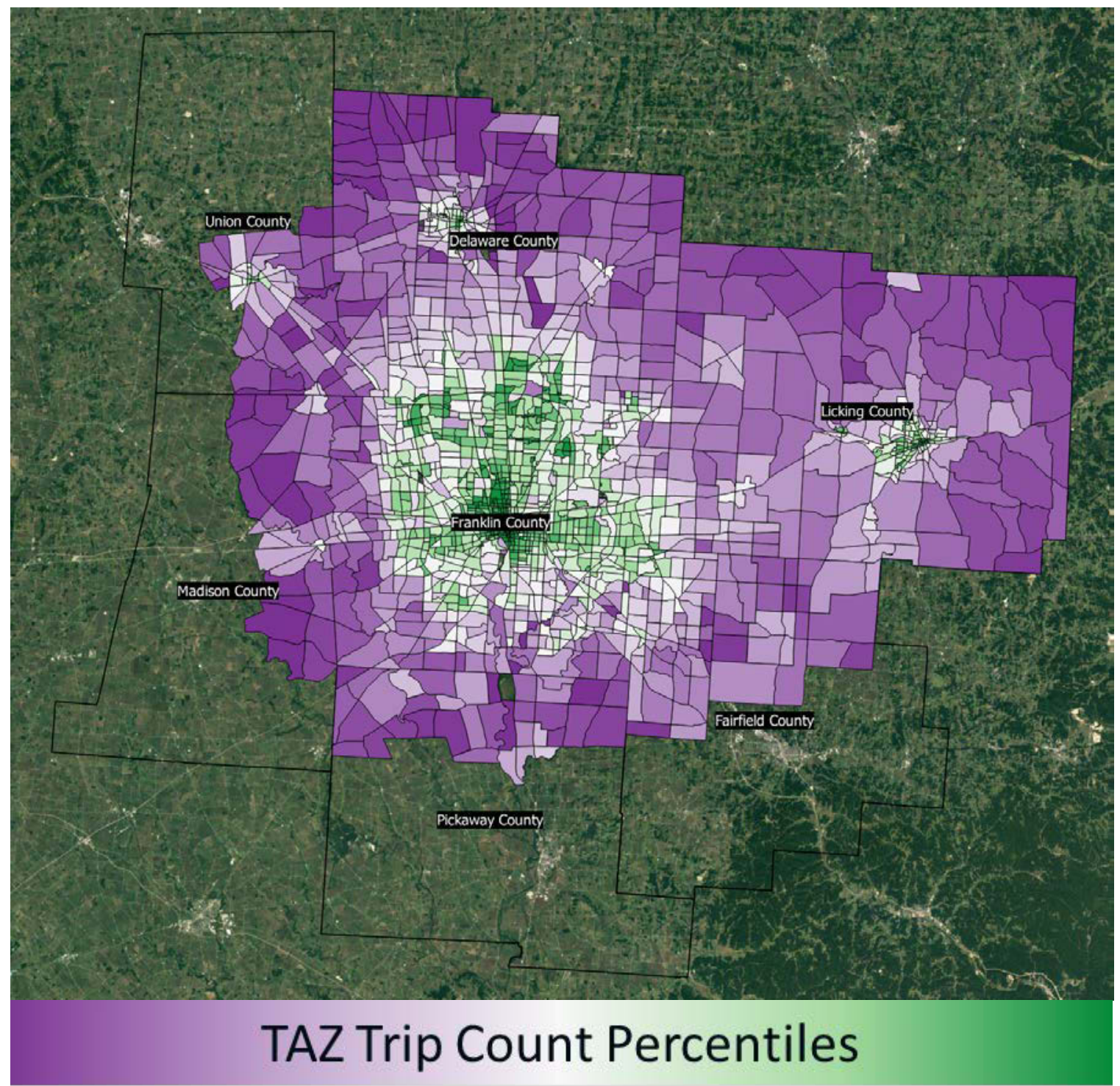

Figure 15. Aggregate LDV trip counts by TAZ from the MORPC 2015 traffic demand model of Columbus.

Satellite imagery credit: @ 2017 Google, Map Data @ 2017 Tele Atlas 


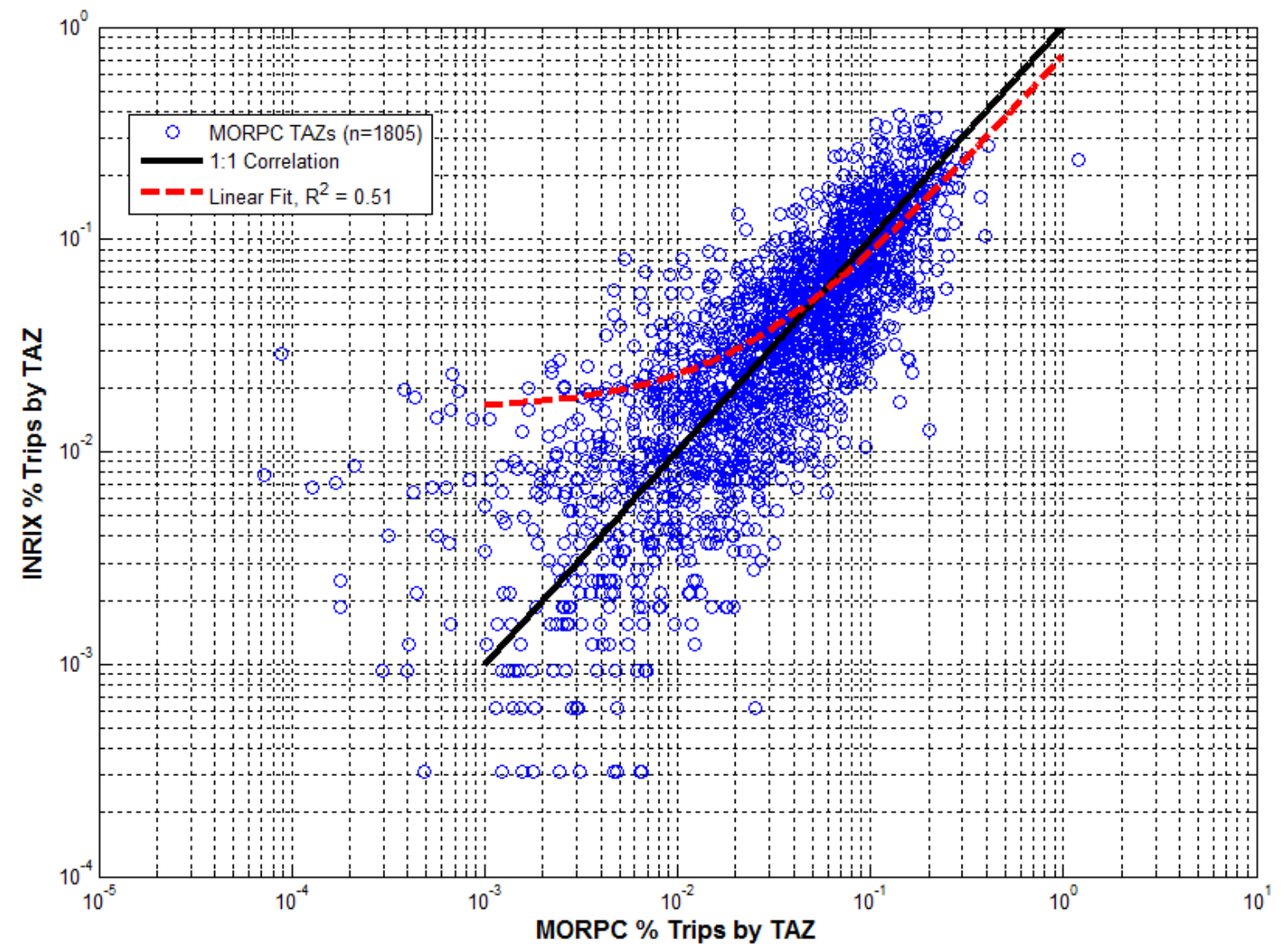

Figure 16. Trip counts from the 2016 INRIX travel data set for Columbus versus MORPC-modeled trip counts by TAZ (each as a percent of all trips). 


\section{PEV Charging Infrastructure Simulation}

NREL's EVI-Pro model was used with the INRIX data to simulate PEV driving and charging, estimate infrastructure requirements, and explore opportunities for siting PEV charging stations in Columbus. Section 4.1 describes the EVI-Pro model and the basic assumptions used in this study, including PEV attributes and charging options. Section 4.2 reports aggregate average charging load profiles and infrastructure requirements for a baseline scenario considering 5,300 PEVs on the road by the end of 2019 (54:46 PHEV/BEV split, spatial PEV adoption in line with that of existing HEVs registrations and mild ambient temperature). To provide a comparison for the EVI-Pro simulations, Section 4.3 reports real-world EVSE utilization data from existing ChargePoint EVSE. Sensitivity analyses around some of the key assumptions are explored in Section 4.4. Finally, a detailed GIS analysis is reported in Section 4.5.

\subsection{EVI-Pro Model Description}

In collaboration with the California Energy Commission, NREL developed EVI-Pro to estimate regional requirements for charging infrastructure to support consumer adoption of light-duty PEVs. EVI-Pro uses PEV market projections and real-world travel data from mass market consumers to estimate future requirements for residential, workplace, and public charging under a variety of scenarios. Outputs of the model include: anticipating spatial/temporal consumer demand for charging accounting for the impact of SUD and MUD residency, weekday/weekend travel behavior, and regional differences in travel behavior and vehicle adoption. A graphical representation of the input/output relationships in EVI-Pro is shown in Figure 17.

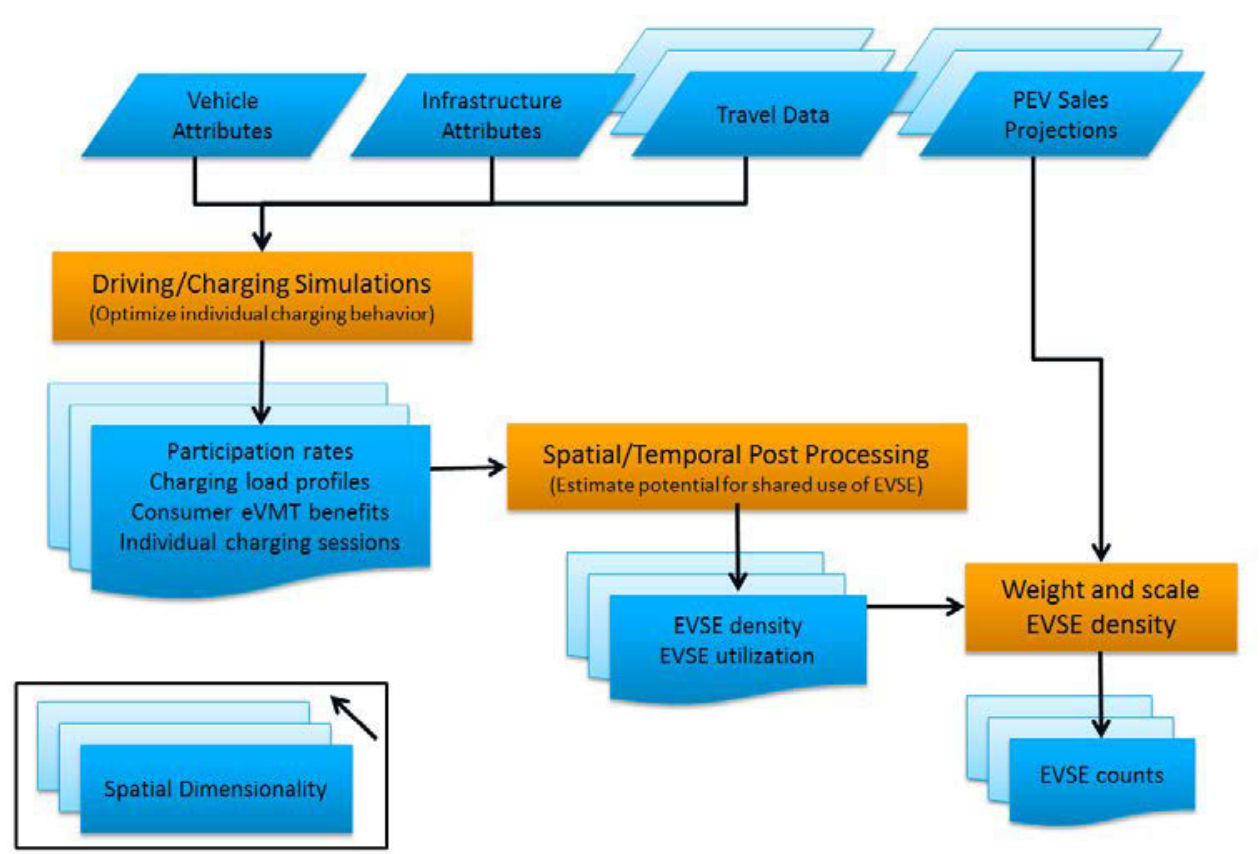

Figure 17. Graphical representation of inputs/outputs and data flow in EVI-Pro.

The fundamental assumption in EVI-Pro is that consumers prefer charging infrastructure that enables them to complete all their travels (based on current vehicle use) while minimizing operating cost. Vehicle energy consumption, which is the main driver of charging requirements, is computed based on highly resolved speed profiles for each different model type and accounts 
for temperature effects on fuel economy (Wood et al. 2017). Table 3 summarizes the attributes of the PEVs considered in this report.

Table 3. Modeled PEV Attributes

\begin{tabular}{lrrrrrr}
\hline & PHEV20 & PHEV50 & BEV100 & BEV250 & $\begin{array}{l}\text { PHEV20 } \\
\text { SUV }\end{array}$ & $\begin{array}{l}\text { BEV250 } \\
\text { SUV }\end{array}$ \\
\hline Chassis Type & Sedan & Sedan & Sedan & Sedan & SUV & SUV \\
\hline $\begin{array}{l}\text { Nominal Electric Driving } \\
\text { Range, mi }\end{array}$ & 20 & 50 & 100 & 250 & 20 & 250 \\
$\begin{array}{l}\text { Nominal Energy } \\
\text { Consumption, Wh/mi }\end{array}$ & 325 & 325 & 325 & 325 & 450 & 450 \\
$\begin{array}{l}\text { Registration Shares } \\
\text { (2016) }\end{array}$ & $22 \%$ & $25 \%$ & $24 \%$ & $17 \%$ & $10 \%$ & $2 \%$ \\
$\begin{array}{l}\text { Assumed Registration } \\
\text { Shares in 2019 Scenario }\end{array}$ & $21 \%$ & $23 \%$ & $22 \%$ & $19 \%$ & $10 \%$ & $5 \%$ \\
\hline
\end{tabular}

Several scenarios are simulated for each consumer to cover a broad range of possible charging options and capture their impact on PEV charging, infrastructure requirements, and resulting electric load. A matrix of all charging options considered is shown in Table 4. Due to the growing interest in high-power direct current fast charging (DCFC), this analysis includes a 150kilowatt $(\mathrm{kW})$ DCFC option for long-range BEVs, while DCFC for BEV100s is limited to 50 $\mathrm{kW}$. PHEVs are assumed to not be capable of DCFC. The effective DCFC charge rate is adjusted for temperature effects as well as charge duration, assuming that charging power tapers as battery state of charge approaches high levels (Wood et al. 2017).

Table 4. Charging Options Available to Consumers in EVI-Pro

\begin{tabular}{|c|c|c|c|}
\hline Location & Level & Power & Comment \\
\hline \multirow[t]{2}{*}{ Home } & L1 & $1.4 \mathrm{~kW}$ & \\
\hline & L2 & $3.6 \mathrm{~kW}$ & $\begin{array}{l}\text { BEVs simulated with higher L2 power to enable full } \\
\text { overnight charge }\end{array}$ \\
\hline Work & L2 & $6.2 \mathrm{~kW}$ & $\begin{array}{l}\text { PHEV on-board charger limits max power to } 3.6 \mathrm{~kW} \\
\text { in EVI-Pro }\end{array}$ \\
\hline \multirow[t]{2}{*}{ Public } & L2 & $6.2 \mathrm{~kW}$ & $\begin{array}{l}\text { PHEV on-board charger limits max power to } 3.6 \mathrm{~kW} \\
\text { in EVI-Pro }\end{array}$ \\
\hline & DCFC & $150 \mathrm{~kW}$ & $\begin{array}{l}\text { BEVs only; charge rate tapers off at high SOC; } \\
\text { BEV100 limited to } 50 \mathrm{~kW}\end{array}$ \\
\hline
\end{tabular}

To estimate aggregate consumer charging demands, individual travel days from real-world data (originally completed using conventional gasoline vehicles) are simulated under different assumptions for charging infrastructure availability and then compared. An example travel day is shown in Table 5. 
Table 5. Example Single-Day Travel Profile

\begin{tabular}{lllll}
\hline Destination & Departure & Arrival & Drive Miles & Dwell Hours \\
\hline Work & 8:20 A.M. & 9:00 A.M. & 32.8 & 5.00 \\
Public & 2:00 P.M. & 3:30 P.M. & 68.9 & 0.25 \\
Public & 3:45 P.M. & 4:00 P.M. & 6.3 & 0.25 \\
Public & 4:15 P.M. & 4:20 P.M. & 0.9 & 0.67 \\
Public & 5:00 P.M. & 5:30 P.M. & 9.2 & 0.25 \\
Public & 5:45 P.M. & 6:00 P.M. & 5.0 & 0.50 \\
Home & 6:30 P.M. & 7:30 P.M. & 46.8 & 12.83 \\
\hline
\end{tabular}

In this study, each individual travel day in the INRIX travel data set is simulated several times for every charging alternative (e.g., Level 1 [L1]-Home, Level 2 [L2]-Home, L1-Home plus L2Work, etc.). For the example travel day shown in Table 5, 18 alternative charging options are simulated, as shown in Figure 18. Each charging option is evaluated based on the total daily electric vehicle miles traveled (eVMT), total daily cost of charging, and the daily electric range (note that for BEVs, an electric range tolerance of 20 miles is implemented, meaning that any charging scenario in which the driving range drops below 20 miles at any point during the simulated day is removed from the list of available options). After all combinations have been evaluated, EVI-Pro selects the scenario that maximizes daily eVMT and minimizes daily cost of charging while satisfying the range constraint. For the example travel day reported in Table 2, the optimized charging strategy for a BEV100 is shown in Figure 19. The charging strategy chosen by EVI-Pro includes three charging events over the course of the 170-mile travel day: a L2 charge upon arriving at work in the mid-morning, a DCFC event just after 4pm, and an L1 overnight charge at home). EVI-Pro repeats this charge behavior selection routine for all travel days in the study and for all vehicle types under consideration.

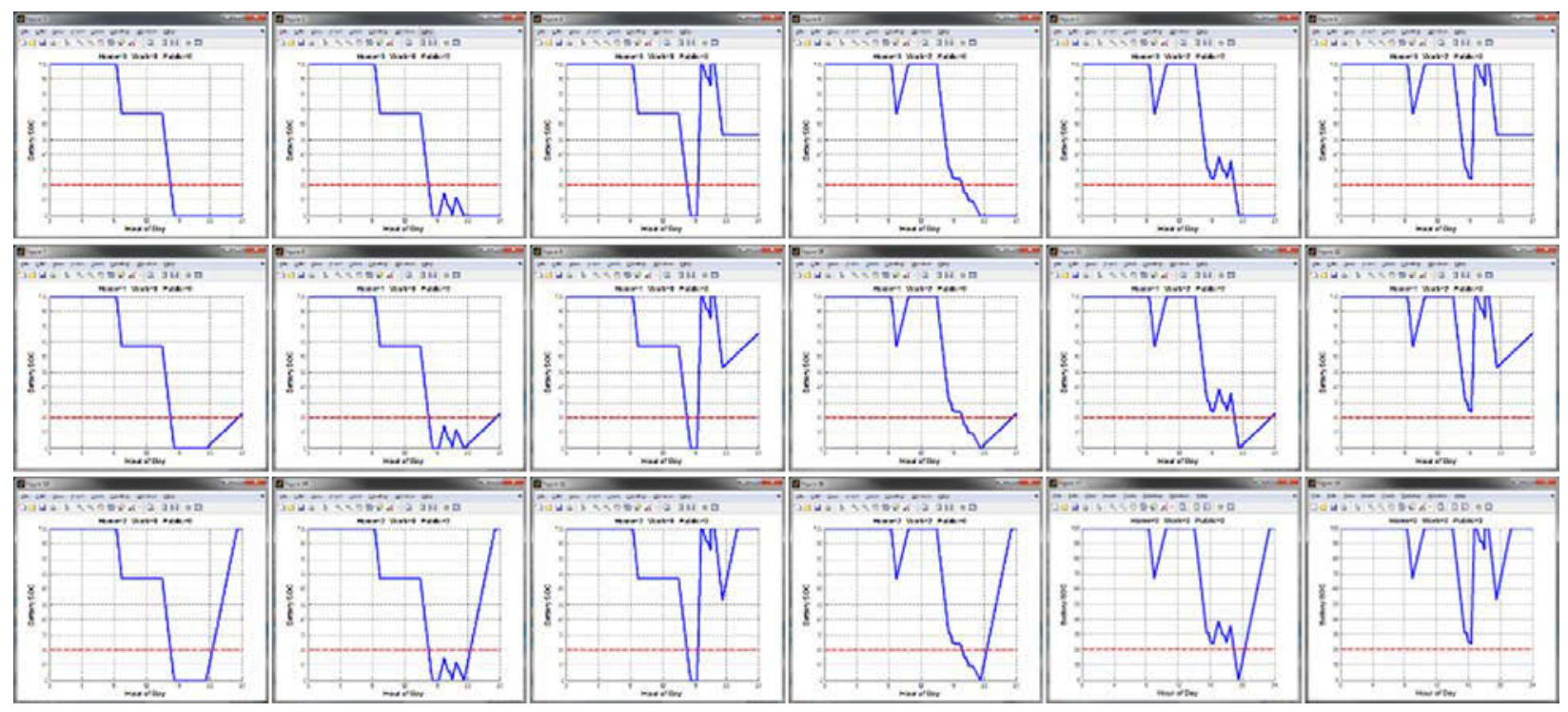

Figure 18. Simulated battery SOC over time for 18 potential combinations of charging of a BEV100 in the example travel day shown in Table 5. 


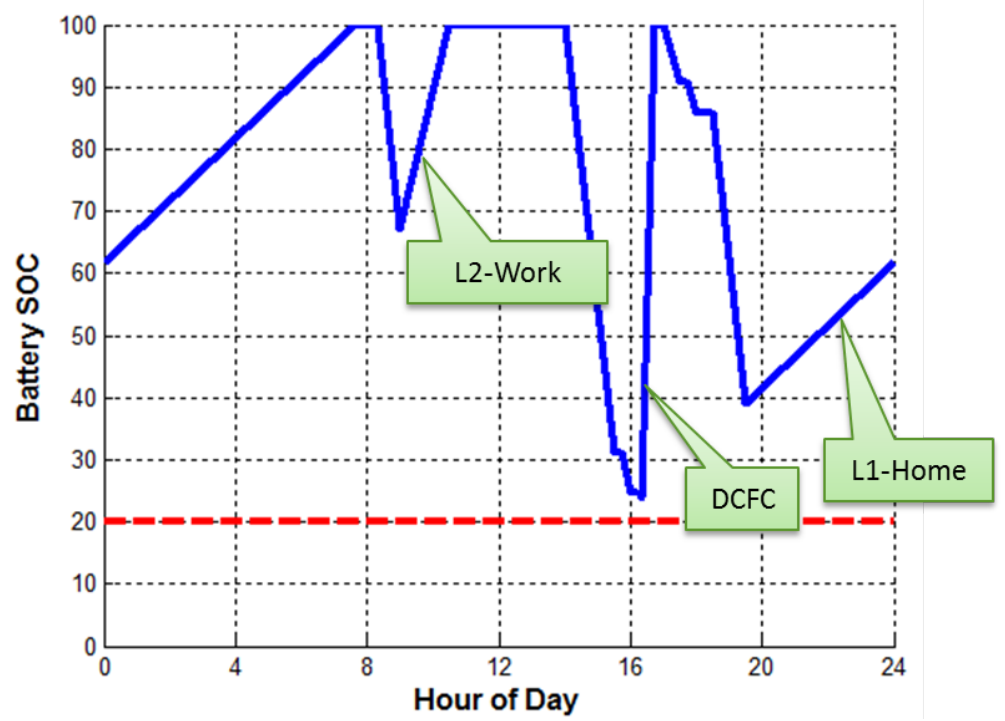

Figure 19. Simulated battery SOC over time for the optimal charging option of a BEV100 in the example travel day shown in Table 5. Red line indicates consumers minimum allowable battery state of charge.

\subsection{Baseline Simulation Results}

A baseline scenario for Columbus is simulated in EVI-Pro using the following set of assumptions:

- 5,300 PEVs on the road by the end of 2019 (based on market shares reported in Table 3)

- 54:46 PHEV/BEV split and an even distribution between short- and long-range PEVs (based on characteristics of the existing national PEV fleet)

- Spatial PEV adoption in line with existing HEVs

- Mild ambient temperature with minimal impact on charge and discharge rates (typical of May in Columbus).

Simulated aggregate charging load profiles by time of day, station type, and vehicle type are shown in Figure 20 as per-vehicle average charging load (not all PEVs charge at the same time, leading to the somewhat low charging loads reported in Figure 20). Simulations assume consumers in both SUDs and MUDs have access to home charging and prefer to do the majority of charging at home (using workplace and public charging as necessary to maximize eVMT). These load profiles are the average charging load of all the PEVs considered, normalized by the total number of the vehicles in the simulation, such that they represent the average charging load of each PEV (total system-level PEV charging loads can be obtained by scaling the results in Figure 20 by the total number of PEVs on the road, per each PEV type). These load profiles indicate that the majority of charging is predicted to happen between 4 p.m. and $12 \mathrm{a} . \mathrm{m}$. at individual households (a result of the assumption that residential charging is available for all PEVs). The use of residential L2 stations (as opposed to residential L1) increases with larger batteries that offer longer electric range, effectively becoming the preferred residential charging option for all BEVs (PHEVs are simulated as utilizing a mix of L1 and L2 at home). Workplace charging loads peak around 8 a.m. for the PHEV20 and PHEV20 SUV as their electric range is 
close to the average commute distance in Columbus, based on the INRIX travel data set. Workplace charging demand is much less prevalent for the PHEV50 and BEV100, and virtually disappears for the longer-range BEVs, since the longer-range vehicles usually do not require non-residential charging to complete daily travel. Public L2 charging is used consistently throughout the day by all PHEVs, under the assumption PHEV owners are invested in maximizing eVMT and actively pursuing opportunities to charge their vehicle away from home (here we assume full support for PHEV charging and consumer willingness to charge as needed). Finally, DCFC demand is modest for the BEV100 and almost nonexistent for longer-range BEVs, since we focus on local travel and do not explicitly simulate long-distance travel from outside the region, which would increase DCFC demand.
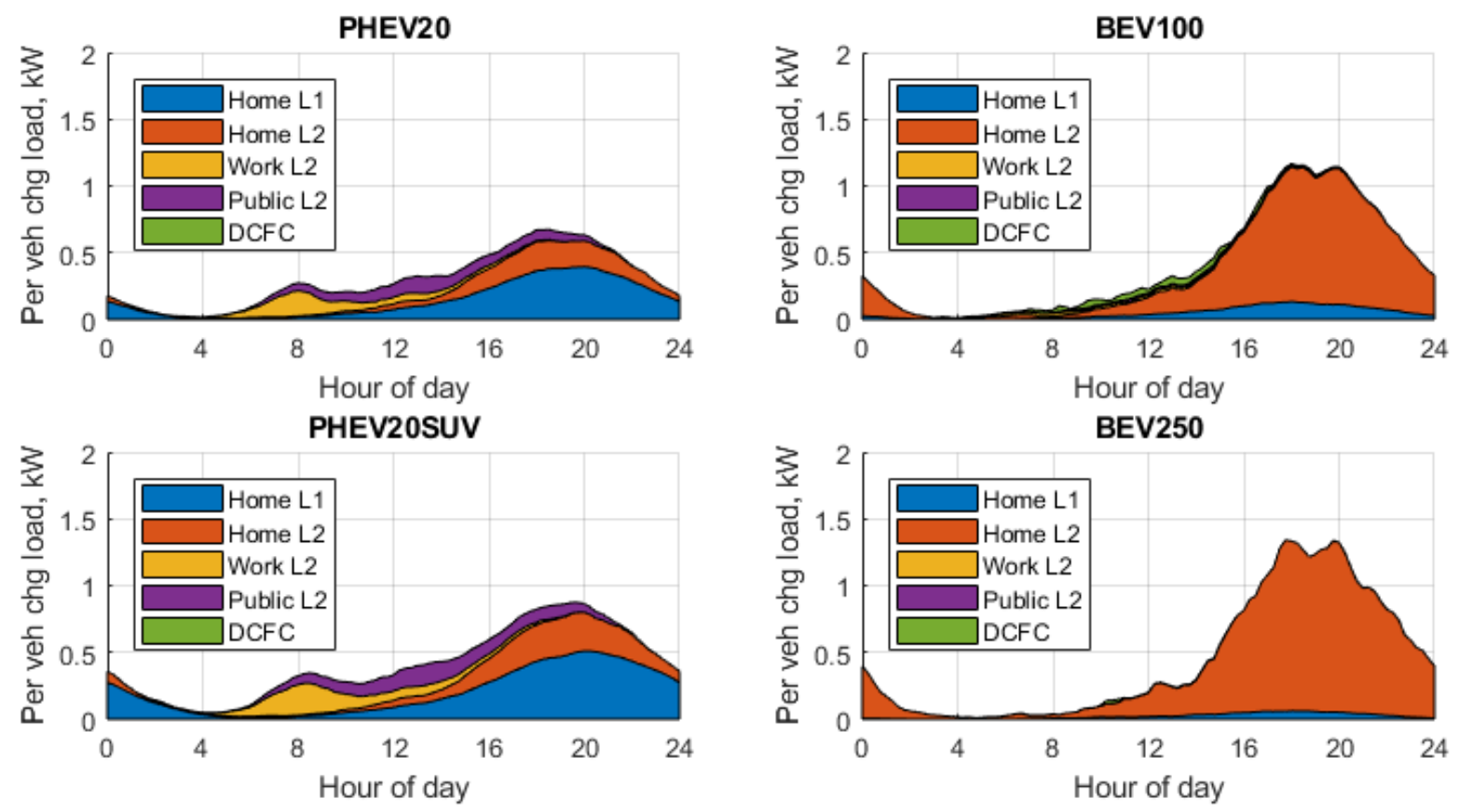

PHEV50
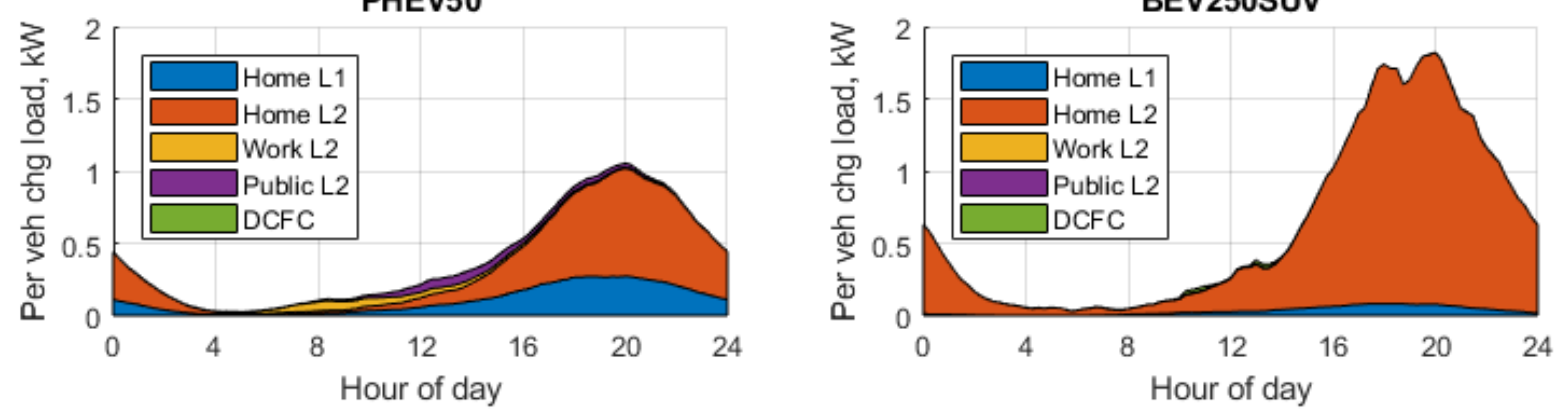

Figure 20. Simulated charging load profiles by time of day, station type, and vehicle type based on the INRIX travel data simulated in EVI-Pro assuming preferential residential charging and PHEVs attempting to maximize eVMT. 
These simulated driving/charging behaviors and related charging power profiles are translated by EVI-Pro into estimates of infrastructure required to meet PEV charging demand in Columbus. Estimated plug counts for Columbus by the end of 2019 are shown in Table 6. A total of 2,424 L1 residential plugs, 2,626 L2 residential plugs (including 404 L2 plugs at MUDs), 138 workplace L2 plugs, 217 public L2 plugs, and 13 public DCFC plugs are estimated to meet charging demands from 5,300 PEVs operating in Columbus by the end of 2019 with the majority of charging requirements coming from the population center of Franklin County.

Table 6. Estimated Plug Counts by County, Location, and Power Level

\begin{tabular}{lrrrrrrrr}
\hline & Delaware & Fairfield & Franklin & Licking & Madison & Pickaway & Union & \multicolumn{2}{c}{ Total } \\
\hline SUD L1 & 319 & 152 & 1,622 & 182 & 36 & 39 & 74 & 2,424 \\
\hline SUD L2 & 313 & 147 & 1,448 & 164 & 32 & 44 & 75 & 2,222 \\
MUD L2 & 27 & 15 & 327 & 18 & 4 & 5 & 8 & 404 \\
Work L2 & 29 & 12 & 70 & 13 & 3 & 8 & 3 & 138 \\
Public L2 & 31 & 13 & 146 & 13 & 2 & 4 & 7 & 217 \\
DCFC & 4 & 1 & 7 & 0 & 0 & 0 & 1 & 13 \\
\hline
\end{tabular}

Home charging at SUDs includes roughly one plug per PEV, split approximately evenly between L1 and L2 EVSE. Prescriptive home charging assignments are implemented in these EVI-Pro results using a heuristic approach that assigns L1 chargers to PEVs with relatively small battery capacity and short daily VMT. Conversely, SUD L2 chargers are assigned to PEVs with relatively large battery capacity and high daily VMT. While the majority of future PEV owners would likely be able to achieve a full overnight charge most of the time using an L1 system that can charge 10kWh over an 8-hour period, corresponding to over 30 miles of electric range (recall that $70 \%$ of travel days in the INRIX data for Columbus were 30 miles or less), EVI-Pro's prescriptive home charger assignment is believed to be a more accurate reflection of consumer home charging preferences in SUDs, with a home L2 charger enabling increased levels of eVMT via mid-day charging and security for infrequent scenarios with high VMT and short overnight dwells where an L1 charger would not permit a full charge.

EVI-Pro estimates that 404 home L2 plugs at MUDs are required to serve the 636 PEVs assumed for adoption by MUD residents by 2019 (12\% of the total assumed Columbus PEVs in this study). This results in approximately two L2 plugs for every three PEVs in Columbus. This level of "sharing" is estimated by EVI-Pro between two extreme scenarios:

1. No EVSE sharing (implying each PEV requires its own L2 plug, as is assumed in SUDs)

2. Ideal sharing (where EVI-Pro examines the aggregate travel patterns of Columbus MUDs and maximizes sharing by ideally scheduling charging events around travel constraints).

While planning for exclusive use of each MUD EVSE by a single PEV is the most conservative assumption, some degree of sharing (particularly at large MUDs) enables more effective use of EVSE investments. The share of PEVs being adopted by MUD residents, access to and use of MUD EVSE, and ability to share MUD EVSE all represent areas warranting further research. A sensitivity scenario investigating non-residential charging as the primary MUD option is presented in Section 4.3. 
Non-residential charging in EVI-Pro is modeled as filling the eVMT "gaps" that are left by home charging. eVMT benefits provided by non-residential charging are most evident with PEVs with relatively short electric ranges and for consumers exhibiting high daily VMT patterns. EVI-Pro projects that a total of 355 non-residential L2 plugs are necessary to support Columbus PEVs maximize their eVMT. This level of non-residential charging support should be considered as a relatively soft requirement considering consumer charging behavior that could significantly relax the non-residential plug requirements. For instance, most of the estimated non-residential L2 charging demand comes from simulated PHEVs, which have the option of using the gasoline engine to complete any trip, reducing EVSE requirements. At the same time, limited availability of residential charging or higher number of long distance trips undertaken by short-range BEV will increase the non-residential infrastructure requirements. Mainstream PHEV consumer dedication to identifying and utilizing non-residential charging and BEV owner attitudes toward public charging remain uncertain.

EVI-Pro estimates consumer demand for fast charging in Columbus can be satisfied by 13 DCFC plugs for the baseline 2019 scenario with 5,300 PEVs. While this estimate may seem low, recall that the baseline scenario assumes only $46 \%$ of Columbus PEVs are BEVs (PHEVs are not simulated as being DCFC-capable). Assuming reliable access to residential charging, BEV250s and BEV250 SUVs are rarely driven more than their electric range in one day based on the travel days in the INRIX data set, implying minimal demand for DCFC. The 1,200 BEV100s trigger the majority of the projected DCFC demand, leading to 13 plugs serving 1,200 BEVs (10.8 DCFC plugs per 1,000 BEV100s), which is consistent with existing studies (Melaina and Helwig 2014, Davis and Alexander 2014, Wood et al. 2017).

Despite EVI-Pro's low projected demand for DCFC, further development of the Columbus DCFC network is likely required to enable growth in the local BEV market and provide a more reliable network of non-residential charging opportunities to cope with range anxiety and enable long-distance travel for vehicles driving across the Columbus region. Reliable, convenient, and visible access to a safety net of fast charging stations is likely required by many consumers to consider a BEV purchase (regardless of the frequency with which consumers use the network). Additionally, the baseline scenario assumes that all PEVs have access to home charging (including residents of MUDs), which will not always be the case. Sensitivity analysis to explore the impact of these assumptions on the results shown in Table 6 are reported in the remainder of Section 4.

\subsection{Real-World EVSE Use}

Examining actual real-world charging data from EVSE currently in operation can help stakeholders anticipate use of future non-residential EVSE. This section presents EVSE use from ChargePoint and compare them with simulated results from EVI-Pro.

\subsubsection{ChargePoint Data}

In support of the Smart Columbus Initiative, ChargePoint provided NREL with individual event data from over 117,000 charging sessions from their networked stations in Columbus as well as from stations in Austin, Texas, and Seattle, Washington, from October 2015 to September 2016. Austin and Seattle were selected for comparison with ChargePoint data from Columbus based on 
having similar population and population density statistics, but larger PEV markets and greater use of public EVSE (relative to existing ChargePoint EVSE in Columbus).

Table 7 compares Columbus, Austin, and Seattle in terms of population (from the U.S. Census), PEV market size (from IHS data), ChargePoint networked plugs (from the U.S. Department of Energy's Alternative Fuels Data Center), and ChargePoint EVSE use (from ChargePoint data). Note that the PEV count in Columbus in this table is lower than the PEV count previously reported since this analysis is conducted at the city level (as opposed to the Columbus sevencounty region used in the rest of this report). Also note that the data provided by ChargePoint did not include station/plug identifiers, so Alternative Fuels Data Center data from this time frame was used to determine the number of ChargePoint plugs in each city.

Table 7. ChargePoint Charging Statistics by Location and Level

\begin{tabular}{|c|c|c|c|c|}
\hline & & $\begin{array}{c}\text { Columbus, } \\
\text { Ohio }\end{array}$ & $\begin{array}{l}\text { Austin, } \\
\text { Texas }\end{array}$ & $\begin{array}{c}\text { Seattle, } \\
\text { Washington }\end{array}$ \\
\hline & Population & 850,000 & 948,000 & 704,000 \\
\hline & Population density, residents $/ \mathrm{mi}^{2}$ & 3,900 & 3,400 & 4,700 \\
\hline & PEVs & 1,900 & 3,700 & 14,800 \\
\hline & BEVs & $34 \%$ & $57 \%$ & $68 \%$ \\
\hline \multirow{5}{*}{$\begin{array}{c}\text { Non- } \\
\text { residential } \\
\text { Level } 2\end{array}$} & Plug Count & 11 & 401 & 132 \\
\hline & Session Count & 1,700 & 81,500 & 28,200 \\
\hline & Sessions/day/plug & 0.42 & 0.56 & 0.59 \\
\hline & Total Energy, kWh & 12,000 & 692,000 & 263,000 \\
\hline & Energy per session, kWh & 7.0 & 8.5 & 9.3 \\
\hline \multirow[t]{5}{*}{ DCFC } & Plug Count & 12 & 3 & 3 \\
\hline & Session Count & 140 & 3,290 & 2,430 \\
\hline & Sessions/day/plug & 0.03 & 3.01 & 2.22 \\
\hline & Total Energy, kWh & 1,800 & 29,000 & 33,100 \\
\hline & Energy per session, kWh & 12.6 & 8.8 & 13.6 \\
\hline
\end{tabular}

While all three cities are similar in terms of population and population density, the PEV markets in Austin and Seattle are significantly larger than the Columbus PEV market (approximately twice as large in the case of Austin and eight times larger than Columbus in Seattle). The ChargePoint network of L2 EVSE in Austin and Seattle are also significantly larger than in Columbus, with many more charging sessions and higher energy dispensed per charge (likely a result of higher BEV shares in Austin and Seattle). Despite these differences, use of ChargePoint L2 EVSE in all three cities is comparable: between 0.42 and 0.59 sessions per day per plug. Average energy dispensed per charging session is also quite similar across all three cities: between 7.0 and $9.3 \mathrm{kWh}$ dispensed per charging session.

In terms of DCFC plugs in the ChargePoint network, Columbus had significantly more infrastructure at 12 DCFC plugs compared to three in both Austin and Seattle. However, despite Columbus having more DCFC infrastructure, Austin and Seattle both experienced significantly higher levels of DCFC use on the ChargePoint network, both overall and on a per-plug basis. ChargePoint DCFC stations in Columbus experienced 0.03 session per day per plug, compared 
to 3.01 and 2.22 sessions per day per plug in Austin and Seattle, respectively. Low DCFC use in Columbus could be related to the fact that Columbus had a small BEV fleet during this period (34\% of 1,900 PEVs in Columbus were BEVs, or about $650 \mathrm{BEVs}$ in total). While ChargePoint DCFC infrastructure was used sparingly, energy throughput per session was comparable to Austin and Seattle.

Understanding charging behavior by location type is another important consideration. ChargePoint data classified sessions by location type, which are summarized in Table 8 for all three cities. The longest dwell times (about 9 hours on average) are found at multifamily buildings, or MUDs, where vehicles are typically plugged in overnight and where the greatest amount of energy per charging event is provided to the vehicles, on average. The average dwell time at workplaces is 4 hours, while the actual charging time is just under 2 hours (leading to an average of $7.4 \mathrm{kWh}$ dispensed per event). Retail locations, with typically short dwell times, show vehicles charging for half an hour on average at DCFC stations, with an average throughput of $11.8 \mathrm{kWh}$.

Table 8. Charging Statistics by Location Type and Level, ChargePoint Data

\begin{tabular}{lllll}
\hline Location type & Level & $\begin{array}{l}\text { kWh / charging } \\
\text { event }\end{array}$ & $\begin{array}{l}\text { Charging } \\
\text { duration (min) }\end{array}$ & $\begin{array}{l}\text { Dwell time } \\
\text { plugged in (min) }\end{array}$ \\
\hline Education & L2 & 8.6 & 133 & 175 \\
\hline Healthcare & L2 & 9.6 & 137 & 217 \\
\hline Hospitality & L2 & 10.7 & 164 & 367 \\
\hline Multifamily & L2 & 14.2 & 177 & 532 \\
\hline Municipal & L2 & 10.1 & 135 & 378 \\
\hline Parking & L2 & 7.9 & 120 & 260 \\
\hline Parks and Rec & L2 & 11.1 & 147 & 338 \\
\hline Retail & L2 & 5.3 & 84 & 189 \\
\hline Workplace & L2 & 7.4 & 112 & 240 \\
\hline Retail & DCFC & 11.8 & 34 & 37 \\
\hline Workplace & DCFC & 11.8 & 57 & 116 \\
\hline
\end{tabular}

The daily distribution of charging events, by EVSE type and day of the week is shown in Figure 21 for all three cities. Results highlight the differences between workplace and public charging. During weekdays, use of L2 EVSE at workplaces peaks between 8 and 9 a.m. and right after noon, with significantly less use in the late afternoon. In contrast, use of public L2 EVSE is fairly constant from the early morning through the evening. Charging sessions for both workplace and public L2 EVSE during weekends are about an order of magnitude lower and both show a more uniform distribution during the day. Use of workplace and public DCFC stations show somewhat similar distributions with charging sessions ramping up around 8 a.m. and extending through the evening. Again, use during weekdays is significantly higher compared to weekends. 

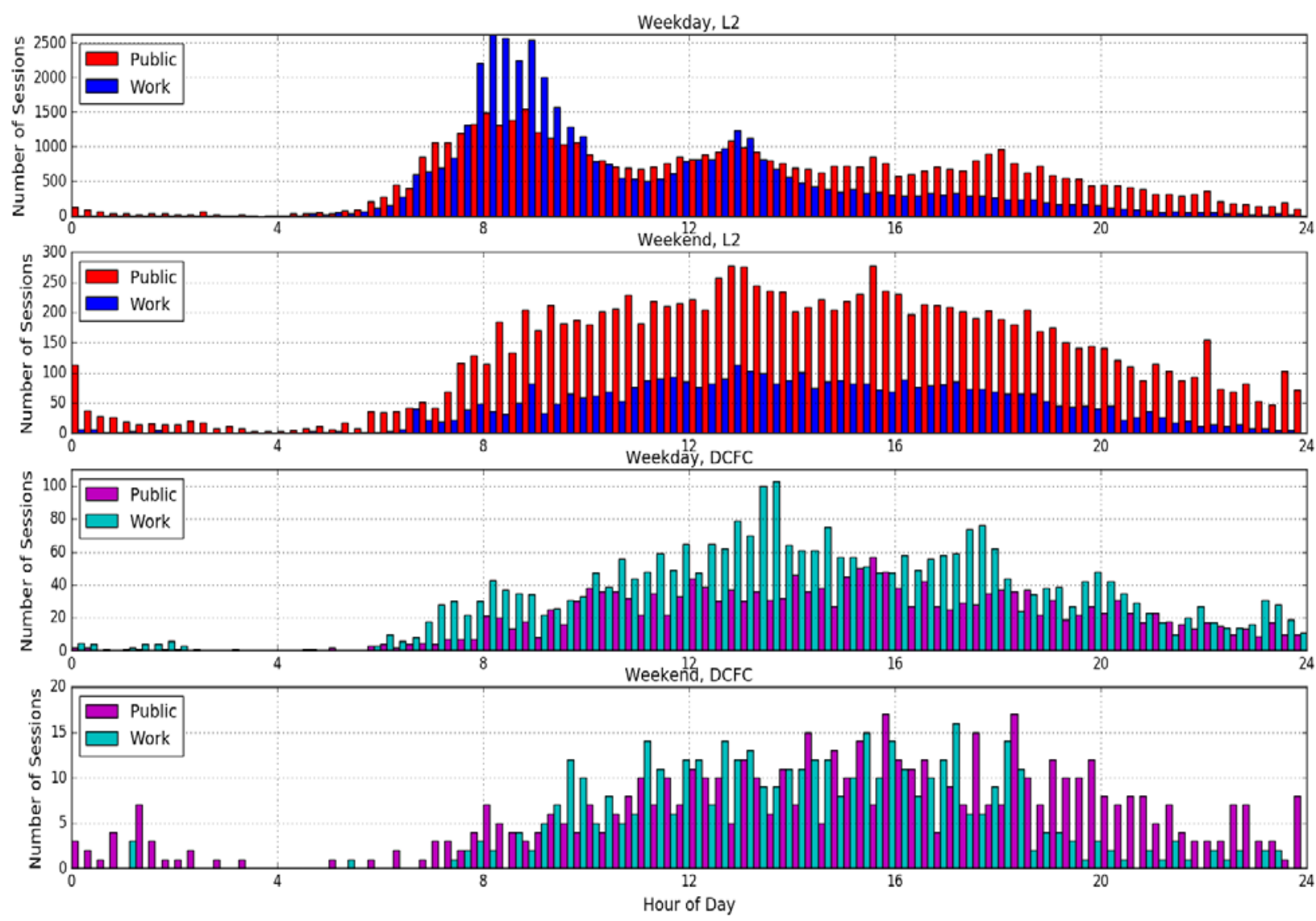

Figure 21. Daily distribution of ChargePoint charging events by EVSE type and day of the week (note the vertical axis scaling differences between subplots).

\subsubsection{Comparison with Simulation Results}

In addition to estimating the demand for charging infrastructure, EVI-Pro simulates the use of these stations based on local travel patterns. Table 9 compares charging events per day per plug as well as energy dispensed per event as projected by EVI-Pro with the ChargePoint data. Simulated results from EVI-Pro in terms of energy dispensed per session are in line with the empirical data for charging at public L2 stations, while EVI-Pro overestimates energy dispensed per session at DCFC stations (potentially due to differences in arrival SOC, implying that consumers may be stopping to charge at DCFC stations prior to the 20-mile range tolerance assumed in EVI-Pro, or might use DCFC for opportunity charging that uses less energy).

In terms of frequency of use (sessions per plug per day), EVI-Pro overestimates use of L2 EVSE by approximately a factor of two. This result likely stems from the fact that EVI-Pro simulates PEV drivers (and PHEV drivers in particular) as attempting to maximize eVMT. In reality, some consumers may elect to forego public charging at L2 EVSE for a variety of reasons, especially for PHEV owners that can rely on their gasoline engine for range extension.

Projected use of DCFC stations in EVI-Pro (1.22 sessions per day per plug) is significantly higher than the existing use of the ChargePoint DCFC network in Columbus ( 0.03 session per day per plug), but still below use in Austin and Seattle (3.01 and 2.22 sessions per day per plug, respectively). 
Table 9. EVI-Pro Station Use Compared to ChargePoint Data

\begin{tabular}{lllll}
\hline & L2 & L2 & DCFC & DCFC \\
& sessions/day/plug & kWh/session & sessions/day/plug & kWh/session \\
\hline EVI-Pro Result & 1.06 & 8.5 & 1.22 & 14.8 \\
CP-Columbus & 0.42 & 7.0 & 0.03 & 12.6 \\
CP-Austin & 0.56 & 8.5 & 3.01 & 8.8 \\
CP-Seattle & 0.59 & 9.3 & 2.22 & 13.6 \\
\hline
\end{tabular}

\subsection{Sensitivity Analysis}

\subsubsection{Local PEV Market and Ambient Conditions}

Results presented in Section 4.2 refer to a baseline scenario. In this section, sensitivity analyses around some of the key parameters are explored to isolate impacts on charging infrastructure requirements. The following sensitivity cases are explored to better inform stakeholders on the implications of different assumptions on the PEV charging network required to support 5,300 PEVs in Columbus by 2019:

- PHEV/BEV split: 1:4 and 4:1 PEV sales by 2019 (as opposed to the 1:1 ratio used in the baseline simulations)

- Range preference: exclusively short- or long-range PEV sales by 2019 (as opposed to the mix shown in Table 3)

- Spatial disaggregation based on existing LDV and PEV registrations (as opposed to existing HEV registrations)

- Winter conditions: $0^{\circ} \mathrm{C}\left(32^{\circ} \mathrm{F}\right)$ ambient temperature, leading to faster discharge and slower DCFC charge rates.

The magnitude and direction of these sensitivities on plug requirements at workplaces, public destinations, and DCFC plugs in Columbus are shown in Figure 22. Results show that the PEV range preference has the largest influence on infrastructure requirements, including demand for L2 plugs ( $-25 \%$ to $+20 \%$ for workplace and $-20 \%$ to $+15 \%$ for public) and DCFC plugs. In particular, assuming all BEVs have a 100-mile range almost doubles the DCFC plugs required. The relative preference between PHEVs and BEVs is another major determinant of plug requirements. Note that an increased share of PHEVs (4:1 scenario) will increase the need for non-residential L2 charging (by about $25 \%$ compared to the baseline; again assuming consumer preference to maximize eVMT), but decreases the need for DCFC by a similar proportion (as PHEVs are assumed to not use DCFC).

While the overall influence of the spatial disaggregation of PEV adoption on charging infrastructure requirements is shown to be small, it will largely affect the geographical distribution of these plugs. Ambient temperature is known to drastically affect the energy consumption of PEVs (Lohse-Busch et al. 2013), both for higher and lower temperatures (due to cabin thermal conditioning, charging efficiency, and battery thermal considerations). This is reflected in the demand for non-residential charging in the winter sensitivity analysis performed here: on a winter day with an ambient temperature of 0 Celsius, $7 \%, 31 \%$ and $36 \%$ more work L2, public L2 and DCFC plugs are needed, respectively, compared to the mild temperature 
assumed in the baseline scenario. Summer conditions in Columbus have a lower effect on the overall infrastructure requirements, and are not considered here since the PEV charging network is designed based on the harshest conditions (this will be different in different climatic zones in which summer is the harshest environment for PEVs).
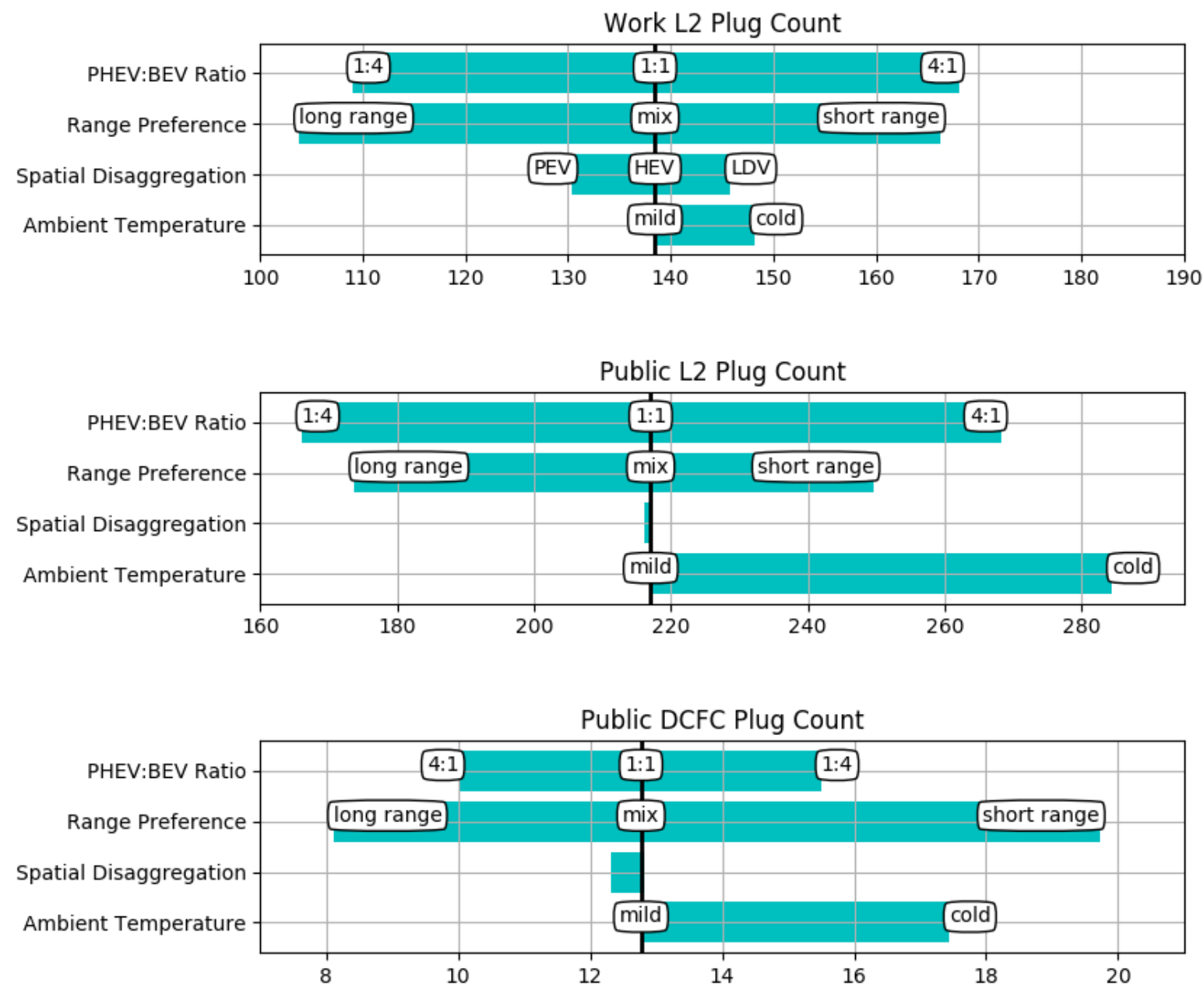

Figure 22. Sensitivity analysis of estimated Columbus PEV charging plug requirements.

Residential charging can be performed with EVSE of different charging power levels: L1 or L2. While the preference for different residential EVSE greatly affects the charging load profiles shown in Figure 20 (greater use of L1 residential charging will smooth the evening peak and sustain demand longer throughout the night), it has little impact on the non-residential plug requirements.

\subsubsection{MUD Charging Sensitivity}

Baseline results assume that all PEVs adopted by residents of MUDs (12\% of the Columbus PEV goal) have regular access to residential charging. However, this will likely not be the case in every situation. Here we explore the impact on non-residential charging infrastructure 
requirements if PEVs in MUDs do not have access to home charging and are exclusively reliant on non-residential infrastructure to meet all their charging needs.

Results for residential charging at SUDs are unaffected by this sensitivity analysis, meaning that SUD results from Table 6 still hold. The 389 L2 plugs at MUDs projected in the baseline scenario are eliminated in this sensitivity. Overall, eliminating home charging at MUDs has a dramatic effect on consumer demand for non-residential charging. PEVs in MUDs see an approximate $750 \%$ increase in demand for L2 charging at workplaces and public locations while demand for DCFC increases by $690 \%$. The aggregate impact on the total charging infrastructure is somewhat mitigated by the fact that only $12 \%$ of PEVs are assumed to be owned by MUD residents, resulting in aggregate increase in non-residential charging demand of $90 \%$ for L2 and $83 \%$ for DCFC charging stations. Note that despite this mitigation, the impacts are still quite significant relative to the other sensitivities explored in Figure 22. Also note that the assumption that $12 \%$ of Columbus PEVs are allocated to MUDs is a rough approximation, and higher levels of PEV adoption in MUDs would be expected to have significant impacts on projected demand for DCFC in Columbus.

\subsubsection{Workplace Charging Sensitivity}

Availability of workplace charging is an attractive convenience for consumers and potentially an effective tool for encouraging the adoption of PEVs (DOE AFDC) and better integrating them with the power system by providing more charging diversity and reducing load clustering. While baseline simulation results in this report assume that consumers prioritize charging at home (as opposed to workplace and public charging) we performed a sensitivity analysis assuming ubiquitous availability of workplace charging at no cost for PEV drivers to estimate bounding impacts on consumer charging behavior.

The EVI-Pro baseline scenario is modified to assume that employers across Columbus offer free workplace charging to employees and PEV drivers attempt to maximize use of workplace charging in an economically efficient manner. We call this scenario "workplace preference", and EVI-Pro simulations reveal an increase of approximately $500 \%$ in demand for workplace charging in the workplace preference scenario compared to the baseline scenario (827 workplace L2 plugs supporting 5,300 PEVs, as opposed to the 138 workplace L2 plugs estimated in the baseline scenario). While not all simulated PEVs made a trip to work during their simulated day of travel, recall from the INRIX data analysis that $37 \%$ of Columbus trips were estimated as trips to work, resulting in significant demand for workplace charging in this scenario.

Increased utilization of workplace charging also has a significant impact on the shape of the PEV charging load profiles. Simulated load profiles resulting from the workplace preference scenario are shown in Figure 23 by PEV type. Relative to the load profiles in the baseline scenario (Figure 20), which assumed home-dominant charging behavior, a significant amount of charging shifts from early evening to the morning hours when PEVs are parked at workplaces. This shift decreases the overall PEV charging peak by approximately $30 \%$ and results in two peaks of smaller magnitude, one in the morning and one in the early evening. 

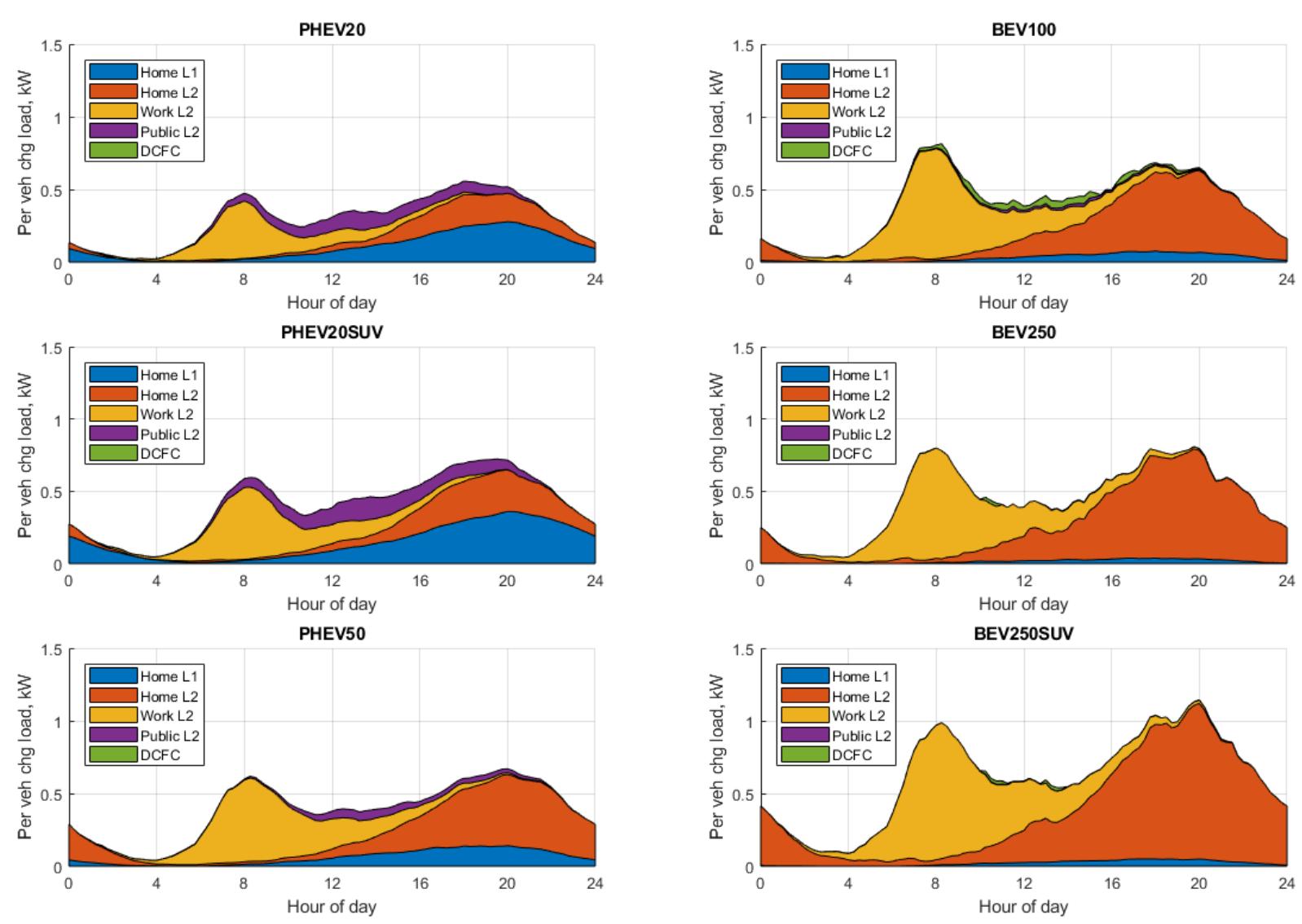

Figure 23. Simulated charging load profiles by time of day, station type, and vehicle type based on the INRIX travel data simulated in EVI-Pro assuming free workplace charging and PHEVs attempting to maximize eVMT.

\subsection{Geographic Information System Analysis}

Projections for the baseline scenario indicate that Columbus would need 404 L2 plugs at MUDs, 138 L2 plugs at workplaces, 217 L2 plugs at public locations, and 13 DCFC plugs to satisfy consumer charging demand from 5,300 PEVs in 2019. This section uses EVI-Pro results from the baseline scenario to conduct a "hot spot" analysis of demand for L2 public charging in Columbus. Moreover, a spatial analysis of existing DCFC stations in Columbus is conducted to highlight synergies and favorable areas for continued development of the local network.

\subsubsection{Public L2 Stations}

To identify promising locations for new public L2 EVSE in Columbus, EVI-Pro results were processed to identify 300 "hot spots", grouped into three tiers (100 locations in each tier, colorcoded by priority) based on simulated use. These results highlight locations where PEVs were simulated to be frequently parked for long durations at low battery SOC - conditions likely to indicate future demand for non-residential L2 charging. These "hot spots" are illustrated in Figure 24 as 0.3 -mile-diameter bubbles, representing a walkable distance of 800 feet from the center of each bubble. The locations of existing L2 chargers and future sites under consideration 
by local planners in Columbus are included for comparison. The majority of these "hot spots" are located in Franklin County, with a smaller number located in the six counties surrounding the city. Additional maps are included in Appendix B.

In many cases, simulated "hot spots" are coincident with the locations of existing or planned public L2 EVSE, confirming local intuition regarding expectations for consumer demand for public charging in such locations, most notably throughout the downtown Columbus area stretching northward towards The Ohio State University campus and in the Easton Shopping Center inside the I-270 beltway on the northeast side of Columbus. The "hot spot" analysis is perhaps most valuable in instances where modeling can complement local intuition. For instance, several high-priority "hot spots" appear throughout the Polaris shopping area just north of Franklin County along the west side of I-71. While this location is included on the list of potential future EVSE sites, modeling suggests that several L2 chargers in this location could be warranted. Similar locations include sites in Dublin, Ohio, just east of the I-270 junction and US33; the Crosswoods area near the junction of I-270 and US-23; and long-term parking outside John Glenn Columbus International Airport. 


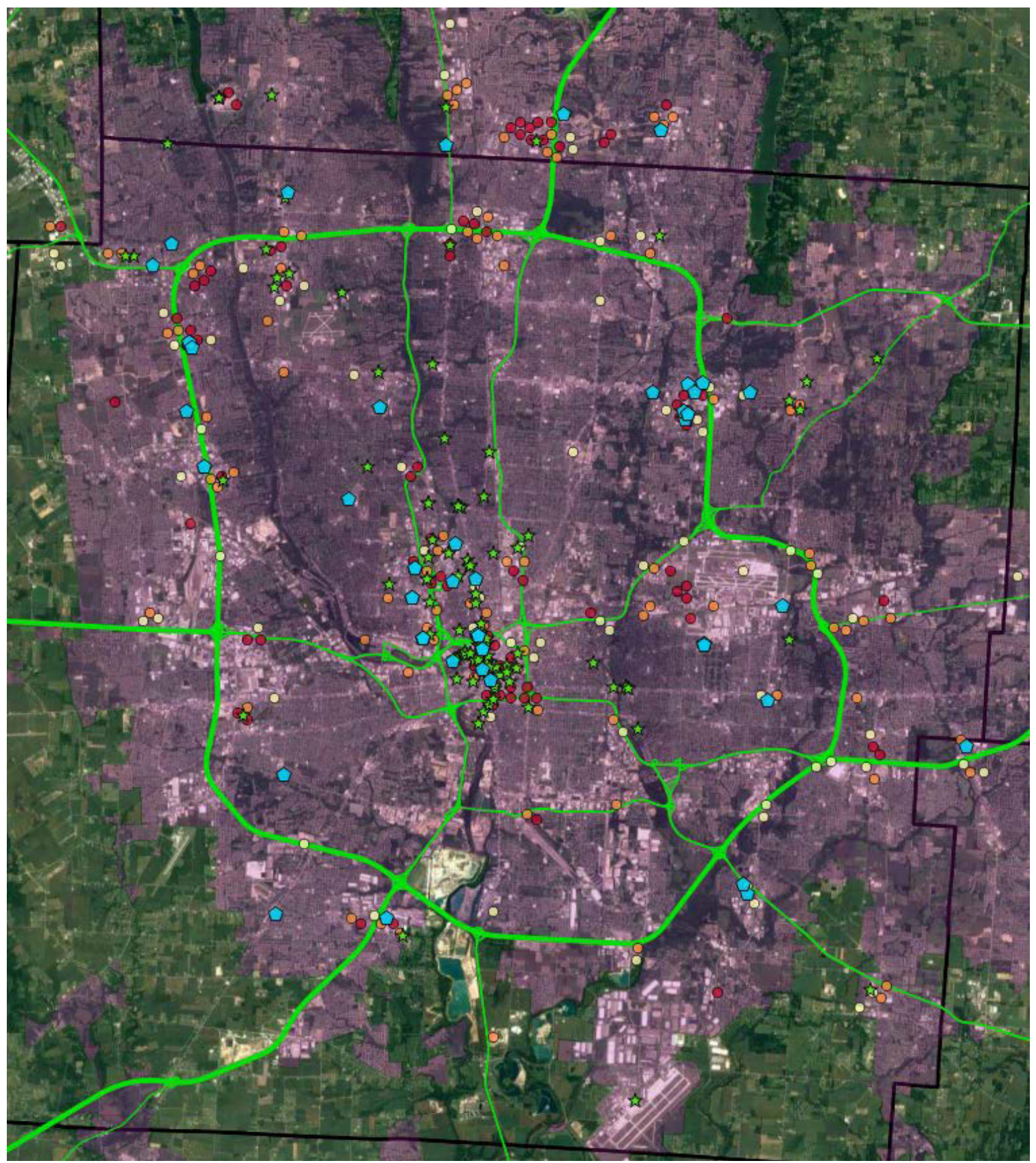

Figure 24. Simulated PEV charging "hot spots" for L2 public charging (0.3-mi diameter) color coded by tier $\left(1^{\text {st }}\right.$ tier $=$ red, $2^{\text {nd }}$ tier $=$ orange, $3^{\text {rd }}$ tier $=$ yellow), existing L2 EVSE (blue pentagons), and future sites under consideration by local planners (green stars). Purple outline denotes Columbus urban area.

Satellite imagery credit: (c) 2017 Google, Map Data @ 2017 Tele Atlas

\subsubsection{Public DCFC Stations}

While the modest number of DCFC plugs projected by EVI-Pro (fewer than the existing DCFC plug count in Columbus) implies that consumer demand for DCFC is expected to remain low in the near term, providing consumers with access to an extensive, convenient, and reliable network of DCFC stations is likely necessary to enable mainstream consumer adoption of BEVs and 
support long-distance travel through the Columbus region. Providing a safety net of charging to help alleviate range anxiety concerns is cited as one of the keys to enabling increased consumer adoption of BEVs (Hall and Lutsey 2017).

To that end, a hypothetical network of 29 DCFC stations that could provide such consumer benefits was synthesized and is shown in Figure 25. This network was developed around the existing 16 DCFC stations in Columbus providing both CHAdeMO and SAE Combo connections (i.e., stations capable of charging all BEV models currently available, including Tesla BEVs with the appropriate CHAdeMO adapter). The hypothetical network attempts to maximize coverage using data on annual average daily traffic from the Federal Highway Administration. Highways and surface streets in the Federal Highway Administration data base are shown with thickness proportional to annual average daily traffic alongside the existing 16 stations and 13 hypothetical station locations. Hypothetical station locations are iteratively assigned to maximize annual average daily traffic coverage with the constraint that new stations are not located within approximately 3 miles of an existing DCFC station. While this hypothetical network focuses on providing DCFC coverage within Franklin County, additional support could be provided by installation of DCFC stations in the six counties adjacent to Franklin County. Researchers from The Ohio State University have developed several similar networks using different methods, which are also recommended for consideration (Wu and Sioshansi 2017). 


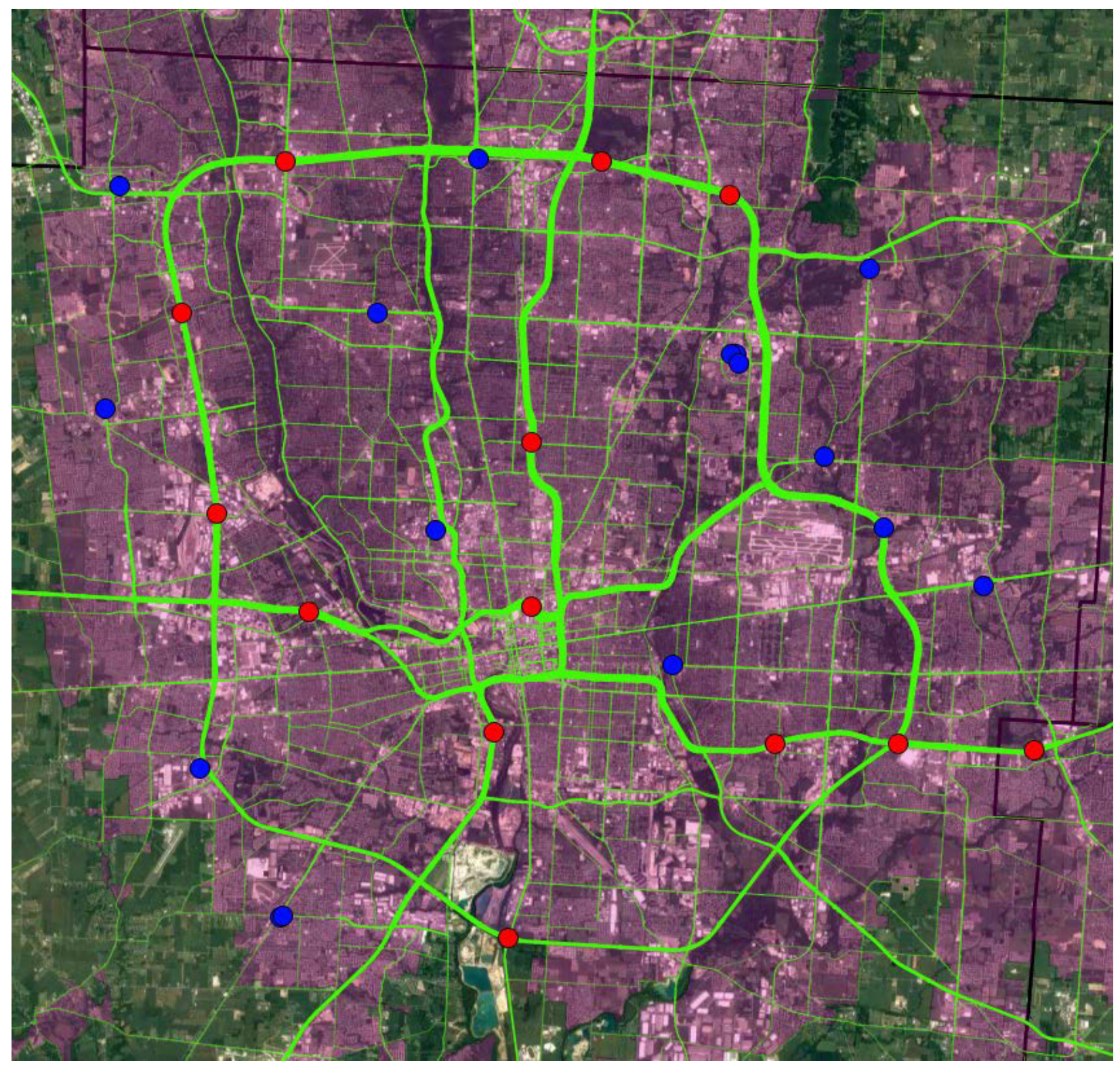

Figure 25. Sixteen existing DCFC station locations in Columbus as of August 2017 (blue dots) and 13 hypothetical future locations to improve DCFC coverage (red dots). Purple outline denotes Columbus urban area.

Satellite imagery credit: @ 2017 Google, Map Data @ 2017 Tele Atlas 


\section{Summary}

A detailed analysis of PEV charging requirements in the Columbus, Ohio, region was conducted to support the U.S. Department of Transportation's Smart City Challenge and Smart Columbus Initiative. A market analysis assessing early PEV adoption trends in Columbus was reported to compare local PEV adoption with statewide and national trends. Based on these trends, a spatially resolved scenario for future PEV adoption in Columbus through 2019 has been proposed. A large, commercial GPS travel data set from INRIX (including 32.9 million trips in the Columbus region in 2016) was used to estimate travel behavior in the region and was compared with other travel survey data for quality assessment. Finally, detailed travel patterns generated from this analysis were used with NREL's EVI-Pro model to determine charging requirements and identify potential charging "hot spots" for consideration by the city. These results were also compared to real-world PEV charging station data from ChargePoint to validate simulated charging results.

Baseline results indicate that approximately 400 L2 plugs at multi-unit dwellings and 350 L2 plugs at non-residential locations are required to support the primary Columbus PEV goal of 5,300 PEVs on the road by the end of 2019 (assuming that $12 \%$ will be adopted by MUD residents). An analysis finds that while consumer demand for fast charging is expected to remain low (due to modest anticipated adoption of short-range BEVs), a minimum level of fast charging coverage across the city is recommended to ease consumer range anxiety concerns by providing a safety net for unexpected charging events. Sensitivity analyses around some key assumptions have also been performed, identifying consumer preference for PHEV versus BEV and for their electric driving range, ambient conditions, and availability of residential charging at multi-unit dwellings as key determinants of the non-residential PEV charging infrastructure required to support PEV adoption. These results can be leveraged by similar U.S. cities as part of a strategy to accelerate PEV adoption in the LDV market. 


\section{References}

Davis, M., and M. Alexander. 2014. Guidelines for Infrastructure Planning: An Explanation of the EPRI Red Line/Blue Line Model. Electric Power Research Institute (EPRI), Palo Alto, CA: Product No. 3002004096. https://www.epri.com/\#/pages/product/000000003002004096/

Egbue, Ona, and Suzanna Long. 2012. "Barriers to Widespread Adoption of Electric Vehicles: An Analysis of Consumer Attitudes and Perceptions.” Energy Policy 48: 717-729. https://doi.org/10.1016/j.enpol.2012.06.009

Hall, Dale, and Nic Lutsey. 2017. Emerging Best Practices for Electric Vehicle Charging Infrastructure. White Paper. International Council on Clean Transportation, Washington, DC. http://theicct.org/sites/default/files/publications/EV-charging-best-practices_ICCT-whitepaper 04102017 vF.pdf

International Energy Agency. 2017. Global EV Outlook 2017. Two Million and Counting.

IHS Automotive. 2017. "MarketInsight: Registrations and Vehicles-in-Operation." https://www.ihs.com/products/automotive-market-data-analysis.html

INRIX. “INRIX Analytics: Trips.” http://inrix.com/products/trips/

Internal Revenue Service. 2016. "Plug-in Electric Vehicle Credit." https://www.irs.gov/businesses/plug-in-electric-vehicle-credit-irc-30-and-irc-30d

Kahn, Matthew E., and Ryan K. Vaughn. 2009. “Green Market Geography: The Spatial Clustering of Hybrid Vehicles and LEED Registered Buildings." The B.E. Journal of Economic Analysis \& Policy. 9(2) (March 2009).

https://www.degruyter.com/view/j/bejeap.2009.9.2/bejeap.2009.9.2.2030/bejeap.2009.9.2.2030.xml

Lohse-Busch, H.; Duoba, M.; Rask, E.; Stutenberg, K.; Gowri, V.; Slezak, L.; Anderson, D. (2013). "Ambient Temperature $\left(20^{\circ} \mathrm{F}, 72^{\circ} \mathrm{F}, 95^{\circ} \mathrm{F}\right)$ Impact on Fuel and Energy Consumption for Several Conventional Vehicles, Hybrid and Plug-In Hybrid Electric Vehicles and Battery Electric Vehicle." Presented at the 2013 SAE World Congress, Detroit, MI, April 2013, 2013-011462. https://saemobilus.sae.org/content/2013-01-1462

Melaina, Marc, Brian Bush, Joshua Eichman, Eric Wood, Dana Stright, Venkat Krishnan, David Keyser, Trieu Mai, and Joyce McLaren 2016. National Economic Value Assessment of Plug-In Electric Vehicles: Volume I. DOE/GO-102016-4902. National Renewable Energy Laboratory, Golden, CO. http://www.nrel.gov/docs/fy17osti/66980.pdf

Melaina, Marc, and Michael Helwig. 2014. California Statewide Plug-In Electric Vehicle Infrastructure Assessment. Prepared by the National Renewable Energy Laboratory for California Energy Commission. Publication Number: CEC-600-2014-003. http://www.nrel.gov/docs/fy15osti/60729.pdf

Mid-Ohio Regional Planning Commission. "Data, Maps \& Tools: GIS Data Download.” http://www.morpc.org/data-maps/ 
Nykvist, Björn, and Måns Nilsson. 2015. "Rapidly Falling Costs of Battery Packs for Electric Vehicles." Nature Climate Change 5(4): 329-332. http://www.nature.com/articles/nclimate2564

U.S. Department of Energy. 2017. "Alternative Fuel Data Center: Federal and State Laws and Incentives." [Online]. Available: https://www.afdc.energy.gov/laws/

U.S. Department of Energy, Alternative Fuels Data Center. "Alternative Fueling Station Locator." http://www.afdc.energy.gov/locator/stations/

U.S. Department of Energy, Alternative Fuels Data Center. "Workplace Charging for Plug-In Electric Vehicles." https://www.afdc.energy.gov/fuels/electricity charging_workplace.html

Wood, Eric, Clement Rames, Matteo Muratori, Sesha Raghavan, and Marc Melaina. 2017. National Plug-In Electric Vehicle Infrastructure Analysis. NREL-TP-5400-69031. Golden, CO: National Renewable Energy Laboratory, https://www.nrel.gov/docs/fy17osti/69031.pdf.

Wu, F., and R. Sioshansi. 2017. "A Stochastic Flow-Catching Model to Optimize the Location of Fast-Charging Stations with Uncertain Electric Vehicle Flows.” Transportation Research Part D: Transport and Environment. 53: 354-376.

https://ise.osu.edu/isefaculty/sioshansi/papers/sfclm.pdf 


\section{Appendix A: INRIX Processing Details}

\section{Home and Secondary Locations Assignment}

To adequately categorize charging events into home, workplace/secondary, and public charging, the location type of each trip destination is needed. Unlike a typical travel survey, the INRIX GPS data set does not contain any information on a given trip destination other than its coordinates and dwell time. Therefore, the destination type or purpose of trips must be inferred from certain heuristics applied at the vehicle level. The INRIX data set contains multiple travel days for each unique device identifiers, which enables the analysis of dwell time patterns at recurring destinations (see Figure A1).

A "home" location assignment algorithm has been implemented following four steps:

1. For each unique vehicle identifier, destinations with dwell times greater than 9 hours are selected, and clustered geographically in $\sim 100 \mathrm{~m}$ x100 m cells.

2. The cumulative dwell time over all travel days is calculated for each of these cells.

3. The cell with the greatest cumulative dwell time is defined as the "home" location for that vehicle.

4. Any trips ending within $1 / 4$ mile from this location are considered "home trips" for this vehicle.

The "secondary" or "workplace" location assignment algorithm follows a similar procedure:

1. For each unique vehicle identifier, destinations from non-"home" trips with dwell times greater than 4 hours are selected and clustered geographically in $\sim 100 \mathrm{~m}$ x $100 \mathrm{~m}$ cells.

2. The cumulative dwell time over all travel days is calculated for each of these cells.

3. The cell with the greatest cumulative dwell time is defined as the "work/secondary" location of the corresponding vehicle.

4. Any trips of this vehicle ending within $1 / 4$ mile from this location are considered "work/secondary" trips.

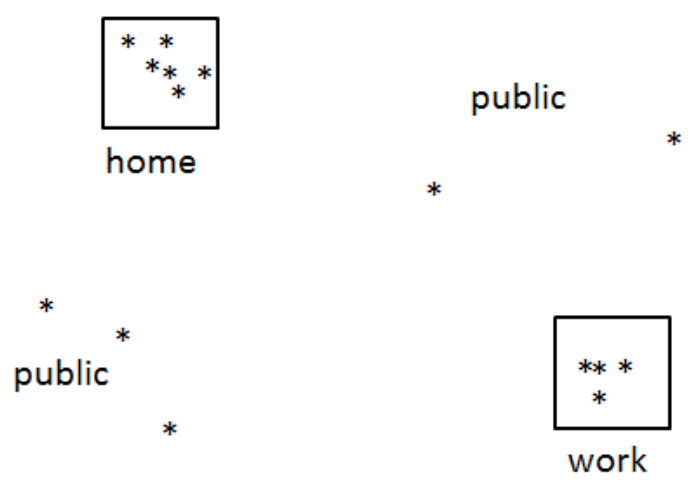

Figure A1. Schematic of trip destinations clustering algorithm 
For both home and work/secondary locations, spatial attributes such as ZIP code, TAZ, and land use were appended by spatially querying the respective databases and assigned to each vehicle.

\section{Assessing Trip Destination Land-Use Type}

A land-use data set from MORPC containing approximately 663 thousand polygons covering the Columbus seven-county area is used to classify the land-use type of each trip destination in the INRIX travel data set. Each polygon is classified into one of 37 land-use types (e.g., agriculture, office, commercial, industrial, park, public use, residential, etc.). A map of the data over the Columbus area is shown in Figure A2, and a zoomed map for the area surrounding the John Glenn Columbus International Airport is shown in Figure A3 with callouts for example land-use types.

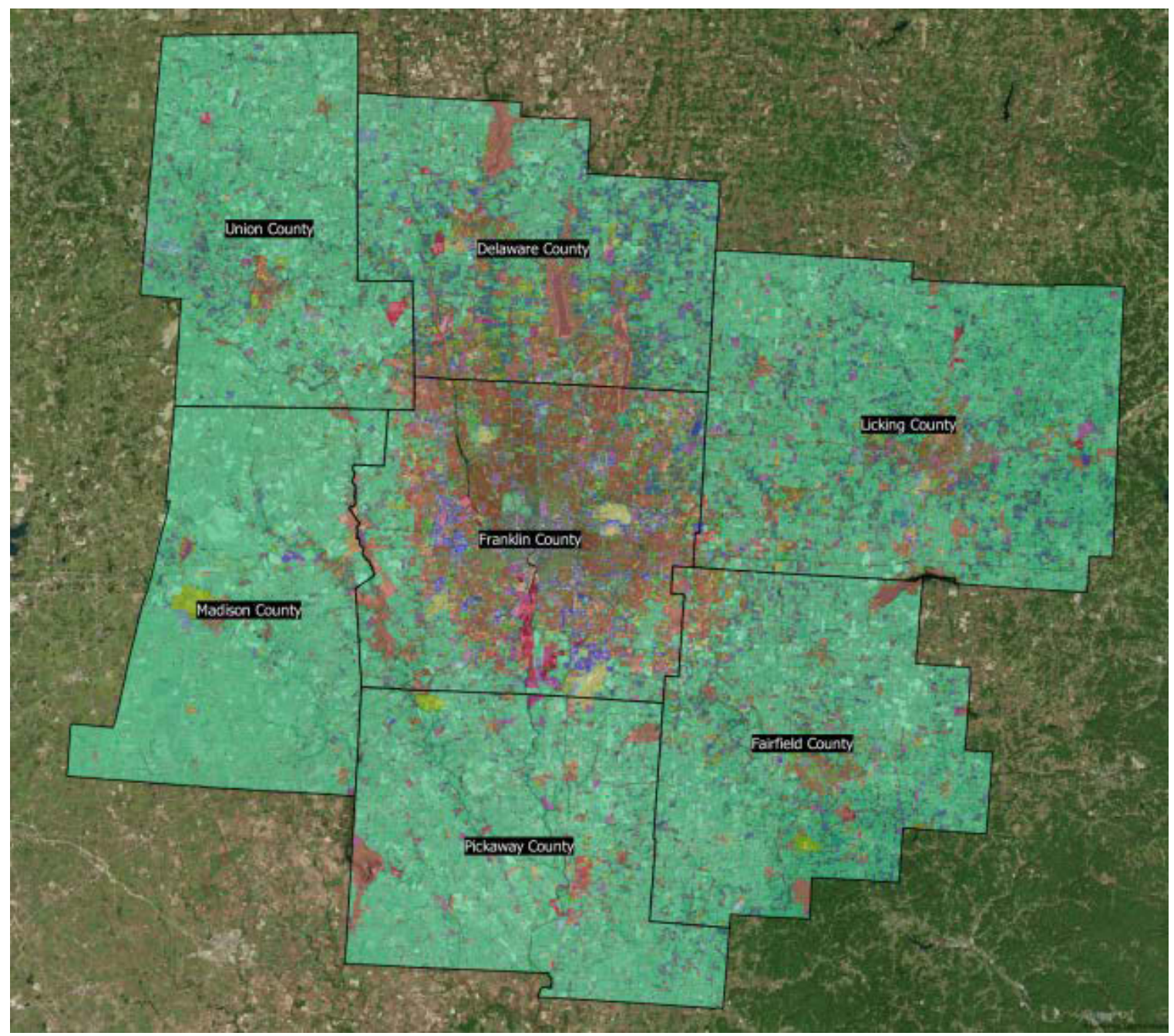

Figure A2. Approximately 663 thousand MORPC land-use polygons covering the Columbus area.

Satellite imagery credit: @ 2017 Google, Map Data $\odot 2017$ Tele Atlas 


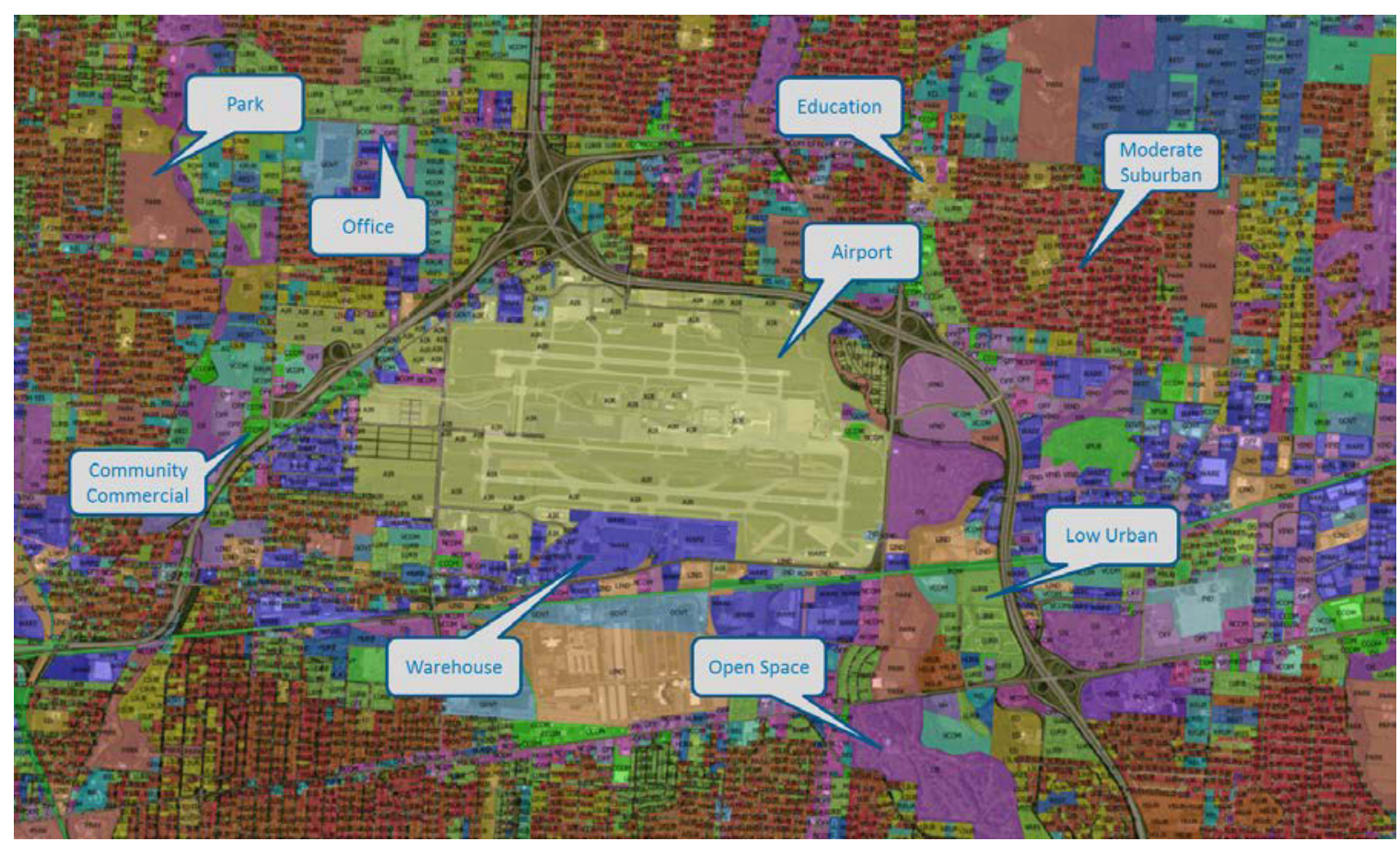

Figure A3. Land-use types for the area surrounding John Glenn Columbus International Airport.

Satellite imagery credit: @ 2017 Google, Map Data @ 2017 Tele Atlas

MORPC land-use data are particularly valuable for classifying trips in the INRIX travel data set as it allows estimating trip purposes, such as trips going to home, work, school, retail stores, or recreational areas. Figure A4 shows median dwell time and trip frequency in the INRIX travel data by MORPC land-use type. A clear stratification between residential and non-residential trips appears, with trips to personal residences exhibiting median dwell times between 10 and 14 hours, and all non-residential locations showing median dwell times of less than 3 hours. The non-residential locations are of particular interest as they represent candidate locations for conveniently locating PEV charging infrastructure. 


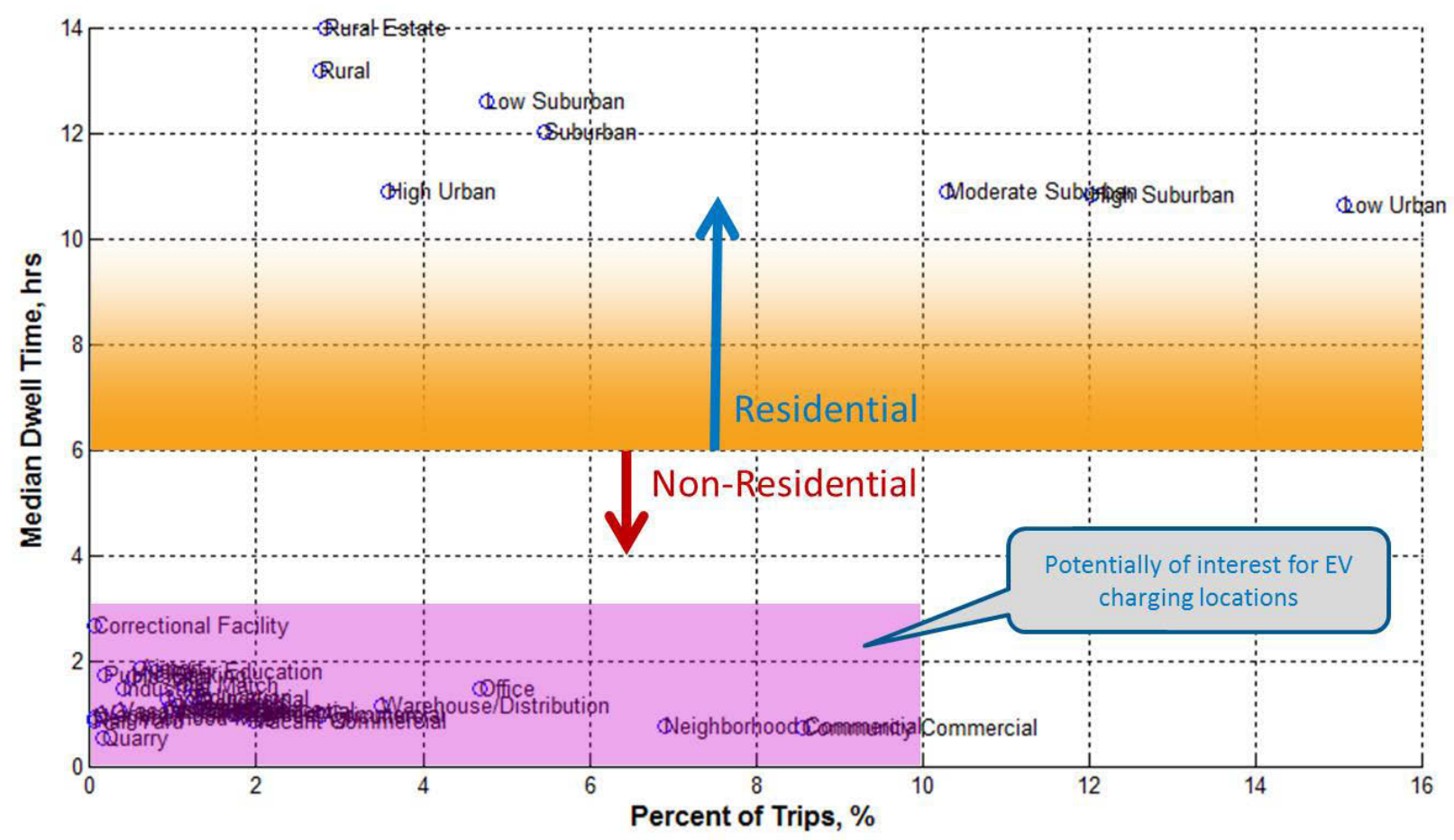

Figure A4. Median dwell times for trip destinations in the INRIX travel data by land-use type.

Figure A5 reports the same data for non-residential destinations only, showing that neighborhood commercial and community commercial land-use types have the highest trip frequencies at approximately $7 \%$ and $8.5 \%$ of all trips, respectively. Despite their high frequency, these commercial locations show median dwell times under one hour, which greatly limits the opportunity for L1 charging and allows for limited recharging even with L2 infrastructure (e.g., less than $6 \mathrm{kWh}$, which translates into approximately 20 miles of all-electric range).

The next tier of land-use types in terms of trip frequency is warehouse/distribution and office at approximately $3.5 \%$ and $4.5 \%$ of all trips, respectively. Likely representing work locations for most trips, these trips feature more favorable median dwell times between 1 and 1.5 hours. However, for work trips this median dwell time is still substantially lower than expected. At this point it is worth recalling that these dwell times represent the median of all trips and not the median cumulative daily dwell time, which would likely be closer to a typical 8- to 10-hour workday. Additionally, it is possible that some trips to these locations are made by individuals that are not employees of the facility and only visiting for a short duration. Efforts to identify trips with an apparent work purpose out of the INRIX data are in progress to improve suitability for this analysis for understanding the potential role of workplace charging in Columbus. 


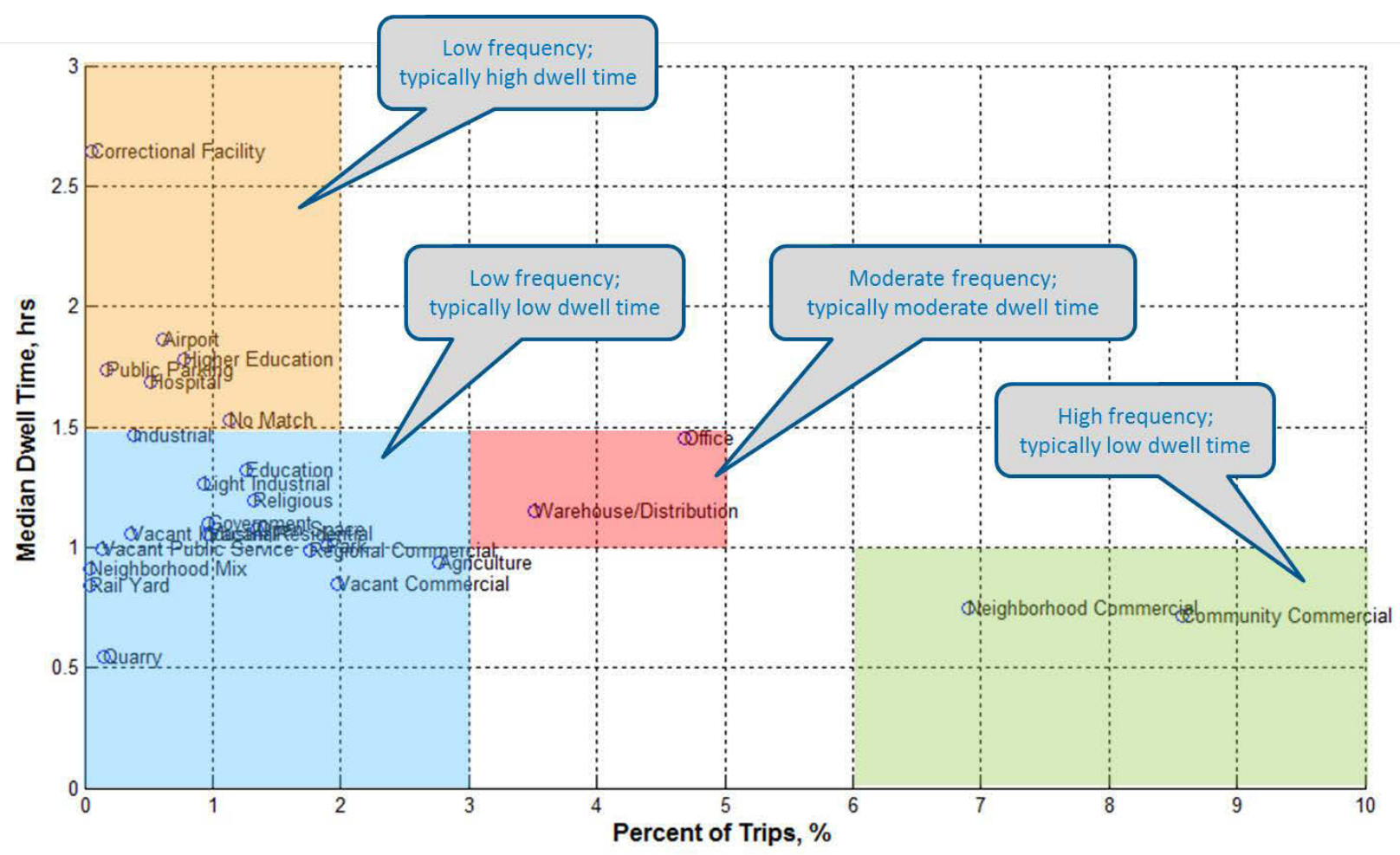

Figure A5. Median dwell times for trip destinations in the INRIX travel data for non-residential destinations by land-use type.

It is worth noting the high degree of variability between trip dwell times for each land-use type. Figure A6 shows box plot distributions of dwell time for the data in the processed 2016 INRIX data set for Columbus by MORPC land-use type. While these distributions show similar trends to those already discussed, this plot emphasizes that even land-use types with low median dwell times include a portion of trips that are well suited for PEV charging. Airports in particular feature a subset of trips with multi-hour dwell times potentially originating from airport employees and air passengers leaving cars in long-term parking lots. 


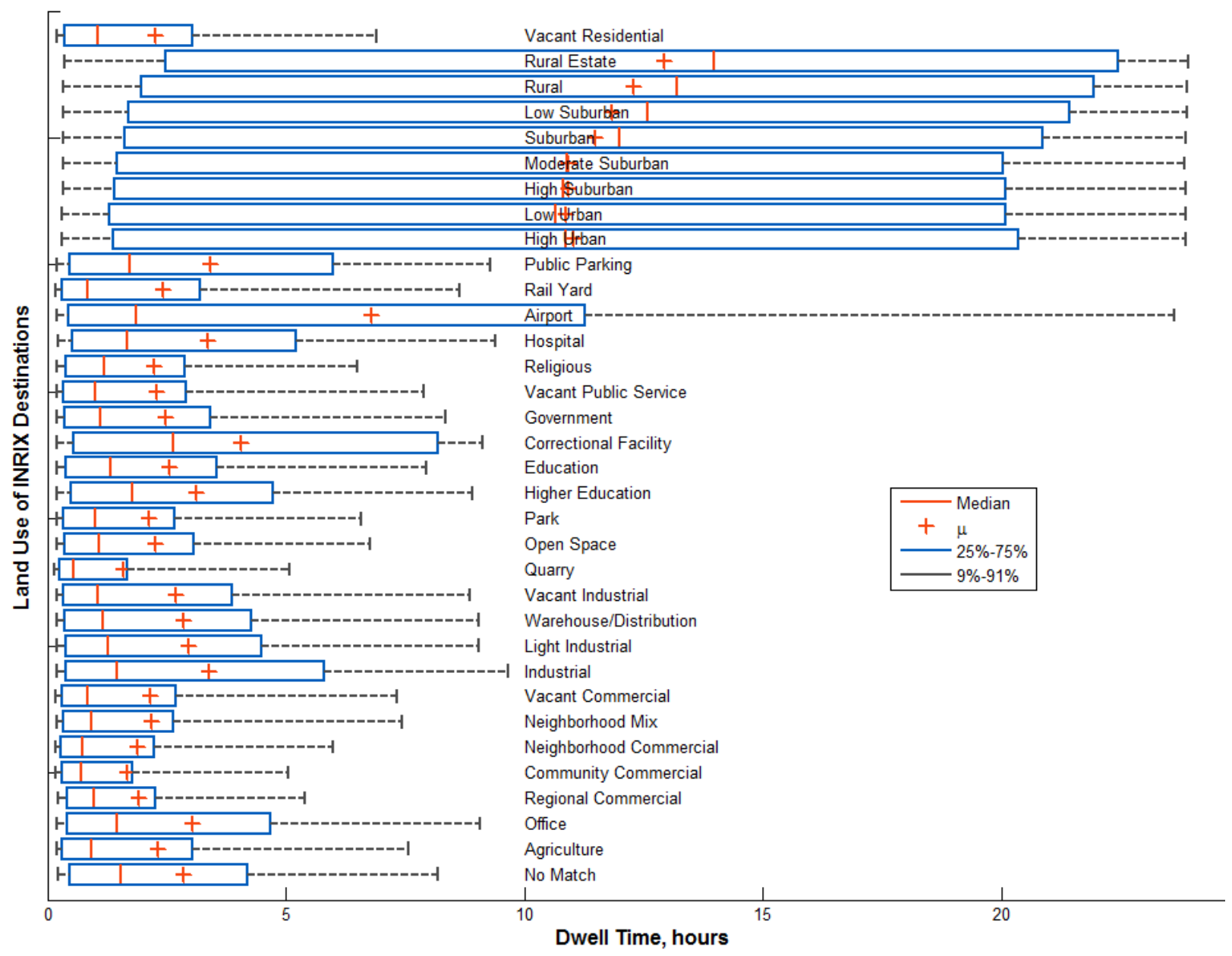

Figure A6. Box plot of dwell time in the processed 2016 INRIX data set for Columbus by MORPC land-use type. 


\section{Appendix B: Columbus Area Map Details, L2 EVSE}

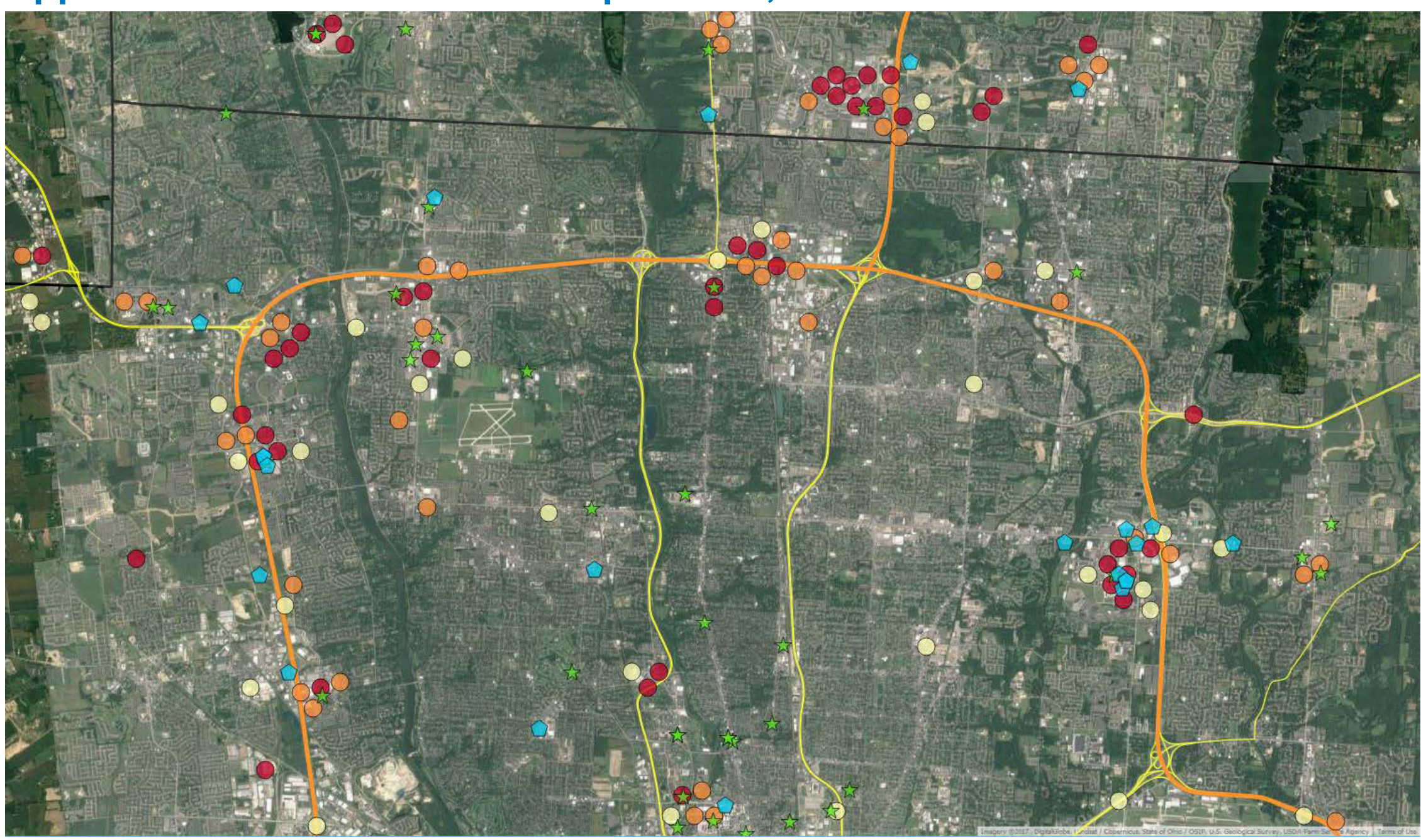

Figure B1. Simulated PEV charging "hot spots" for public L2 EVSE (0.3-mi diameter) color coded by use $\left(1^{\text {st }}\right.$ tier $=$ red, $2^{\text {nd }}$ tier $=$ orange, $3^{\text {rd }}$ tier = yellow), existing public L2 EVSE (blue pentagons), and future sites under consideration (green stars). Northern half of Franklin County.

Satellite imagery credit: @ 2017 Google, Map Data @ 2017 Tele Atlas 


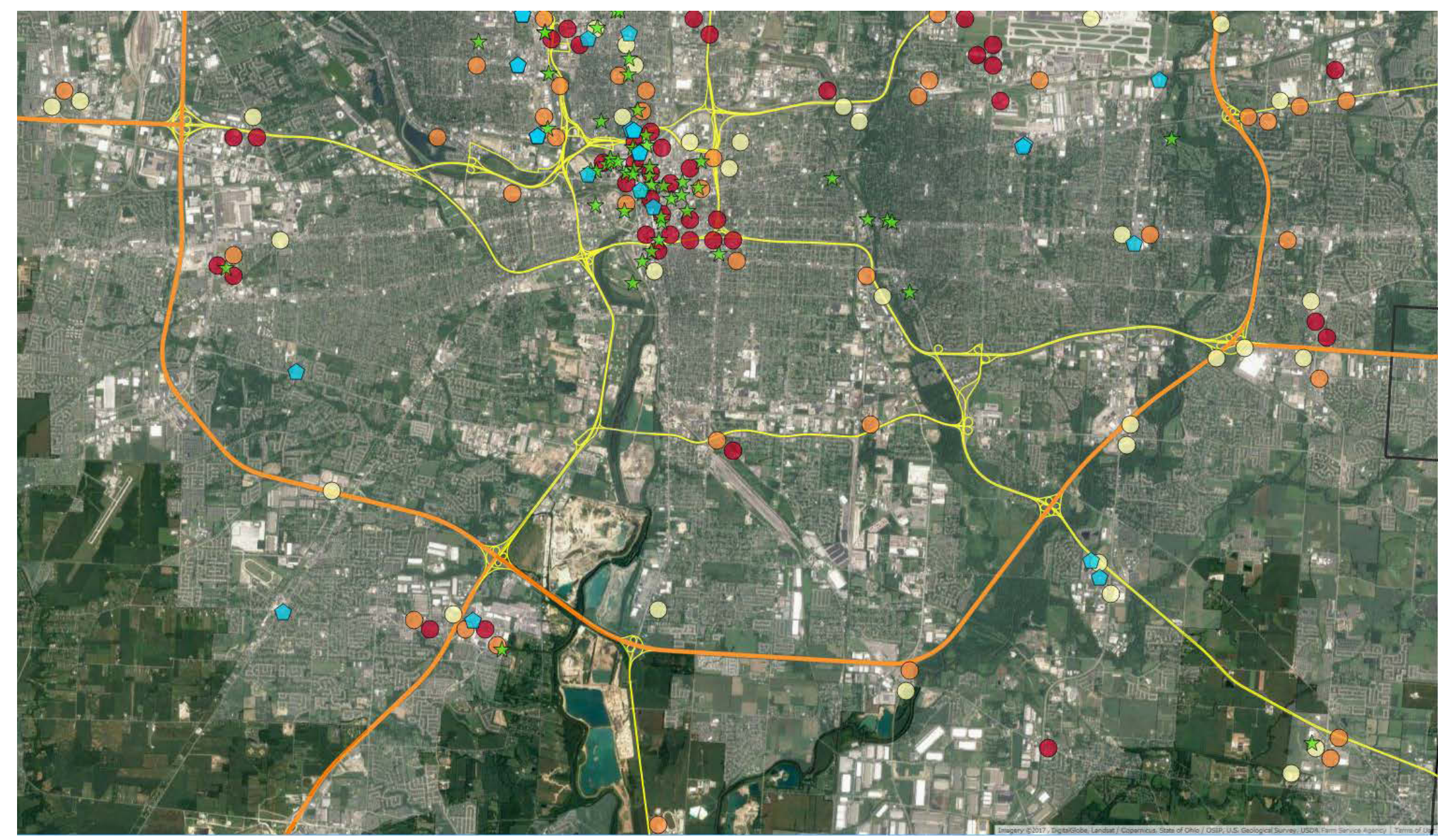

Figure B2. Simulated PEV charging "hot spots" for public L2 EVSE (0.3-mi diameter) color coded by use $\left(1^{\text {st }}\right.$ tier $=$ red, $2^{\text {nd }}$ tier $=$ orange, $3^{\text {rd }}$ tier = yellow), existing public L2 EVSE (blue pentagons), and future sites under consideration (green stars). Southern half of Franklin County.

Satellite imagery credit: @ 2017 Google, Map Data @ 2017 Tele Atlas 


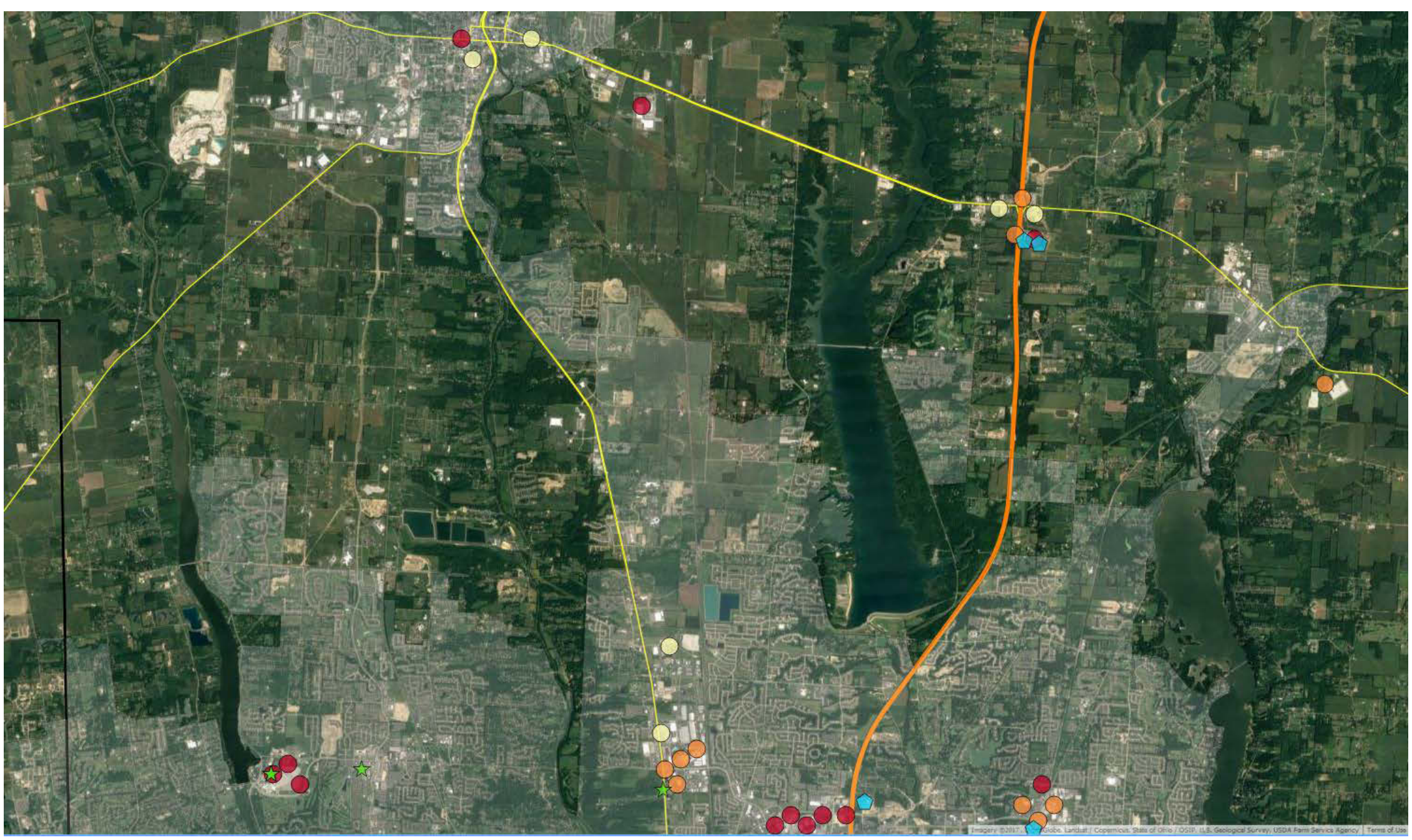

Figure B3. Simulated PEV charging "hot spots" for public L2 EVSE $(0.3-\mathrm{mi}$ diameter $)$ color coded by use $\left(1^{\text {st }}\right.$ tier $=$ red, $2^{\text {nd }}$ tier $=$ orange, $3^{\text {rd }}$ tier = yellow), existing public L2 EVSE (blue pentagons), and future sites under consideration (green stars). Delaware County.

Satellite imagery credit: @ 2017 Google, Map Data $\odot 2017$ Tele Atlas 


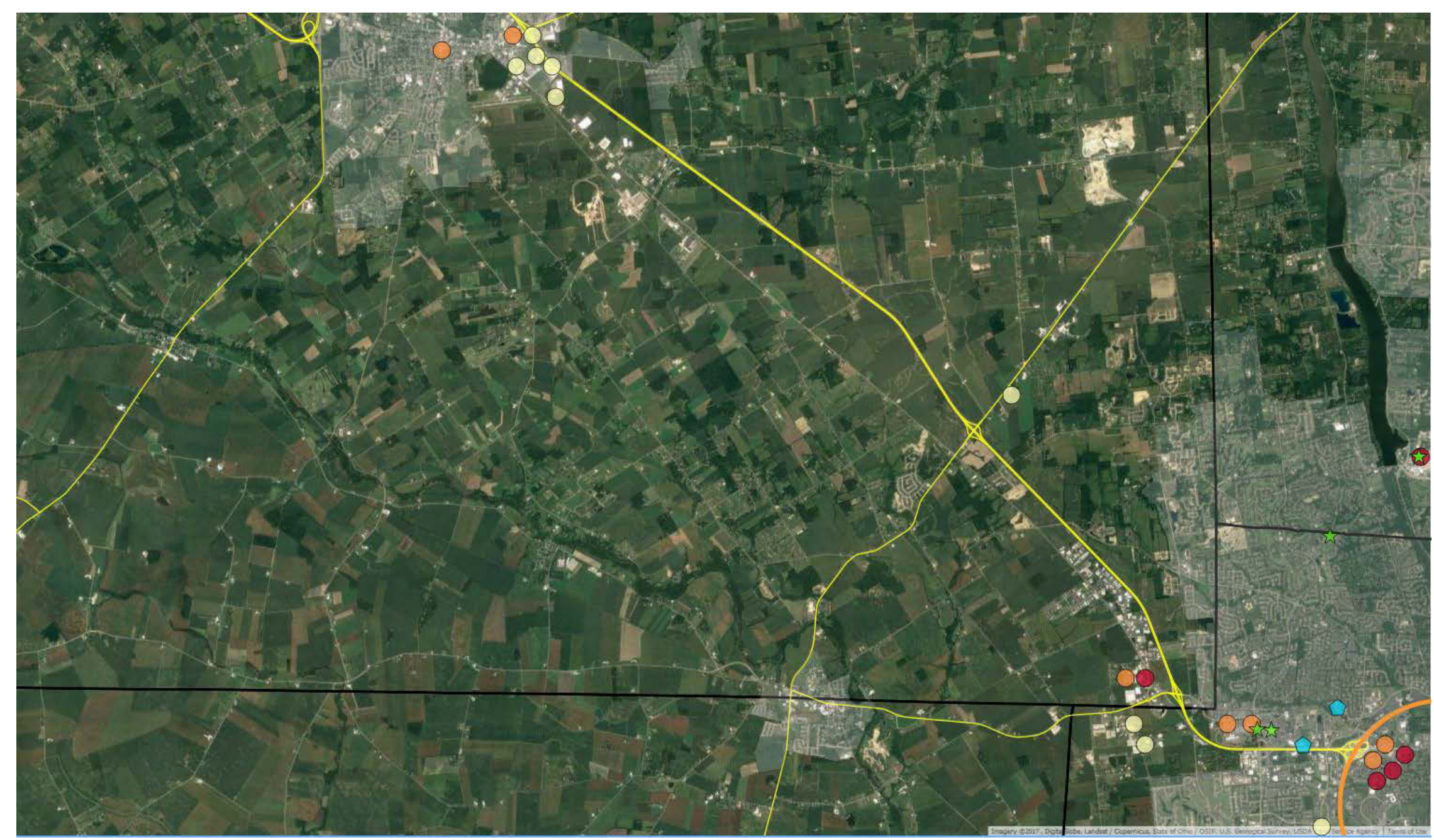

Figure B4. Simulated PEV charging "hot spots" for public L2 EVSE (0.3-mi diameter) color coded by use $\left(1^{\text {st }}\right.$ tier $=$ red, $2^{\text {nd }}$ tier $=$ orange, $3^{\text {rd }}$ tier = yellow), existing public L2 EVSE (blue pentagons), and future sites under consideration (green stars). Union County. Satellite imagery credit: @ 2017 Google, Map Data @ 2017 Tele Atlas 


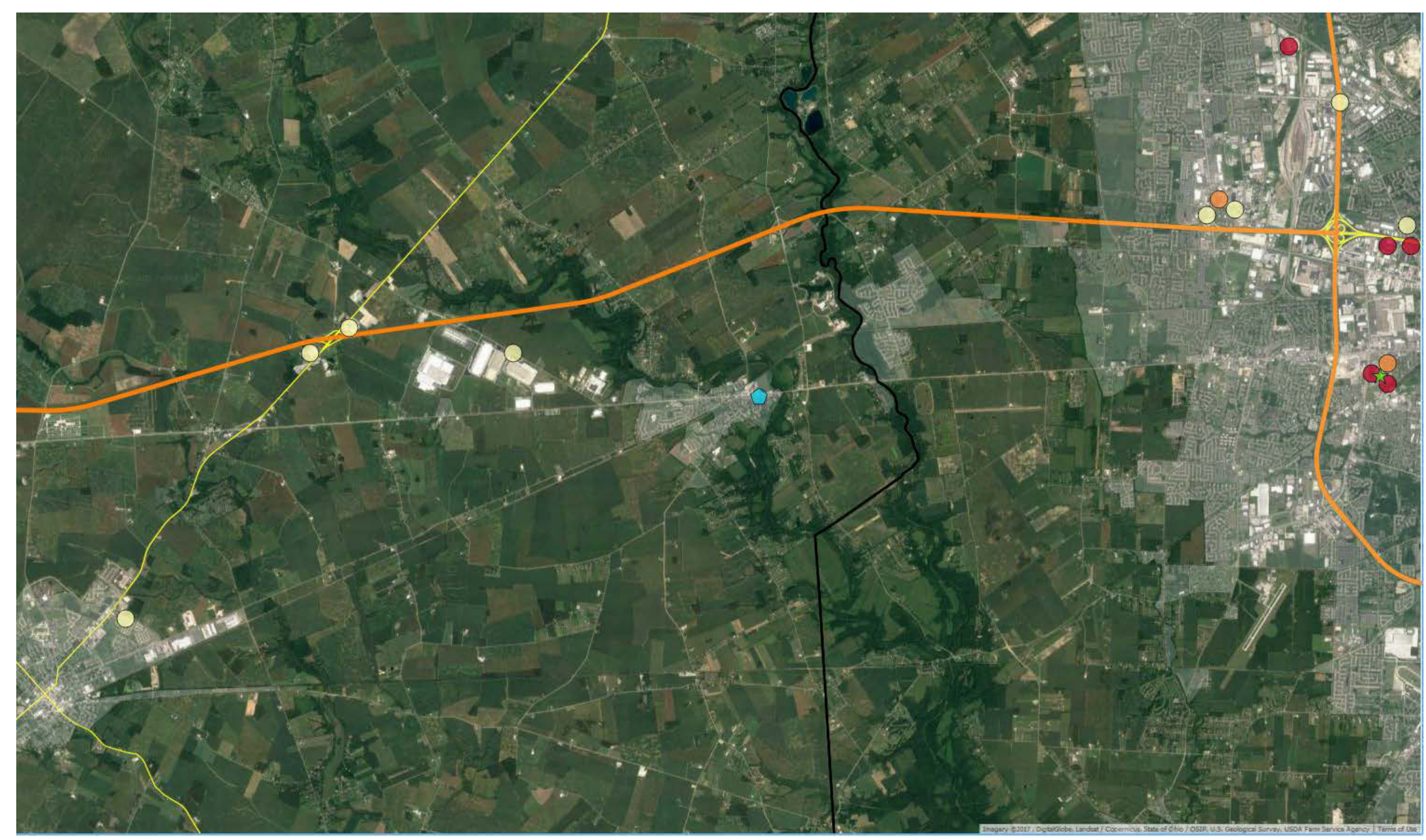

Figure B5. Simulated PEV charging "hot spots" for public L2 EVSE (0.3-mi diameter) color coded by use $\left(1^{\text {st }}\right.$ tier $=$ red, $2^{\text {nd }}$ tier $=$ orange, $3^{\text {rd }}$ tier = yellow), existing public L2 EVSE (blue pentagons), and future sites under consideration (green stars). Madison County.

Satellite imagery credit: @ 2017 Google, Map Data @ 2017 Tele Atlas 


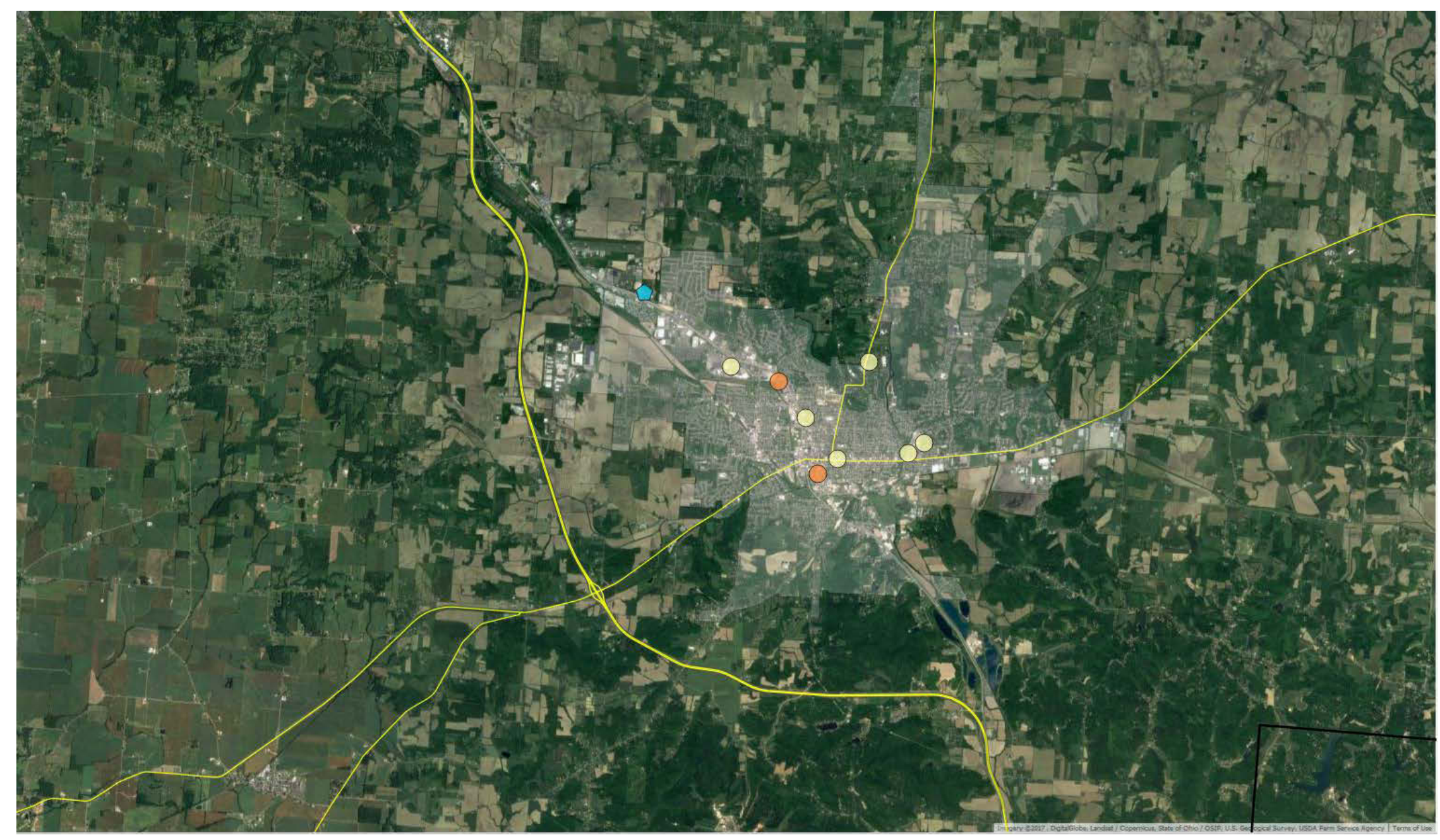

Figure B6. Simulated PEV charging "hot spots" for public L2 EVSE (0.3-mi diameter) color coded by use $\left(1^{\text {st }}\right.$ tier $=$ red, $2^{\text {nd }}$ tier $=$ orange, $3^{\text {rd }}$ tier = yellow), existing public L2 EVSE (blue pentagons), and future sites under consideration (green stars). Fairfield County. Satellite imagery credit: @ 2017 Google, Map Data @ 2017 Tele Atlas 


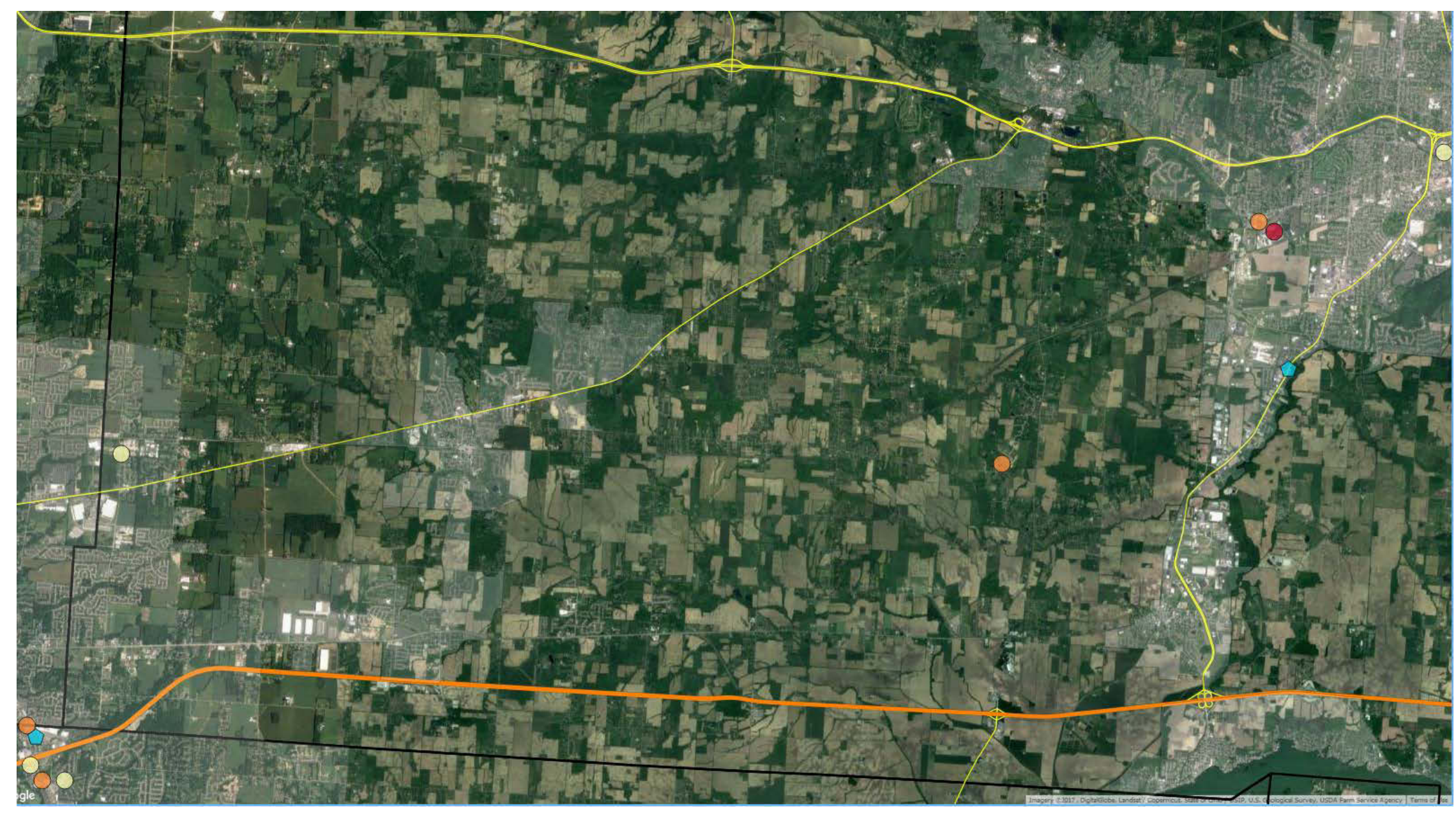

Figure B7. Simulated PEV charging "hot spots" for public L2 EVSE (0.3-mi diameter) color coded by use $\left(1^{\text {st }}\right.$ tier $=$ red, $2^{\text {nd }}$ tier $=$ orange, $3^{\text {rd }}$ tier $=$ yellow), existing public L2 EVSE (blue pentagons), and future sites under consideration (green stars). Licking County. Satellite imagery credit: @ 2017 Google, Map Data @ 2017 Tele Atlas 


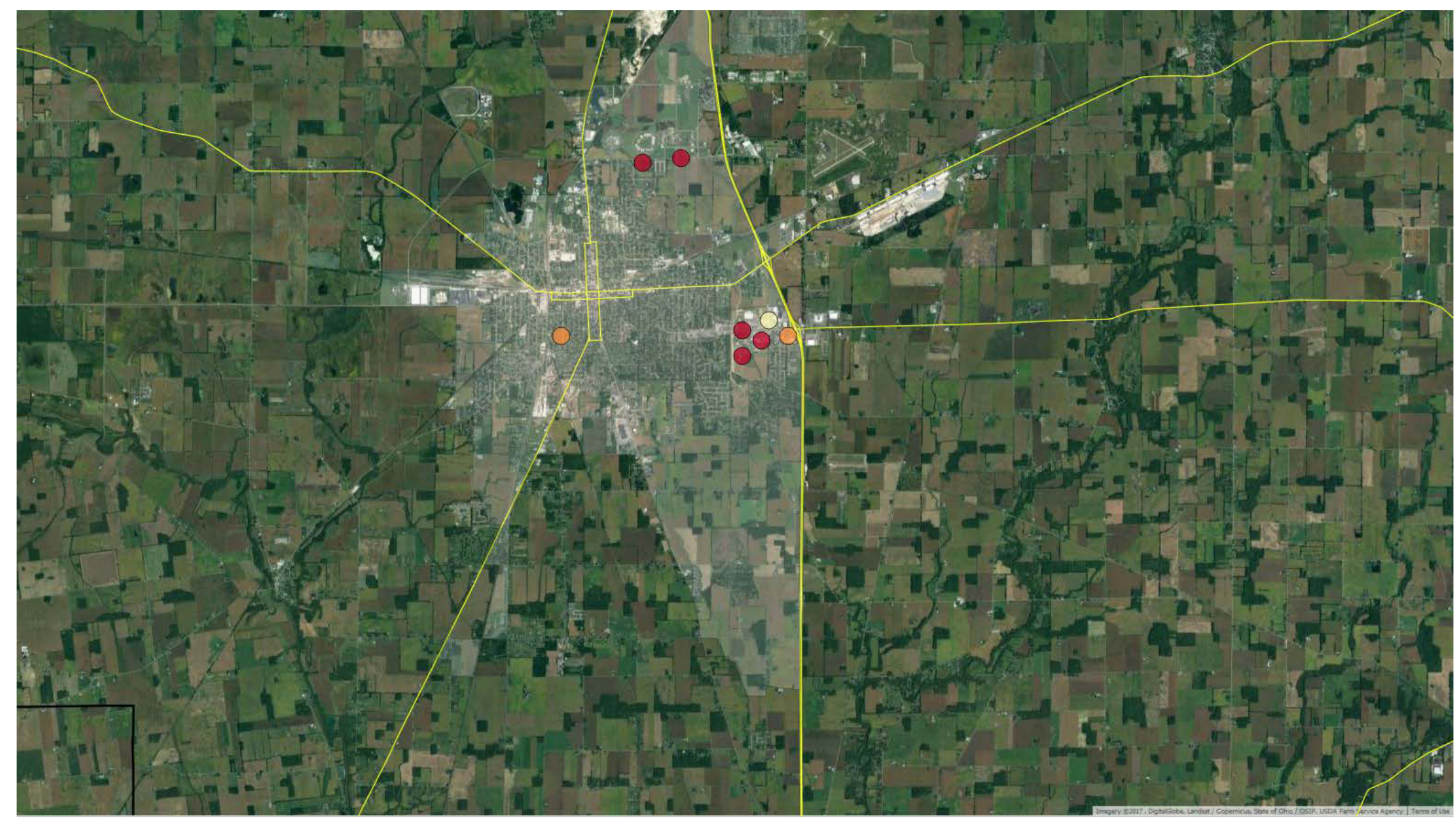

Figure B8. Simulated PEV charging "hot spots" for public L2 EVSE $(0.3-\mathrm{mi}$ diameter $)$ color coded by use $\left(1^{\text {st }}\right.$ tier $=$ red, $2^{\text {nd }}$ tier $=$ orange, $3^{\text {rd }}$ tier = yellow), existing public L2 EVSE (blue pentagons), and future sites under consideration (green stars). Marion County.

Satellite imagery credit: @ 2017 Google, Map Data @ 2017 Tele Atlas 